NASA Technical Memorandum 106736

AIAA-95-0733

\title{
Numerical Mixing Calculations of Confined Reacting Jet Flows in a Cylindrical Duct
}

Victor L. Oechsle

Allison Engine Company

Indianapolis, Indiana

and

J.D. Holdeman

Lewis Research Center

Cleveland, Ohio

Prepared for the

33rd Aerospace Sciences Meeting and Exhibit

sponsored by the American Institute of Aeronautics and Astronautics

Reno, Nevada, January 9-12, 1995

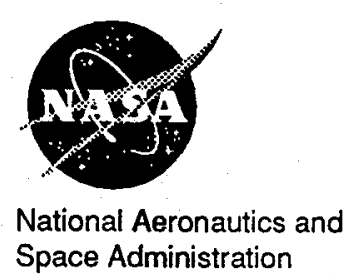




\title{
Numerical Mixing Calculations of Confined Reacting Jet Flows in a Cylindrical Duct
}

\author{
Victor L. Oechsle* \\ Allison Engine Company \\ Indianapolis, Indiana \\ J. D. Holdeman \\ NASA Lewis Research Center \\ Cleveland, Ohio
}

\begin{abstract}
The results reported in this paper describe some of the main flow characteristics and NOx production results which develop in the mixing process in a constant cross-sectional cylindrical duct. A 3-dimensional numerical model has been used to predict the mixing flow field and NOx characteristics in a mixing section of an RQL combustor. Eighteen configurations have been analyzed in a circular geometry in a fully reacting environment simulating the operating condition of an actual RQL gas turbine combustion liner. The evaluation matrix was constructed by varying three parameters: 1 ) jet-to-mainstream momentum-flux ratio $(J), 2$ ) orifice shape or orifice aspect ratio, and 3) slot slant angle. The results indicate that the mixing flow field and NOx production significantly vary with the value of the jet penetration and subsequently, slanting elongated slots generally improve the NOx production at high $\mathrm{J}$ conditions. Round orifices produce low NOx at low $J$ due to the strong jet penetration. The NOx production trends do not correlate with the mixing non-uniformity parameters described herein.
\end{abstract}

\section{Nomenclature}

$\mathrm{A}_{\mathrm{jk}} \quad$ cross-sectional area of the control volume at $\mathrm{i}$ and $\mathrm{j}$

location, $\mathrm{m}^{2}$

$A_{m}$ duct cross-sectional area, also $A_{\text {tot }}, m^{2}$

ACd effective orifice area, $\mathrm{m}^{2}$

Ar area ratio (jet/mainstream) $=\mathrm{ACd} / \mathrm{A}_{\mathrm{m}}$

AMIX area weighted deviation from equilibrium, Eq-3

B area determined half width of the distribution func tion

* AIAA member

\$ Senior Research Engineer, AIAA Associate Fellow

Copyright 1994 by V.L. Oechele and J.D. Holdeman. No copyright is aserted in the United Stares under Title 17 U.S. Code. The U.S. Government has the royalty-free license to exercise all rights ander the copyright claimed bere in for Government Purposes. All other rights are reserved by the copyright owner.

\begin{tabular}{|c|c|}
\hline $\mathrm{C}$ & constant of proportionality in Eq-6 \\
\hline$d$ & diameter of the orifice \\
\hline DR & density ratio (jet/mainstream) \\
\hline $\mathrm{DP} / \mathrm{P}$ & total pressure loss across the mixing wall, $\%$ \\
\hline $\mathrm{f}$ & non-dimensional equivalence ratio, Eq-2 \\
\hline $\mathrm{f} / \mathrm{a}$ & fuel to air ratio \\
\hline $\mathrm{J}$ & $\begin{array}{l}\text { momentum-flux ratio }(\text { jet/mainstream })=M^{2} / D R \text {, } \\
\text { also }(M R)^{2} /\left[(D R)\left(A C d / A_{m}\right)^{2}\right]\end{array}$ \\
\hline & overall mixer mass flowrate, $\mathrm{kg} / \mathrm{sec}=\dot{\mathrm{m}}_{\mathrm{jet}}+\dot{\mathrm{m}}_{\text {main }}$ \\
\hline MMIX & mass flow weighted deviation from equil, $\mathrm{Eq}-4$ \\
\hline MR & mass flowrate ratio (jet/mainstream) \\
\hline $\mathrm{n}$ & optimum number of orifices / row, Eq- 6 \\
\hline $\mathbf{P}$ & total pressure, atm. \\
\hline $\mathbf{R}$ & radius of the mixing section, $m$ \\
\hline $\mathbf{r}$ & radial distance from the centerline of the mixer, $\mathrm{m}$ \\
\hline $\mathbf{S}$ & $\begin{array}{l}\text { spacing between orifice centers at the circumference } \\
\text { of the can }\end{array}$ \\
\hline $\mathrm{T}$ & temperature, $\mathrm{K}$ \\
\hline $\mathbf{u}$ & local axial velocity, $\mathrm{m} / \mathrm{sec}$ \\
\hline $\begin{array}{l}U_{\text {main }} \\
\text { VR }\end{array}$ & $\begin{array}{l}\text { approach mainstream axial velocity, } \mathrm{m} / \mathrm{sec} \\
\text { velocity ratio (jet/mainstream) }=\mathrm{V}_{\text {jet }} / \mathrm{U}_{\text {main }}\end{array}$ \\
\hline $\mathrm{V}_{\text {jet }}$ & radial velocity of the jet, $\mathrm{m} / \mathrm{sec}$ \\
\hline $\mathbf{z}$ & $\begin{array}{l}\text { arc distance in the tangential direction evaluated at } \\
r=R ; z \text { equals } 0 \text { at midplane between orifices } m\end{array}$ \\
\hline$x$ & axial distance from the leading edge of the orifice, $m$ \\
\hline$\delta$ & value of the cumul volume fraction at $\mathrm{f}_{\text {equil }}$, Fig- 4 \\
\hline$p$ & fluid density, $\mathrm{kg} / \mathrm{m}^{3}$ \\
\hline$\phi$ & equivalence ratio $(\mathrm{f} / \mathrm{a})_{\text {local }} /(\mathrm{f} / \mathrm{a})_{\text {stoi }}$ \\
\hline
\end{tabular}

\section{$\underline{\text { Subscripts }}$}

$\begin{array}{ll}\text { equil } & \text { equilibrium } \\ \mathrm{i} & \text { axial vector direction } \\ \mathrm{j} & \text { radial vector direction } \\ \mathrm{k} & \text { tangential vector direction } \\ \mathrm{m} & \text { mainstream, also (main) } \\ \mathrm{RZ} & \text { rich-zone } \\ \text { stoi } & \text { stoichiometric }\end{array}$




\section{Introduction}

In recent years, the design and development of gas turbine engines for the aeropropulsion and ground based power generation systems has been channeled towards decreasing the gaseous emissions without adversely affecting the system performance. The environmental effects of both carbon monoxide $(\mathrm{CO})$ and oxides of nitrogen (NOx) have been investigated extensively for many years and their potential hazards are increasingly becoming a more world wide sensitive issue. The trend in gas turbine engine design advancement has been channeled towards increasing both engine pressure ratio and rotor inlet temperature levels in order to increase the overall thermodynamic cycle efficiency. However, this evolution has been adversely affecting both engine durability and gaseous emissions, especially that of NOx, since the production of NOx is generally a function of the combustion system design, hot section temperature distribution, residence time, and localized fuel/air mixture.

The development of an efficient and low-emission combustion system demands increased insight into combustion chemical kinetics, efficient air/fuel mixture, and advanced materials and cooling techniques. Current gas turbine combustion liner technology employs a single-stage combustion process in which both fuel and air are admitted into a controlled mixing chamber and are allowed to react. However, with the advent of higher temperature operating conditions, the reduction of NOx becomes a very difficult task to accomplish using single axial staged combustion. Therefore, alternative combustion methods are being explored by the primary gas turbine engine manufacturers and other research organizations. Two of the main low NOx designs being developed are rich burn / quick mix / lean burn (RQL), and lean premixed prevaporized (LPP). Both have advantages and disadvantages regarding both operation range and hardware complexity.

This paper focuses on the performance of the mixing section of an RQL combustor. The successful performance of this combustor depends on a quick and efficient mixing of the rich zone combustion products with compressor discharge air to effectively reduce the overall equivalence ratio from about 1.8 to about 0.5 . This process must be accomplished with a minimum transient time (near equivalence ratio of 1) where most of the NOx is produced due to the high resulting temperature levels and oxygen availability.

An experimental and analytical effort (e.g. Bain, Smith, and Holdeman, 1992, 1993, and 1994; Doerr and Hennecke, 1993; Hatch, et al., 1992a and 1992b; Howe, et al., 1991; Kroll, et al., 1993; Liscinsky et al., 1992; Liscinsky, True, and Holdeman, 1993 and 1994; Oechsle, Mongia, and Holdeman. 1992, 1993, and 1994; Smith. Talpallikar, and Holdeman, 1991; Sowa, et al., 1994); Talpallikar, et al., 1991; Vranos, et al., 1991; and Zhu and Lai, 1992) is underway to study and identify the critical design and flow parameters affecting the mixing effectiveness.
In this study, a $3-D$ numerical tool is used to predict the performance of an RQL mixing section. The 3-D flow structure of the mixer can be modeled in detail and predictions can be obtained with a host of scalar and vector quantities to accurately evaluate the mixing flowfield. In addition. a relatively large number of configurations can be easily analyzed to predict the trends of both mixing uniformity and NOx production in a generalized jet in a crossflow problem. In this study, the flowfield of several different mixer configurations are evaluated and compared with their corresponding NOx predictions. For this purpose, 18 different mixer configurations were analyzed with the 3-D numerical tool and the localized NOx and overall mixer NOx production flowrates were calculated from each case. The mixer configurations include the following orifice shapes: a) round holes, and b) elongated slots with aspect ratios of $L / W=4$ and 8 and different slant angles from 0 degrees (aligned with the flow) to 90 degrees (transversely oriented to the flow). The jet to mainstream momentum-flux ratio was varied from 25 to 80 . An analysis was further carried out to evaluate and quantify the mixing flowfields in order to rank mixing and NOx production configurations.

\section{Mathematical Model}

\section{3-D Flow Model}

A production 3-D combustor code, COM-3D (Bruce, Mongia, and Reynolds, 1979) is used that solves the turbulent reacting flow transport equations using the SIMPLE algorithm of Patankar and Spalding (Patankar, 1980). This program simulates turbulence by the two-equation $k-\varepsilon$ model (Launder and Spalding, 1974), and combustion following vaporization is determined by a four-step chemical reaction model based on Arrhenius and modified eddy breakup concepts. The transport equations for all dependent variables are of the following form as shown in Eq-1

$$
\operatorname{div}\left[p_{\mathrm{r}} \mathrm{u} \xi-\left(\mu_{\mathrm{eff}} / \mathrm{P}_{\mathrm{r}}\right) \operatorname{grad}(\xi)\right]=S_{\xi}
$$

where $\rho_{r}$ is the mixture density, $u$ is the velocity, $\mu_{\text {eff }}$ is the effective turbulent viscosity, $P_{r}$ is the effective Prandtl/Schmidt number, and $S_{\xi}$ is the source term for the variable $\xi$. The following variables are computed by COM-3D: 1) axial. radial, and swirl velocity components; 2) specific enthalpy and temperature; 3) turbulence kinetic energy and dissipation rate; 4) unburned fuel, $\mathrm{CO}, \mathrm{H}_{2}$, intermediate fuel, and composite fuel mass fractions; and 5) fuel spray trajectory and evaporation rate.

The computational effort is significantly reduced by modeling a sector of the mixing section comprising a single orifice. Therefore, the shape of the sector was dependent on the number of orifices equally spaced in the circumferential direction. It should be noted that all configurations shown in this paper contain 8 orifices/row and each yield a 45 degree sector computational domain. Periodic boundary conditions 
were applied in the circumferential direction. No-slip and adiabatic boundary conditions were applied at the outer wall defining the inside wall of the mixing section. Zero-gradient boundary conditions were applied at the center axis. Axial gradients at the exit boundary condition were assumed zero.

\section{NOx Model}

The NOx model described herein was developed by Rizk and Mongia (1993). Because the NOx formation in the combustion liner is significantly affected by the details of the front end of the RQL and the subsequent admittance of air into the various downstream zones, the combustion liner needs to be divided into a number of regions for modeling purposes. The hybrid modeling technique therefore consists of using the 3-D simulation resuits obtained with COM-3D such as gas flowrate, flow averaged temperature, fuel/air ratio, in addition to the turbulence characteristics to accurately describe the flow nuances affecting the NOx production.

The input flow field exiting the rich zone and entering the mixing zone is assumed to be fully reacted and in equilibrium. Species mole fractions for $\left(\mathrm{CO}, \mathrm{CO}_{2}, \mathrm{H}_{2} \mathrm{O}\right.$, and $\left.\mathrm{H}_{2}\right)$ were determined based on the given rich-zone equivalence ratio at chemical equilibrium at the prescribed operating conditions using JP-5 for typical fuel properties. This assumption was necessary in order to duplicate the inlet flowfield to all the mixing configurations analyzed herein. The four specified species used in the inlet mainstream condition correspond to the four-step chemical reaction used in COM-3D.

The hybrid model consists in grouping the results obtained from a typical COM-3D grid with about 50,000 to 80,000 nodes into about 2,000 larger sub-volumes comprised of several computational nodes representing the entire mixing section. The reacting flow model results can therefore be accurately represented and modeled using significantly less computational effort. For the NOx predictions only, the model of the mixing zone extends to $x / R=5$. This was implemented to prevent any unrealistic discontinuities in the predictions near the real interface between the mixing and lean zones $(x / R=1)$ where $x$ is the downstream axial distance from the leading edge of the orifice and $R$ is the mixer radius evaluated at the outer wall.

\section{Geometric Configuration}

In this study, the mixing section was modeled as a constant diameter cylindrical duct with a single row of equally spaced orifices. The outer wall diameter is 3 inches $(0.076 \mathrm{~m})$ and the axial length of the mixing section extended from $x / R=-1.4$ to $x / R=6$. Sufficient axial distance was provided both upstream and downstream of the orifice to minimize the impact of the inlet and exit boundary conditions on the calculated flow structure in the primary domain of interest which is $(0 \leq x / R \leq 1)$. The downstream limit $(x / R=1)$ of the mixing zone has been defined arbitrarily by this and many other authors listed in the reference.

The computational grid domain was typically discretized into 50,000 to 80.000 finite control volumes generally arranged with about 70 nodes in the axial direction. and 30 nodes in both the radial and tangential directions. The grid was typically denser near the orifice and near the outer wall to resolve the high velocity and temperature gradients resulting from the inlet of the crossflow jet. An orthogonal view of a typical grid arrangement is shown in Figure-1. The grid is normally configured to allow smooth progressive volume change between adjacent control volumes to help speed up the convergence of the solution. In the 3-D numerical model, a secondary grid (staggered grid) is interpolated from that shown in Figure-1 to obtain the boundaries for the vector quantities. The staggered grid becomes the control surfaces of the micro control volumes that constitute the inner volume of the mixing section.

The geometric configuration of the mixer showing a slanted slot is also shown in Figure-1. A total of 18 circular and slanted slot hole configurations were analyzed as shown in Tables- 1 and 2 and are also shown graphically in Figure- 2 . The blockage is defined as the circumferential projection of the orifice divided by the spacing between the orifice centers. and the T.E. $x / R$ is the non-dimensional axial location $(x / R)$ of the trailing edge of the orifice with respect to its leading edge $(x / R=0)$. Both these parameters are shown in Tables- 1 and 2. The matrix of slanted slot orifices summarized in this report include shape variations with an aspect ratio $(\mathrm{L} / \mathrm{W}=$ long/short) of 4 and 8 , and slant angles of $0,22.5,45,67.5$, and 90 degrees with respect to the mainstream flow direction. Note that the nomenclature that identifies the configurations range from 19 through 36 . Configurations 1 through 18 have previously been reported by Oechsle, Mongia, and Holdeman (1993), and they are the non-reacting counterparts of the same geometric configurations.

In this study, the following main parameters were kept constant throughout this analysis. The control of these parameters is essential for a valid comparison of both mixing non-uniformity and NOx production between the appropriate configurations.

1) rich zone equivalence ratio $\phi_{\mathrm{r}}=1.80$

2) lean zone equivalence ratio $\phi_{\mathrm{lz}}=0.416$

3) overall mixer pressure $=14.1 \mathrm{~atm}$.

4) jet temperature $=950 \mathrm{~K}$

5) mainstream temperature $=2164 \mathrm{~K}$, from the chemical equilibrium code (CEC) developed by NASA

6) mixer diameter $=0.076 \mathrm{~m}$

7) jet to mainstream mass flow rate $M R=2.96$

8) jet to mainstream density ratio $D R=2.28$

9) number of equally spaced orifices per row $=8$

The following were allowed to vary: 
1) jet to mainstream momentum-flux ratio $\mathrm{J}$ from nominal values of 25 to 80

2) overall mixer total pressure drop between 1.3 to $5 \%$

3) orifice ACd depending on the value of $J$ in order to maintain the same MR

4) orifice blockage and T.E. $x / R$ values depending on the orifice shape and orientation

5) jet velocity depending on the value of $\mathrm{J}$

\section{Modeling Specifications}

The species mole fractions, temperature, and velocity profiles exiting the rich zone and entering the mixer were assumed to be uniform across the inlet cross-section of the mixing section. The air jet flow was characterized by a radial, uniform flow across the orifice effective area. COM-3D is not a body conforming code therefore accurate modeling of the orifice shape was obtained by defining the orifice with 80 to 150 control surfaces. In this way the stair-stepping approximation in the slanted and round contours could be maximized. The assumption of uniform mass injection/area for the orifice air entry is applied in the mathematical model in all the analyzed configurations. The turbulence kinetic energy of the mainstream and jet flows were $0.3 \%$ of the square of the mean velocities. The turbulence length scales of the mainstream flow were $2 \%$ of the mixer diameter, and the turbulence length scale of the jet was of the order of the orifice diameter. The results from COM-3D were post processed into about 2000 sub-volumes typically 20 in the axial direction, 10 in the radial, and 10 in the circumferential direction. This input was used to generate the NOx predictions based on the flow characteristics.

A typical numerical solution took about 500 iterations for full reacting flow convergence with overall mass flow residuals of $0.05 \%$ of the total mixing section mass flowrate. All solutions were obtained using the Cray C-90 and a typically converged solution took about $2 \mathrm{hrs}$ of CPU time.

\section{$\underline{\text { Analysis }}$}

The mixing performance for all configurations analyzed in this study were ultimately evaluated at $x / R=1$. It is however recognized that the performance throughout the mixing section volume of interest $(0 \leq x / R \leq 1)$ should also be considered since complex structures are present in the flow field especially near the entry of the jet. Two different methods were used to analyze the numerical results: observational analysis and statistical analysis. Both of these are described in detail below.

\section{Observational analysis}

Normalized equivalence ratio contour distributions, and velocity vector plots are represented for each configuration. The equivalence ratio results are presented as normalized values with respect to the overall differential between the mainstream flow and the jet flow inlet values. The param- eter $(\mathrm{f})$ is defined in $\mathrm{Eq}-2$. Note that the parameter $(\mathrm{f})$ is a conserved scalar.

$$
f=\frac{\phi_{j k}-\phi_{j e t}}{\phi_{\text {main }}-\phi_{j e t}}
$$

The value of (f) varies from 0 to 1 , where 0 is the equivalence ratio value of the unmixed jet and 1 is the equivalence ratio value of the mainstream flow. Note that $f=1-\theta$, where $\theta$ is as defined previously (Holdeman, 1993) and used elsewhere also. The equilibrium (f) value was calculated in a purely adiabatic system at any location downstream of the jet injection. The equivalence ratio and velocity plots as shown in the example plot in Figure-3a are given in the axial-radial plane through the center of the orifice where the axial direction is in the same direction as the mainstream flow direction (flow towards the turbine). Both axial and radial directions are non-dimensionalized with respect to the mixer radius. The $x / R=0$ location denotes the leading edge of the orifice and a $r / R$ location of 1 is the outer wall location. The view is such that the left side of the plot is the upstream side of the mixer.

Three-dimensional orthogonal views of the local NOx production in gr of NOx / $\left\{\mathrm{sec} \mathrm{m}^{3}\right\}$, fuel/air ratio, and temperature are shown in this paper (see example plot in Figure-3b for the NOx production only). The 3-D orthogonal view plots show four different planes that essentially lengthwise split the mixer domain in half. The planes shown are: a) the radial-tangential planes at slightly upstream of $x / R=0, b$ ) slightly downstream of $x / R=1, c$ ) axial-radial plane through the center of the orifice, and d) axial-tangential plane at the outer wall of the mixing section. In order to eliminate any 3-dimensional ambiguity in the interpretation of these 3-D plots, it is necessary to understand that the viewer is looking up at the inside surface of the outer wall of the mixing section and half of the orifice can be seen since the axial-radial plane slices the orifice. It should also be noted that the viewer is located downstream of the mixing section. In these plots, the flow moves from left to right.

The interpolated iso-surface of $10^{-3} \mathrm{gr} \mathrm{NOx} /\left\{\mathrm{sec} \mathrm{m}^{3}\right\}$ is also shown in a different perspective as compared to the previous plots (see example plot in Figure-3c). These 3-D orthogonal plots show the mixing section $(0 \leq x / R \leq 1)$ looking downstream from the upstream end of the mixer. This edge closest to the observer is shown to eliminate the ambiguity of the 3-D perspective. Note that the outer contour (showing the pie section of the mixer) is slightly smaller than the actual mixer (the outer wall is located at $r / R=1$ ) since it is described by the center points of each of the outer most sub-volumes in the NOx analysis. Figure-3d shows the mixer domain and sub-volume breakup used in the NOx calculations. The intersecting points correspond to the center of the sub-volumes. The true 3-D location of the orifice is also shown. The flow is moving from left to right, and the coordinates have been normalized in the $x, y$, and $z$ directions. 


\section{Statistical analysis}

This analysis method involves the detailed characterization of the mixing flowfield using several different statistical techniques. This technique is especially useful for the numerical results since a copious amount of data are obtained from the numerical model with a host of different scalar and vector quantities at several thousand locations in the flowfield. The statistical techniques reported herein therefore characterize the mixing non-uniformity only. Three different statistical methods are reported in this paper:

a) The performance of the mixing section at the radial-tangential planes at $x / R=1$ was quantified by using area weighted planar deviation parameter. The smallest deviation with respect to the equilibrium value indicates the best mixing configuration. This parameter (AMIX) is described in Eq-3. It is also important to note that AMIX does not correct the mixing non-uniformity for the bias introduced in the region of the mixer where the air is being injected through the orifice. However, AMIX is only evaluated at the exit of the mixer $x / R=1$ and is therefore applicable since this plane is downstream of the air injection in all 18 configurations summarized in this report. The area-weighted non-uniformity results are shown in Table-3.

$$
\mathrm{AMIX}=\left[\frac{1}{A_{t o x}} \sum_{*} A_{*}\left(\frac{\phi_{k}-\phi_{* q}}{\phi_{\operatorname{main}}-\phi_{j e t}}\right]^{2}\right]^{1 / 2}
$$

b) The mass flow weighted planar deviation parameter (also evaluated at $\mathrm{x} / \mathrm{R}=1$ ) as defined in $\mathrm{Eq}-4$ is also used to evaluate the mixing region. Note that this parameter is similar to the area weighted parameter in Eq-3, with the added density and velocity weighting terms. The mass flow weighted mixing non-uniformity results for all configurations are shown in Table-3. The smallest MMIX value with respect to the $f_{\text {equil }}$ corresponds to the best mixing uniformity.

$$
\operatorname{MMIX}=\left[\frac{1}{\dot{m}_{m+1}} \sum_{A_{j k} \rho_{k}} u_{i k}\left[\frac{\phi_{k}-\phi_{m q}}{\phi_{\text {min }}-\phi_{j+1}}\right]^{2}\right]^{1 / 2}
$$

c) The flow field was also evaluated by performing a numerical volume integration throughout the mixing section of interest $(0 \leq x / R \leq 1)$ as shown in Eq-5.

$$
\frac{\text { Volume Fraction }}{\text { bin }}=\frac{\sum_{\mathrm{f}_{1 ;}}^{\mathrm{f}_{\mathrm{h}_{\mathrm{i}}}} \text { Volume }_{\mathrm{ijk}}}{\sum_{\mathrm{f}_{\mathrm{mat}}} \text { Volume }_{\mathrm{j} \mathrm{jk}}}
$$

The volume integration parameter allows the analysis of the entire flow field mixture which is more descriptive of the overall flow phenomena in the mixing section as compared to a planar deviation analysis shown in Eqs-3 and 4 . This volume integration was only performed on the equivalence ratio distributions. The entire range of the normalized parameter $f$ (from 0 to 1 ) was sub-divided into 200 equal size bins and the volume of the computational control volumes corresponding to the value of $(f)$ at a certain bin size $\left(f_{i}\right.$ to $\left.f_{i+\Delta f}\right)$ was integrated as shown in Figure-4. The integrated volume in each bin was normalized based on the entire analyzed mixer volume, thus obtaining the normalized volume fraction. The volume fraction for each bin was plotted in the ordinate with the corresponding value of $f$ on the abscissa forming a histogram plot.

The cumulative volume fraction shown in Figure- 4 is the integrated histogram for the range $(0 \leq f \leq 1)$ and used to evaluate the shape of the volume fraction histogram by the definition of $\mathrm{B}(+)$ and $\mathrm{B}(-)$. This evaluation is similar to that used by Oechsle, Mongia, and Holdeman, (1992). The value of $B(t)$ is the "area determined" distribution half width above $f_{\text {oquil }}$ such that the integrated area under the histogram above $f_{\text {equil }}$ is $1 / 2$ that of the overall histogram area above $f_{\text {equil. }}$. The same applies to $B(-)$ for the area below $f_{\text {equil }}$. The definitions of $B(+)$ and $B(-)$ are shown pictorially in Figure-4. The most uniform mixing results yields lowest $\mathrm{B}(+)$ and $B(-)$, meaning that the histogram distribution width effectively collapses towards the equilibrium value of (f). The histogram shape value SUM-B (which is the value reported in this paper) is defined as the sum of $B(+)$ and $B(-)$.

The summary of both mixing uniformity and NOx production flowrate trends for the 18 configurations are described in the following sections:

1) effect of orifice shape on mixing and NOx

2) effect of J on mixing and NOx production,

3) effect of slot slant angle on mixing and NOx

4) configuration optimization at different $J$, and

5) correlation between NOx production and the mixing flowfield 


\section{Results and Discussion}

Effect of orifice shape on NOx production and mixing non-uniformity

Note that the corresponding non-reacting distributions appear in Oechsle, Mongia, and Holdeman (1992) and corresponding experimental equivalence ratio plots and NOx inference distributions appear in Hatch, et al. (1992a and b). The mixing non-uniformity and NOx production were compared for the round orifices, $45^{\circ}$ slots with $\mathrm{L} / \mathrm{W}=4$, and $45^{\circ}$ slot with $\mathrm{L} / \mathrm{W}=8$ for $\mathrm{J}=25$ (configuration numbers 19,20 , and 24 respectively), at $\mathrm{J}=52$ (configuration numbers 23,29 , and 25 ), and $J=80$ (configuration numbers 22,30 , and 26 ). These configurations are shown in Figure-2.

\section{$\mathrm{J}=\mathbf{2 5}$}

The results at $\mathrm{J}=25$ shown in Figures-5a and 6 indicate that the round orifice produces less NOx for eight orifices at this momentum-flux ratio. Figure-5a shows the results of all three statistical parameters AMIX, MMIX, and SUM-B depicting the mixing non-uniformity. Figure- 6 indicates the flowfield development throughout the mixing section with the normalized equivalence ratio on the left column and velocity vectors on the right. As mentioned previously, the lowest values are desired for all three parameters. In addition to the mixing, the cumulative NOx production in $\mathrm{gr} / \mathrm{sec}$ up to $x / R=1$ is also plotted. The cumulative NOx value at $x / R=1$ is the total NOx flowrate produced throughout the mixer including any that may be produced upstream of the orifice injection due to the upstream jet flow recirculation in some of the configurations. In order to make relative comparisons between the mixing and NOx, the SUM-B and CUM-NOx parameters have been scaled to adequately fit in the bar charts ranging from 0 to 0.35 and all configurations are equally scaled to eliminate any bias. Note that these charts are only useful in the extrapolation of general trends and relative comparisons between configurations and should not be used for absolute evaluations. The resuits indicate that even though the round orifice has stronger jet penetration and lower cumulative NOx production as compared to the slanted slots which generally underpenetrate. Figure-7 indicates the location of NOx production for the round hole and elongated slot $(L / W=8)$. The slot configuration (\#24), shown in the interpolated iso-surface for max NOx production in Figure-7b indicates that additional NOx is produced below the orifice near the center of the mixer due to shallow penetration and induced swirl (see Figure-7d). Also note that the results generally indicate an increase in NOx production near the $x / R=1$ for both best and worst NOx production configurations shown in Figure-7. which is caused by mixing the hot gases entering the domain and the cool gases from the jets along with the high residence time which mainly occurs downstream of the orifice.

The mixing results indicate marginal improvement in the mixing nonuniformity with increased orifice aspect ratio (best mixer is the $\mathrm{L} / \mathrm{W}=8$ slot conf \# 24) as shown consistently by ail the three statistical parameters (AMIX, MMIX, and volume histograms) in Figure-5a. Both mixing results and NOx predictions show no general correlating trends. Note that the volume histograms denoting the mixture non-uniformity indicate that the round orifice has a significantly large portion of the overall volume at the nondimensionalized equivalence ratio (f) near zero (see Figure-7e) as compared to the $\mathrm{L} / \mathrm{W}=8$ slanted slot in Figure-7f. This indicates that the NOx production with the round orifice is low since the jet flow quenches the mainstream flow. It is also recognized (although not analyzed in this study) that the production of $\mathrm{CO}$ and unburned hydrocarbons may be high since the jet flow appears to be overly quenching the rich zone products to a value much below the equilibrium value. It is also recognized that the unmixed jet could eventually mix with the mainstream flow downstream of the $x / R=1$ boundary and therefore produce NOx.

$\mathrm{J}=\mathbf{5 2}$

The results at $J=52$ are shown in Figures-5b, 8, and 9. At $\mathrm{J}=52$, the increase in penetration for the round jet appears to increase the NOx production since the wake behind the jet is larger (see top plot in Figure-8). Similarly, the slanted orifices appear to have better NOx performance as compared to the round orifice due to a more shallow jet penetration. Therefore, the jet penetration appears to be an essential parameter in controlling the NOx production. The lowest NOx configuration was the 45 degree slot $L / W=4$ (conf \#29) and the highest NOx producer at $\mathrm{J}=52$ is the $\mathrm{L} / \mathrm{W}=8$ slot. Both of these configurations are shown in Figure-9.

The area weighted parameters (AMIX, MMIX, and volume integrals) indicate improvement in mixing uniformity as the slot aspect ratio increases (assume the round hole as a slot with an aspect ratio $L / W=1$ ). Both NOx and mixing trends are seemingly opposing each other in this comparison since the best mixing configuration is the highest NOx producer and these results seem to agree with the comparison at $\mathrm{J}=25$ summarized previously. The volume histograms shown in Figure-9e and $f$ however indicate marginal change in the overall mixing flowfield equivalence ratio non-uniformity.

\section{$\mathrm{J}=\mathbf{8 0}$}

The results at $\mathrm{J}=80$ are shown in Figures-5c, 10, and 11 As $\mathrm{J}$ is increased to 80 , the results indicate that the highest NOX production is attained with the round holes and lowest NOx production is attained with the 45 degree slots, $\mathrm{L} / \mathrm{W}=8$. The ratio of the highest to the lowest NOx production is about 1.8 (see Figure-5c). The round orifice jet appears to penetrate to the core of the mixer as shown in Figure-10. The $45^{\circ}$ slot with $\mathrm{L} / \mathrm{W}=4$ seems to be somewhat over penetrating but the $\mathrm{L} / \mathrm{W}=8$ slot appears to approach optimum penetration. The best and worst NOx production configurations at $\mathrm{J}=80$ for the change in orifice geometry are shown in Figure-11. The 45 degree slot with aspect ratio $(\mathrm{L} / \mathrm{W}=8)$ indicates no NOx 
formation upstream of the orifice (see Figure-11c) as opposed to the over-penetrating jet produced by the hole (Figure-11d). Both configurations however produce NOx downstream of the orifice near the outer wall behind the orifice. It is aiso worthy to note that the secondary peak at $\mathrm{f}=0.31$ shown in Figure-11f corresponds to significant $\mathrm{NOx}$ production for the round hole.

The NOx production reduction trends appear to agree with the improvement in the mixing at $\mathrm{J}=80$ as one would expect. This probably is due to the general decrease in jet penetration as the slot aspect ratio is increased from 1 (round) to 8 only superseded by the fact that optimum jet penetration is being approached from the over-penetrating side. Conversely, the previous comparison at $\mathrm{J}=25$, optimum jet penetration appears to be approached from the under-penetrating side, and therefore NOx production and mixing trends appear to contradict. It is therefore apparent that optimizing the jet penetration could lead to minimized NOx formation as long as the downstream region behind the orifice is small enough not to produce NOx. Consequently, deviations from this optimum jet penetration could lead to increased NOx formation.

Figure-12 indicates the comparison of the NOx production evolution throughout the mixing section for the change in orifice configuration at $\mathrm{J}=25,52$, and 80 . The results show significant NOx production downstream of the orifice at $x / R$ $>1$ which is important to note. Several cases that over-penetrate indicate NOx production upstream of the orifice (see Figure-12e and $\mathrm{f}$ ). It is also important to note that the lowest overall NOx production configuration of the 9 cases cited in this section is the 45 degree slot $L / W=8$ at $J=80$ (see Table-3).

\section{Effect of $J$ on NOx production and mixing non-uniformity}

Three different orifice shapes were compared for increasing $\mathrm{J}$ : round orifices (configuration numbers 19,23 , and 22 ) , 45 degree slanted slots with aspect ratio $\mathrm{L} / \mathrm{W}=4$ (configuration numbers 20,29 , and 30 ), and 45 degree slanted slots with aspect ratio $\mathrm{L} / \mathrm{W}=8$ (configuration numbers 24,25 , and 26 ) see Figure-2.

\section{Round orifices}

The effect of the increase in J on the NOx production of the round orifices indicates that over-penetration tends to increase the NOx formation by increasing the orifice wake volume as shown in Figures-13a. 14, and 15. The increase in jet penetration produces an upstream recirculation near the center core of the mixer (see Figure-14) and this added mixing structure produces NOx formation upstream of the orifice (see Figure-13a). The area weighted parameters AMIX and MMIX indicate increased mixing non-uniformity for increasing J. The best mixing configuration is the lowest NOx producer in this case (Round hole conf \# 19 at $J=25$ ) and worst mixing configuration is the round hole at $J=80$ due to the over-penetrating jet shown in Figure- 15 .

\section{$45^{\circ}$ Slots, with aspect ratio $L / W=4$}

The effect of the increase in $J$ on the NOx production of the $45^{\circ}$ slots with aspect ratio $\mathrm{L} / \mathrm{W}=4$ is shown in Figures $-13 \mathrm{~b}$. 16 and 17 . The results in Figure-12b indicate that the NOx production with this slanted slot decreases with increasing $J$ from 25 to 80 probably mostly due to the optimization of the jet penetration as approached from the under-penetrating side. The planar mixing non-uniformity deviations (AMIX and $\mathrm{MMIX}$ ) indicate deteriorating mixing performance at $x / R=1$ with increasing $J$ from 25 to 80 which generally opposes the NOx production trends (see Figure-13b). This is caused by the hot mainstream flow which tends to be stratified near the outer wall region of the mixer. This phenomena was discussed previously by Oechsle, Mongia, and Holdeman (1993). The best mixing configuration (45 degree slot. $\mathrm{L} / \mathrm{W}=4$ at $\mathrm{J}=25$ ) appears to be the highest $\mathrm{NOx}$ producer. Similarly, the worst mixing configuration (45 degree slot. $\mathrm{L} / \mathrm{W}=4$ at $\mathrm{J}=80$ ) produces the lowest $\mathrm{NOx}$ producer.

\section{$45^{\circ}$ Slots, with aspect ratio $L / W=8$}

The effect of the increase of $\mathrm{J}$ on the NOx production of the $45^{\circ}$ slots with aspect ratio $L / W=8$ is shown in Figures $-13 \mathrm{c}$. 18 , and 19 . The results indicate that this configuration approaches optimal jet penetration from the under-penetrating side with the increase in J from 25 to 80. Minimum NOx production is obtained with the highest $J$ condition and highest NOx production obtained at $\mathrm{J}=25$ (see Figure-13c), Figures-19b and d show the effect of jet under-penetration on NOx formation near the center of the mixer for configuration \#24 ( $\mathrm{L} / \mathrm{W}=8$ slot, $\mathrm{J}=25$ ). As $\mathrm{J}$ is increased to $J=80$, the jet penetration sufficiently prevents any NOx production in the center core of the mixer (Figure-19a and $c$ ). The planar deviations (AMIX and MMIX) indicate small changes in mixing non-uniformity for increasing $J$ probably due to the weak effect of jet penetration with changes in $\mathrm{J}$ for this particular orifice shape as shown in Table-3. Aside from a slightly higher peak at $\mathrm{f}=0.1$, the volume histograms shown in Figures-19e and for the best and worst NOx production cases are nearly the same. This also correlates with the planar mimxing deviation parameters AMIX and MMIX results shown in Figure-13c.

Figure-20 shows the history of the NOx formation throughout the mixer for the different orifice shapes as $J$ is increased from 25 to 80 . Note that the rate of increase in NOx cumulative production (Figure-20b and d) are nearly the same for the round annd 45 degree slots $(L / W=4)$ up to $x / R=1$.

\section{Effect of slot slant angle on NOx production and mixing non-uniformity}

In this section. a parametric study was performed by varying the slot slant angle from $0^{\circ}$ (in line with the flow) to $90^{\circ}$ (transverse direction) for the aspect ratio $\mathrm{L} / \mathrm{W}=4$ slot oniy. The results are presented for constant $J$ conditions. The cases 
compared are: at $\mathrm{J}=25$, configuration numbers are 34,27 , and 20 at slant angles 0,22.5, and 45 degrees respectively; at $\mathrm{J}=52$, configuration numbers are $21,28,29$, and 31 at slant angles of $0,22.5,45$, and 67.5 degrees respectively; and at $J=80$, configuration numbers are $32,35,30,33$, and 36 for slant angles of $0,22.5,45,67.5$, and 90 degrees respectively. Note that some of the slant angles have been omitted from the study since they do not fit in the mixer.

\section{$\mathrm{J}=\mathbf{2 5}$}

At the lowest $\mathrm{J}$ condition ( $\mathrm{J}=25)$, the change in NOx production for slant angles (varying from 0 to $45^{\circ}$ ) are shown in Figures-21a, 22, and 23. It is apparent that slot slant angle at low $\mathrm{J}$ has a significant effect on NOx production at $\mathrm{x} / \mathrm{R}=1$ with a $45 \%$ increase in NOx production from the best to worst (see Figure-21a). In addition, the jet penetration also changes significantly in these three cases (see Figure-22 and Table-3). The trends of both NOx formation and mixing appear to contradict since minimum NOx formation was obtained with the configuration with a the highest jet penetration which is the aligned slot. However. improved mixing was obtained with the 45 degree slot. All statistical mixing parameters indicate that the 45 degree slot is the most uniformly mixed of all three cases as shown in Figure-21a. The best and worst NOx production configurations for the variation of the slot slant angle at $J=25$ are plotted in Figure-23. The mixing results shown in Figure-23e indicate that the ( 0 degree) aligned slot has significant portion of the volume near $f=0$ as opposed to Figre-23f for the 45 degree slot. This means that NOx production tends to be lower for the slot however, this also means that mixing may eventually take place downstream of the mixer and NOx may be produced.

\section{$J=52$}

The results for the comparison at $J=52$ are shown in Figures-21b, 24, and 25. At $\mathrm{J}=52$, the NOx production appears to change significantly with slant angle and the lowest NOx producer was obtained with the largest slant angle slot $\left(67.5^{\circ}\right)$ slant angle slot as seen in Figure-21b. Conversely, the highest NOx (only $25 \%$ above the lowest NOx producer) was obtained with the $0^{\circ}$ slant (in-line slot). Note that the NOx production appears to be directly proportional to the increase in slant angle, which itself is inversely proportional to the jet penetration (see Figure-24). The mixture of gases which recirculate upstream of the orifice tend to produce NOx which would not be produced in a configuration producing more optimum jet penetration as shown for the 67.5 degree slanted slot results (configuration \# 31 in Figure-25c and d).

The area and mass flow weighted mixing non-uniformity results shown in Figure-21b indicate that slot slant angle variation from 0 to 45 degrees does not appear to significantly affect the mixing performance. There however seems to be a noticeable improvement in the mixing when the slant angle is increased from 45 to 67.5 degrees. All statistical parameters indicate the same trend. In addition, the histogram plots in Figure-25e and $f$ indicate that the lowest NOx configuration gives a histogram shape that would more likely indicate better equivalence ratio uniformity with a peak near $\mathrm{f}_{\text {equil }}$ (see Figure-25e) as opposed to the worst NOx production configuration identified in Figure-25f. Apparentiy, the blockage value and jet penetration are optimal such that only a small amount of the mainstream flow is entrained in the wake area behind the orifice. Perhaps the combination of the jet penetration and blockage forms the right size and shape wake region to optimize mixing near the outer wall of the circular mixer.

\section{$\mathrm{J}=\mathbf{8 0}$}

The results for the comparison at $\mathrm{J}=80$ are shown in Figures-21c, 26, and 27. the NOx production changes significantly with slant angle and the lowest NOx was obtained with the $67.5^{\circ}$ slant angle slot at $x / R=1$ as seen in Figures-21c. It is also important to note that the $67.5^{\circ}$ slot produced the lowest NOx compared to all the 18 configurations reported herein and this correlates with one of the best mixing configuration as reported by Oechsle. Mongia, and Holdeman (1992). As the slot slant angie increases, mixing improves and NOx production decreases. The highest NOx production configuration at $J=80$ for varying slant angles is the aligned slot (see Figure-27b, d, and $f$ ). Figure-27 shows that NOx formation around the orifice becomes significant for the low slant angle high jet penetration configuration \# 32 (see Figures $27 \mathrm{~b}$ and d). As the slant angle increases, the NOx production becomes localized only in the region behind the orifice (see Figures-27a and c). It is therefore evident that the jet penetration, which is directly proportional to the slant angle, affects the NOx production. Adequate penetration is therefore necessary to minimize NOx and deviations from this value (for any given configuration) would probably tend to increase this emission in a mixing zone. However. it is also evident from the results shown in Figure-27c that other factors. in addition to the jet penetration, generally affect the NOx production and this will be examined later in this paper.

The NOx production comparison in Figure-28 indicate that most of the configurations except for the 67.5 degree slanted slot $(\mathrm{L} / \mathrm{W}=4)$ shown in Figure-28e and $\mathrm{f}$ at $\mathrm{J}=80$ produce significant NOx downstream of the $x / R=1$ boundary. Therefore, configurations with moderate penetration with good mixing near the outer wall of the mixer generally produce low NOx in a circular mixer. Over-penetrating jets produce NOx upstream of the orifice. However, the amount of NOx produced upstream of the orifice as shown in Figure-28f is generally low compared to that produced in the mixing section itself between $x / R=0$ to 1 .

According to the mixing non-uniformity results, the best mixing configuration is the transverse slot configuration \#36. 
This configuration also is the best overall mixing configuration of all 18 compared in this paper. The trends of both the mixing results and NOx results do not appear to correlate in this comparison. Worst mixing was obtained with the 45 degree slot at $J=80$ due to the flow stratification similar to that described by Oechsle, Mongia, and Holdeman (1992). Therefore it is apparent from this comparison as well as the previous ones described above that NOx production does not correlate with the statistical parameters used to describe the mixing criteria. Therefore selecting a specific mixer configuration for low NOx production just on the basis of the mixing non-uniformity flowfield requires a different approach. The results of the NOx and mixing criteria correlations are described in the next section.

\section{Configuration optimization at different J conditions}

The best and worst NOx production cases as a function of $\mathrm{J}$ are shown in Figure-29. All configurations at a particular $J$ condition are compared, noting that both MR and $D R$ are constant in the comparison. It is also worth considering that the 18 configurations analyzed herein may not display the particularly optimum condition for either best mixing (best jet penetration and/or NOx production) for a particular $\mathrm{J}$ since the number of orifices is not considered as a variable in this study. It is apparent in Figure-29 that the bulk of the NOx production is formed in the wake and downstream region behind the orifice and these results are also shown in Figure-30. In this figure, the localized NOx production for all configurations is plotted as a function of non-dimensional position. The $\pm 2 \sigma$ variations indicate the spread of the data with respect to the numerical mean as a function of position. Figure-25a indicates that the NOx production increases with distance from the orifice leading edge, Figure-25b indicates that NOx formation is more concentrated towards the outer wall of the mixer, and finally, Figure-25c indicates that the NOx is generally independent of transverse position in this global comparison.

The round hole appears to be lowest NOx production configuration at the lowest $J$ condition due to its optimum penetration. The optimum number of orifices for best penetration is also calculated by Holdeman (1993) using Eq-6 where $\mathrm{n}$ is the number of orifices and $\mathrm{C}=2.5$. Based on Eq-6, the optimum number of holes is 9 which is similar to the 8 round hole case modeled in conf \# 19. Similarly for $\mathrm{J}=52$ and 80 , the optimum number of round holes would be 13 and 16 respectively, which is consistent with the observed over-penetration for 8 holes at these momentum-flux ratios.

$$
\mathrm{n}=\frac{\pi \sqrt{2 \mathrm{~J}}}{\mathrm{C}}
$$

For 8 orifices, increasing the operating condition $(\mathrm{J})$ appears to shift the optimum low NOx configuration from the round holes to the slanted slots. Lowest NOx was produced with the large slant angle slots (67.5 degrees) with aspect ratio of 4. It is believed that the optimum $L / W=8$ slot was not within the $J$ range analyzed in this parametric study since these exhibited the lowest jet penetration. Therefore, if RQL applications require a high mixing region pressure drop ( $\mathrm{J}$ above 80 ), it is possible that the optimum low NOx configuration could be shifted to this type of orifice. This extrapolation is based on the fact that the second lowest overall NOx production configuration of those reported herein is the $\mathrm{L} / \mathrm{W}=8$ slot at 45 degree slant angle at $\mathrm{J}=80$.

\section{Correlation between NOx production and mixing results}

After reviewing these results, it becomes apparent that jet wake volume is a possible correlating parameter between mixing and NOx production. For this purpose, a non-dimensional wake volume parameter was constructed using Eq-7. This non dimensional volume approximates the volume of the wake behind the orifice up to $x / R=1$. Note that it is only an approximation because this parameter does not consider the jet penetration transition angle as the jet flow is assimilated into the mainstream flow. Therefore its purpose is only to establish general trends between mixing flow characteristics and the cumulative NOx production rate up to $\mathrm{x} / \mathrm{R}=1$.

$$
\text { Wake Vol }=\left[1-(1-\text { pen })^{2}\right](\text { blockage })(1-(\text { T.E. } x / R))
$$

Where,

$$
\begin{aligned}
& \text { pen } \quad=\text { non-dimensional jet penetration }(r / R) \text { from th } \\
& \text { outer wall of the mixer (see Table-3) } \\
& \text { blockage = orifice blockage (see Tables-1, 2, and 3) } \\
& \text { T.E. } X / R=\text { orifice trailing edge } x / R \text {, (see Tables-1, \& 2). }
\end{aligned}
$$

The results showing the correlation between NOx production and the non-dimensional wake volume are given in Figure-31. The results shown in Figure-3 la indicate that as the non-dimensional shape orientation ratio (blockage / T.E. $x / R$ ) increases, the NOx production decreases regardless of $J$ for the symmetrical orifice configurations. The non-dimensoinal orifice shape orientation ratio is the smallest for the aligned slot and the largest for the transverse slot (conf \# 36). The results shown in Figure-31b indicate that as slot slant angle increases, NOx increases only for the low J condition since a somewhat under penetrated case $(22.5$ degree slot conf \# 27) becomes even more under penetrated with the increase of slant angle to 45 degree (conf \# 20). This trend however reverses for the higher $J$ conditions which have sufficient jet momentum to allow for slot slant angle variation to a more optimized geometric configuration. All the data points plotted in Figure- $31 \mathrm{~b}$ are only for the $\mathrm{L} / \mathrm{W}=4$ slots. The results shown in Figure-31c indicate the approach towards NOx reduction optimization of each orifice configuration as $\mathrm{J}$ is increased. For the orifices with lower orifice shape orientation ratio such as the aligned slot, 22.5 degree 
slot, and the round hole, the NOx production increases for increasing $J$, generally as a result of over penetration. However, higher orifice shape orientation ratios such as the 67.5 degree slot and transverse slot reverse the trend due to their inherent low jet penetration, and approach the optimum desired jet penetration from the under-penetrated side as $J$ increases from 25 through 80 . This correlation indicates that the non-dimensional wake volume is a possible correlating parameter linking the mixing flow structure to the NOx production; however, improvements could be made if parameters such as J, orifice shape orientation, and velocity distribution are added in order to obtain a more generalized correlating parameter.

\section{Conclusions}

1) The mixing statistical parameters in most cases do not correlate with the NOx production rates at $x / R=1$. The planar variances at $x / R=1$ lack the mixing history throughout the entire mixing region and the volume integrals require the residence time factor for completeness.

2) NOx production is shown to be highly related to the jet penetration. Over penetrating configurations show increased NOx production as so do under-penetrating cases. At low $J$ conditions, an orifice with large orientation shape ratio tends to under penetrate and show characteristics of a non-optimal NOx reduction configuration: and subsequently higher $J$, tends to decrease the NOx production. Similarly, in the range of $J$ analyzed herein, orifices with low orientation shape ratios tend to over penetrate indicating non-optimal mixer configurations; and subsequent increase $J$, increases the amount of NOx produced.

3) NOx production correlation with position indicates that for all the 18 configurations summarized in this report, most of the NOx produced occurs near or in the orifice wake region. After correlating the NOx production with the non-dimensional wake volume, results indicate that trends do exist but additional terms such as orifice shape ratio, velocity, and $\mathrm{J}$ need to be incorporated to obtain a more general relation to correlate mixing with NOx.

4) At the lowest $J$ condition, the circular orifice indicated the lowest NOx production, and at higher $J$ conditions. the optimization shifted towards the large slant angle slots such as the 67.5 degree slot $L / W=4$. High NOx production was obtained with the aligned slots due to the over-penetrating jet structure. Over penetrating jets also cause additional NOx to be produced upstream of the orifice.

5) The lowest NOx formation in a mixing region may not necessarily mean lowest NOx in the overall RQL combustor. The mixture non-uniformity in the mixing section needs to also be evaluated along with the NOx production to prevent any further unmixed flow from developing in the lean zone and producing NOx where is currently not accounted for in this paper.

\section{Acknowledgements}

This work was supported by NASA Contract NAS3-25950, Task Order \# 1.

\section{References}

Bain, D.B., Smith, C.E., and Holdeman, J.D. (1992), "CFD Mixing Analysis of Jets Injected from Straight and Slanted Slots into Confined Crossflow in Rectangular Ducts," AIAA paper No. 92-3087. (Also NASA TM 105699).

Bain, D.B., Smith, C.E., and Holdeman, J.D. (1993), "Parametric CFD Analysis of Jet Mixing into Confined Crossflow in Rectangular Ducts," AIAA paper No. 93-2044. (Also NASA TM 106179).

Bain, D.B., Smith, C.E., and Holdeman, J.D. (1994), "CFD Assessment of Orifice Aspect Ratio and Mass Flow Ratio on Jet Mixing in Rectangular Ducts," AIAA Paper No. 94-0218. (Also NASA TM 106434).

Bruce, T.W., Mongia, H.C., and Reynolds, R.S. (1979), "Combustion design criteria validation,", (USARTL-TR78. $55 \mathrm{~A}, \mathrm{~B}$, and $\mathrm{C})$.

Doerr, Th., and Hennecke, D.K. (1993), "The Mixing Process in the Quenching Zone of the Rich-Lean-Combustion Concept," AGARD-PEP 81st Sympossium of Fuels and Combustion Technology for Advanced Aircraft Engines.

Hatch, M.S., Sowa, W.A., Samuelsen, G.S., and Holdeman, J.D. (1992a), "Jet Mixing Into a Heated Cross Flow in a Cylindrical Duct: Influence of Geometry and Flow Variations," AIAA Paper No. 92-0773. (Also NASA TM 105390).

Hatch, M.S.. Sowa, W.A., Samuelsen, G.S., and Holdeman, J.D. (1992b), "Influence of Geometry and Flow Variations on NO Formation in the Quick Mixer of a Staged Combustor," NASA TM 105639.

Holdeman, J.D., "Mixing of Multiple Jets with a Confined Subsonic Crossflow (1993)," Prog. Energy Combust. Sci., (1993), Vol 19, pp 31-70. (Also see AIAA Paper No. 91-2458 and NASA TM 104412).

Howe, G.W., Li, Z., Shih, T.I.-P., and Nguyen, H.L. (1991), "Simulation of mixing in the quick quench region of a rich burn - quick quench mix - lean burn combustor," AIAA Paper No. 91-0410.

Kroll, J.T., Sowa, W.A., Samuelsen, G.S., and Holdeman, J.D. (1993), "Optimization of Circular Orifice Jets Mixing into a 
Heated Crossflow in a Cylindrical Duct," AIAA Paper No. 93-0249.

Launder, B.E., and Spalding, D.B. (1972), "Lectures in Mathematical Models of Turbulence," Academic Press Inc. (London) LTD.

Liscinsky, D.S.. True, B., Vranos, A., and Holdeman. J.D. (1992), "Experimental Study of Cross-Stream Mixing in a Rectangular Ducts," AIAA Paper No. 92-3090. (Also NASA TM 106194).

Liscinsky, D.S., True, B., and Holdeman, J.D. (1993), "Experimental Investigation of Crossflow Jet Mixing in a Rectangular Duct." AIAA Paper No. 93-2037. (Also NASA TM 106152).

Liscinsky, D.S., True, B., and Holdeman, J.D. (1994), "Mixing Characteristics of Directly Opposed Rows of Jets Injected Normal to a Crossflow in a Rectangular Duct," AIAA Paper No. 94-0217. (Also NASA TM 106477).

Oechsle, V.L., Mongia, H.C., and Holdeman, J.D. (1992), "A Parametric Numerical Study of Mixing in a Cylindrical Duct," AIAA Paper No. 92-3088. (Also NASA TM 105695).

Oechsle, V.L., Mongia, H.C., and Holdeman, J.D. (1993), "An Analytical Study of Jet Mixing in a Cylindrical Duct," AIAA Paper No. 93-2043. (Also NASA TM 106181).

Oechsle, V.L., Mongia, H.C., and Holdeman, J.D. (1994), "Comparison of the Mixing Calculations of Reacting and Nonreacting Flows in a Cylindrical Duct," AIAA Paper No. 94-0865. (Also NASA RM 106435).

Patankar,S.V. (1980), "Numerical Heat Transfer and Fluid Flows," Hemisphere, Washington D.C.

Rizk, N.K.. Mongia, H.C. (1993), "Three-Dimensional $\mathrm{NO}_{\mathrm{X}}$ Model for Rich/Lean Combustor," AIAA Paper No. 93-0251.

Shaw, R.J. (1991), "Engine Technology Challenges for a 21st Century High Civil Speed Transport," AIAA 10th International Symposium on Air Breathing Engines. (Also NASA TM 104361).

Smith, C.E., Talpallikar, M.V., and Holdeman, J.D. (1991), "A CFD Study of Jet Mixing in Reduced Flow Areas for Lower Combustion Emissions," AIAA Paper No. 91-2460. (Also NASA TM 104411).

Sowa, W.A., Kroll, J.T., Samuelsen, G.S., and Holdeman, J.D. (1994), "Optimization of Orifice Geometry for Cross-FLow Mixing in a Cylindrical Duct," AIAA Paper No. 94-0219. (Also NASA TM 106436).

Talpallikar, M.V., Smith, C.E., Lai, M.C., and Holdeman, J.D. (1992), "CFD Analysis of Jet Mixing in Low $\mathrm{NO}_{\mathrm{x}}$ Flametube
Combustors, "J. Eng. Gas Turbine Pwr. 114. 416. (Also ASME Paper No. 91-GT-217; NASA TM 104466).

Vranos. A., Liscinsky, D.S., True, B., and Holdeman, J.D. (1991). "Experimental Study of Cross-Stream Mixing in a Cylindrical Duct." AIAA Paper No. 91-2459. (Also NASA TM 105180).

Zhu, G.. and Lai, M.-C. (1992), "A parametric study of penetration and mixing of radial jets in necked-down cylindrical crossflow," AIAA Paper No. 92-3091. 


\begin{tabular}{|c|c|c|c|c|c|c|c|c|c|c|}
\hline PARAMETER & UNITS & 19 & 20 & 21 & 22 & 23 & 24 & 25 & 26 & 27 \\
\hline OVERALL & & & & & & & & & & \\
\hline J (jet/mian) & & 26.7 & 30.5 & 51.1 & 84.1 & 55.3 & 28.1 & 50.9 & 88.4 & 28.0 \\
\hline MR (jet/main) & & 2.96 & 2.96 & 2.96 & 2.96 & 2.96 & 2.96 & 2.96 & 2.96 & 2.96 \\
\hline DR(jet/main) & & 2.278 & 2.278 & 2.278 & 2.278 & 2.278 & 2.278 & 2.278 & 2.278 & 2.278 \\
\hline VR (jet/main) & & 3.424 & 3.659 & 4.736 & 6.080 & 4.896 & 3.512 & 4.727 & 6.233 & 3.506 \\
\hline Ar (jet/main) & & 0.380 & 0.355 & 0.274 & 0.214 & 0.264 & 0.370 & 0.275 & 0.209 & 0.371 \\
\hline Phi (rich zone) & & 1.80 & 1.80 & 1.80 & 1.80 & 1.80 & 1.80 & 1.80 & 1.80 & 1.80 \\
\hline Phi (lean zone) & & 0.42 & 0.42 & 0.42 & 0.42 & 0.42 & 0.42 & 0.42 & 0.42 & 0.42 \\
\hline $\mathbf{D P} / \mathbf{P}$ & $\%$ & 1.38 & 1.58 & 2.64 & 4.35 & 2.86 & 1.45 & 2.63 & 4.57 & 1.45 \\
\hline & & & & & & & & & & \\
\hline MAINSTREAM & & & & & & & & & & \\
\hline P main & atm. & 14.1 & 14.1 & 14.1 & 14.1 & 14.1 & 14.1 & 14.1 & 14.1 & 14.1 \\
\hline T main & $\mathbf{K}$ & 2,164 & 2,164 & 2,164 & 2,164 & 2,164 & 2,164 & 2,164 & 2,164 & 2,164 \\
\hline U main & $\mathrm{m} / \mathrm{sec}$ & 25.4 & 25.4 & 25.4 & 25.4 & 25.4 & 25.4 & 25.4 & 25.4 & 25.4 \\
\hline$\dot{\mathrm{m}}$ main & $\mathrm{kg} / \mathrm{sec}$ & 0.266 & 0.266 & 0.266 & 0.266 & 0.266 & 0.266 & 0.266 & 0.266 & 0.266 \\
\hline Mixer diameter & m & 0.076 & 0.076 & 0.076 & 0.076 & 0.076 & 0.076 & 0.076 & 0.076 & 0.076 \\
\hline & & & & & & & & & & \\
\hline$J E T$ & & ROUND & SLOT & SLOT & ROUND & ROUND & SLOT & SLOT & SLOT & SLOT \\
\hline$P_{\text {jet }}$ & atm. & 14.1 & 14.1 & 14.1 & 14.1 & 14.1 & 14.1 & 14.1 & 14.1 & 14.1 \\
\hline T jet & $\mathbf{K}$ & 950 & 950 & 950 & 950 & 950 & 950 & 950 & 950 & 950 \\
\hline$v_{\text {jet }}$ & $\mathrm{m} / \mathrm{sec}$ & 86.8 & 92.8 & 120.1 & 154.1 & 124.1 & 89.0 & 119.8 & 158.0 & 88.9 \\
\hline$\dot{\text { m jet }}$ & $\mathrm{kg} / \mathrm{sec}$ & 0.788 & 0.788 & 0.788 & 0.788 & 0.788 & 0.788 & 0.788 & 0.788 & 0.788 \\
\hline ACd jet/row & $\mathbf{m}^{2}$ & $1.732 \mathrm{e}-03$ & $1.620 \mathrm{e}-03$ & $1.252 \mathrm{e}-03$ & $9.753 \mathrm{e}-04$ & $1.202 \mathrm{e}-03$ & $1.688 \mathrm{e}-03$ & $1.254 \mathrm{e}-03$ & $9.512 \mathrm{e}-04$ & $1.691 \mathrm{e}-03$ \\
\hline Orifice Cd & & 0.75 & 0.74 & 0.77 & 0.74 & 0.76 & 0.75 & 0.77 & 0.76 & 0.75 \\
\hline Number of orifices & & 8 & 8 & 8 & 8 & 8 & 8 & 8 & 8 & 8 \\
\hline Orifice L/W & & 1 & 4 & 4 & 1 & 1 & 8 & 8 & 8 & 4 \\
\hline Orifice slant angle & & 0 & 45 & O & 0 & 0 & 45 & 45 & 45 & 22.5 \\
\hline Orifice length $(L)$ & m & 0.017 & 0.029 & 0.026 & 0.012 & 0.014 & 0.042 & 0.036 & 0.031 & 0.030 \\
\hline Orifice width $(\mathrm{W})$ & m & 0.017 & 0.007 & 0.006 & 0.012 & 0.014 & 0.005 & 0.004 & 0.004 & 0.007 \\
\hline Blockage & & 0.5548 & 0.7630 & 0.2149 & 0.4164 & 0.4623 & 1.0351 & 0.8922 & 0.7770 & 0.5364 \\
\hline Orifice T.E. $\mathbf{x} / \mathbf{R}$ & & 0.4357 & 0.5992 & 0.6750 & 0.3270 & 0.3631 & 0.8130 & 0.7007 & 0.6103 & 0.7398 \\
\hline
\end{tabular}

Table-1. Configuration description and parameter specifications for configurations 19 through 27 


\begin{tabular}{|c|c|c|c|c|c|c|c|c|c|c|}
\hline PARAMETER & UNITS & 28 & 29 & 30 & 31 & 32 & 33 & 34 & 35 & 36 \\
\hline OVERALL & & & & & & & & & & \\
\hline$J$ (jet/mian) & & 53.2 & 57.6 & 92.9 & 59.9 & 93.0 & 99.3 & 26.0 & 88.1 & 106.2 \\
\hline MR (jet/main) & & 2.96 & 2.96 & 2.96 & 2.96 & 2.96 & 2.96 & 2.96 & 2.96 & 2.96 \\
\hline DR(jet/main) & & 2.278 & 2.278 & 2.278 & 2.278 & 2.278 & 2.278 & 2.278 & 2.278 & 2.278 \\
\hline VR (jet/main) & & 4.832 & 5.033 & 6.390 & 5.128 & 6.393 & 6.603 & 3.378 & 6.219 & 6.831 \\
\hline Ar (jet/main) & & 0.269 & 0.258 & 0.203 & 0.253 & 0.203 & 0.197 & 0.385 & 0.209 & 0.190 \\
\hline Phi (rich zone) & & 1.80 & 1.80 & 1.80 & 1.80 & 1.80 & 1.80 & 1.80 & 1.80 & 1.80 \\
\hline Phi (lean zone) & & 0.42 & 0.42 & 0.42 & 0.42 & 0.42 & 0.42 & 0.42 & 0.42 & 0.42 \\
\hline $\mathbf{D P} / \mathbf{P}$ & $\%$ & 2.75 & 2.98 & 4.81 & 3.10 & 4.81 & 5.13 & 1.34 & 4.55 & 5.49 \\
\hline & & & & & & & & & & \\
\hline MAINSTREAM & & & & & & & & & & \\
\hline$P$ main & atm. & 14.1 & 14.1 & 14.1 & 14.1 & 14.1 & 14.1 & 14.1 & 14.1 & 14.1 \\
\hline T main & $\mathbf{K}$ & 2,164 & 2,164 & 2,164 & 2,164 & 2,164 & 2,164 & 2,164 & 2,164 & 2,164 \\
\hline U main & $\mathrm{m} / \mathrm{sec}$ & 25.4 & 25.4 & 25.4 & 25.4 & 25.4 & 25.4 & 25.4 & 25.4 & 25.4 \\
\hline$\dot{\mathrm{m}}$ main & $\mathrm{kg} / \mathrm{sec}$ & 0.266 & 0.266 & 0.266 & 0.266 & 0.266 & 0.266 & 0.266 & 0.266 & 0.266 \\
\hline Mixer diameter & m & 0.076 & 0.076 & 0.076 & 0.076 & 0.076 & 0.076 & 0.076 & 0.076 & 0.076 \\
\hline & & & & & & & & & & \\
\hline JET & & SLOT & SLOT & SLOT & SLOT & SLOT & SLOT & SLOT & SLOT & SLOOT \\
\hline P jet & atm. & 14.1 & 14.1 & 14.1 & 14.1 & 14.1 & 14.1 & 14.1 & 14.1 & 14.1 \\
\hline$T$ jet & $\mathbf{K}$ & 950 & 950 & 950 & 950 & 950 & 950 & 950 & 950 & 950 \\
\hline$V$ jet & $\mathrm{m} / \mathrm{sec}$ & 122.5 & 127.6 & 162.0 & 130.0 & 162.1 & 167.4 & 85.6 & 157.7 & 173.2 \\
\hline$\dot{\mathrm{m}}$ jet & $\mathrm{kg} / \mathrm{sec}$ & 0.788 & 0.788 & 0.788 & 0.788 & 0.788 & 0.788 & 0.788 & 0.788 & 0.788 \\
\hline ACd jet/row & $\mathbf{m}^{2}$ & $1.227 \mathrm{e}-03$ & $1.178 \mathrm{e}-03$ & $9.277 \mathrm{e}-04$ & $1.156 \mathrm{e}-03$ & $9.274 e-04$ & $8.977 \mathrm{e}-04$ & $1.755 \mathrm{e}-03$ & $9.531 \mathrm{e}-04$ & $8.679 \mathrm{e}-04$ \\
\hline Orifice Cd & & 0.75 & 0.71 & 0.73 & 0.70 & 0.74 & 0.71 & 0.79 & 0.76 & 0.68 \\
\hline Number of orifices & & 8 & 8 & 8 & 8 & 8 & 8 & 8 & 8 & 8 \\
\hline Orifice $L / W$ & & 4 & 4 & 4 & 4 & 4 & 4 & 4 & 4 & 4 \\
\hline Orifice slant angle & & 22.5 & 45 & 45 & 67.5 & $\underline{0}$ & 67.5 & 0 & 22.5 & 90 \\
\hline Orifice length (L) & $\mathbf{m}$ & 0.025 & 0.025 & 0.022 & 0.025 & 0.022 & 0.022 & 0.030 & 0.022 & 0.021 \\
\hline Orifice width (W) & $\mathbf{m}$ & 0.006 & 0.006 & 0.006 & 0.006 & 0.006 & 0.005 & 0.008 & 0.006 & 0.005 \\
\hline Blockage & & 0.4569 & 0.6506 & 0.5774 & 0.7787 & 0.1849 & 0.6863 & 0.2544 & 0.4027 & 0.7156 \\
\hline Orifice T.E. $\mathrm{x} / \mathbf{R}$ & & 0.6300 & 0.5110 & 0.4535 & 0.3483 & 0.5810 & 0.3070 & 0.7991 & 0.5554 & 0.1405 \\
\hline
\end{tabular}

Table-2. Configuration description and parameter specifications for configurations 28 through 36 


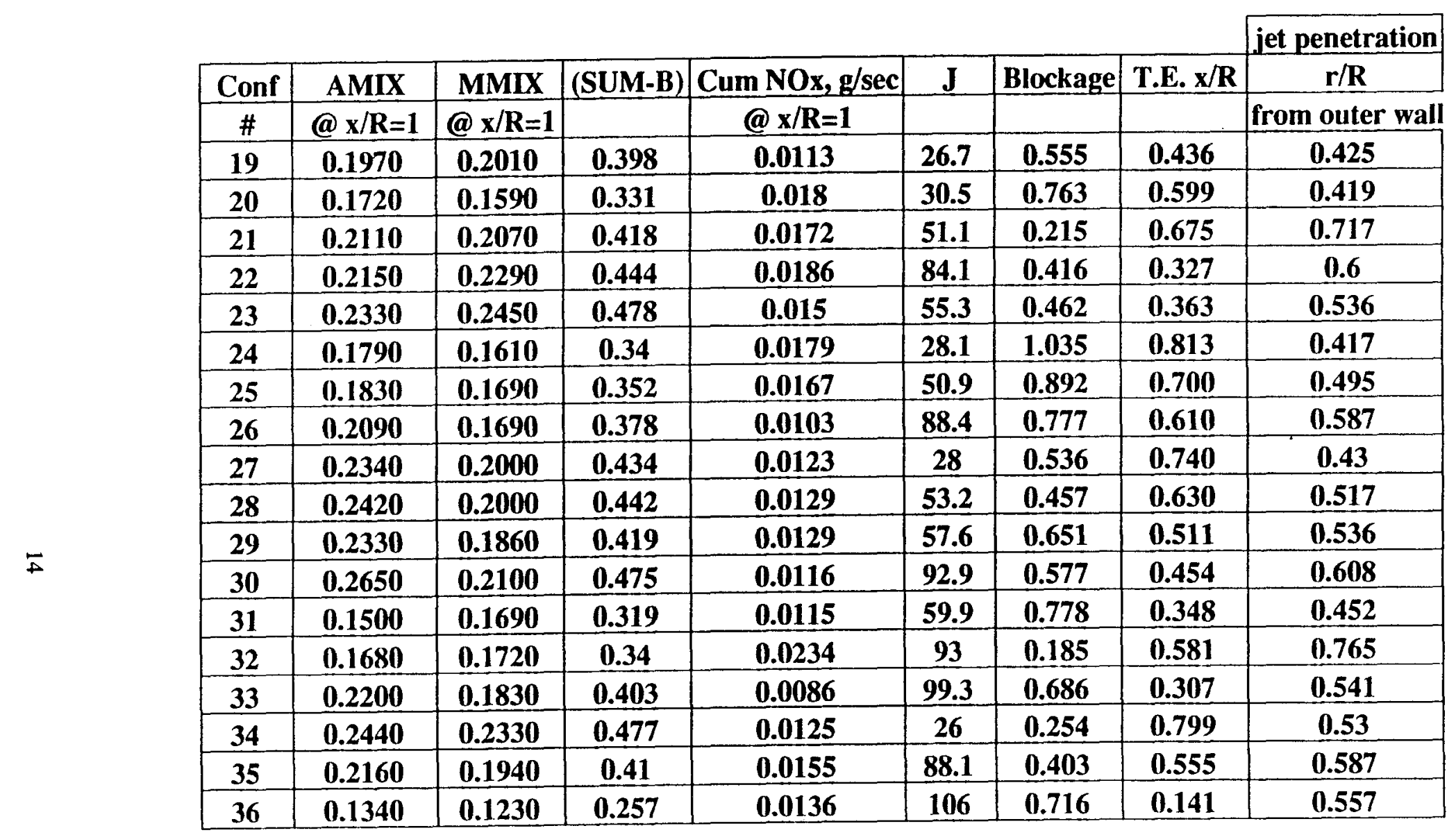

Table-3. Mixing non-uniformity and NOx production results for configuraions \# 19 through 36. 

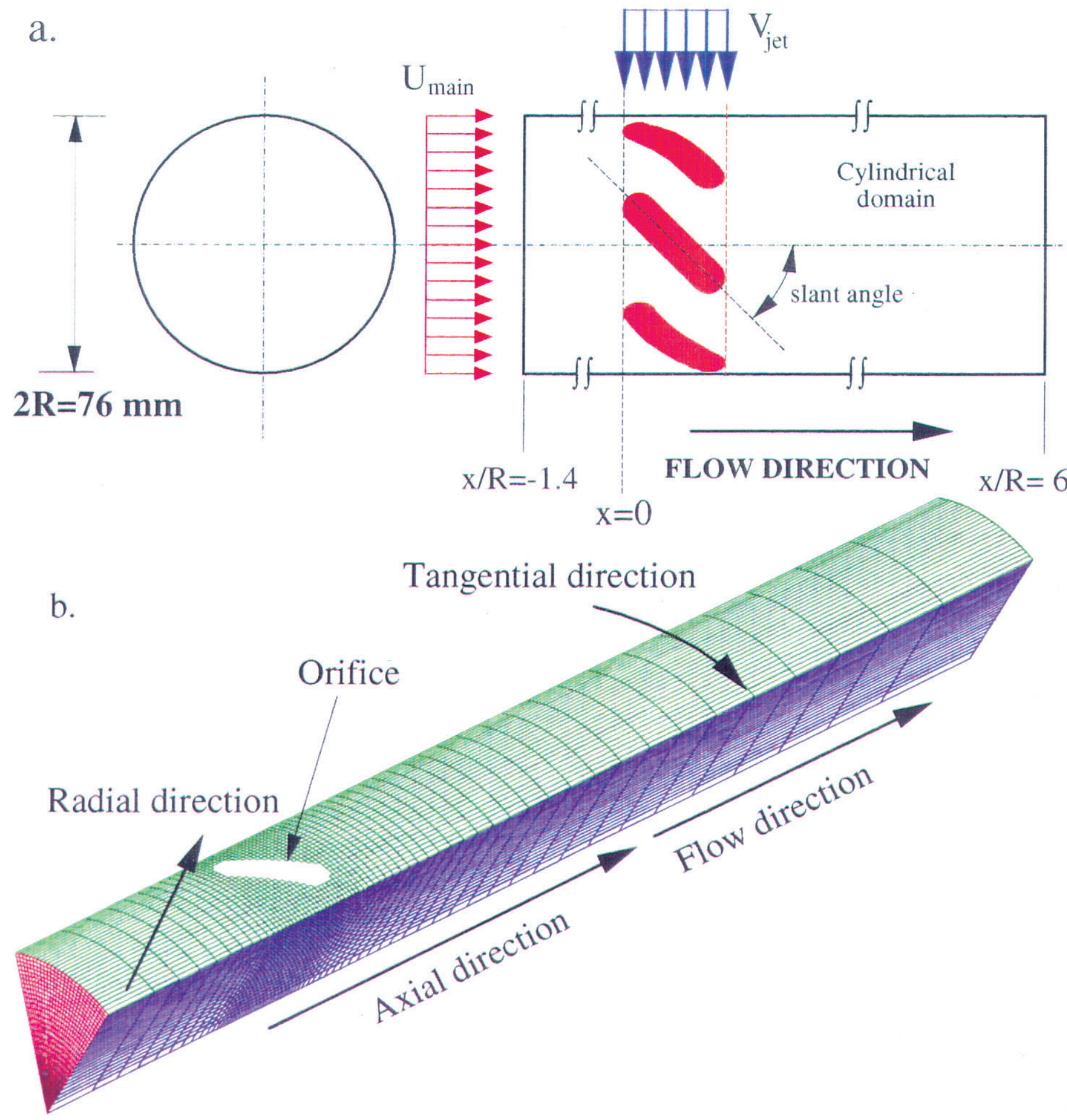

Figure-1. a) Geometric configuration of the mixing section, and

b) orthogonal view of the computational grid with a $45^{\circ}$ slot 


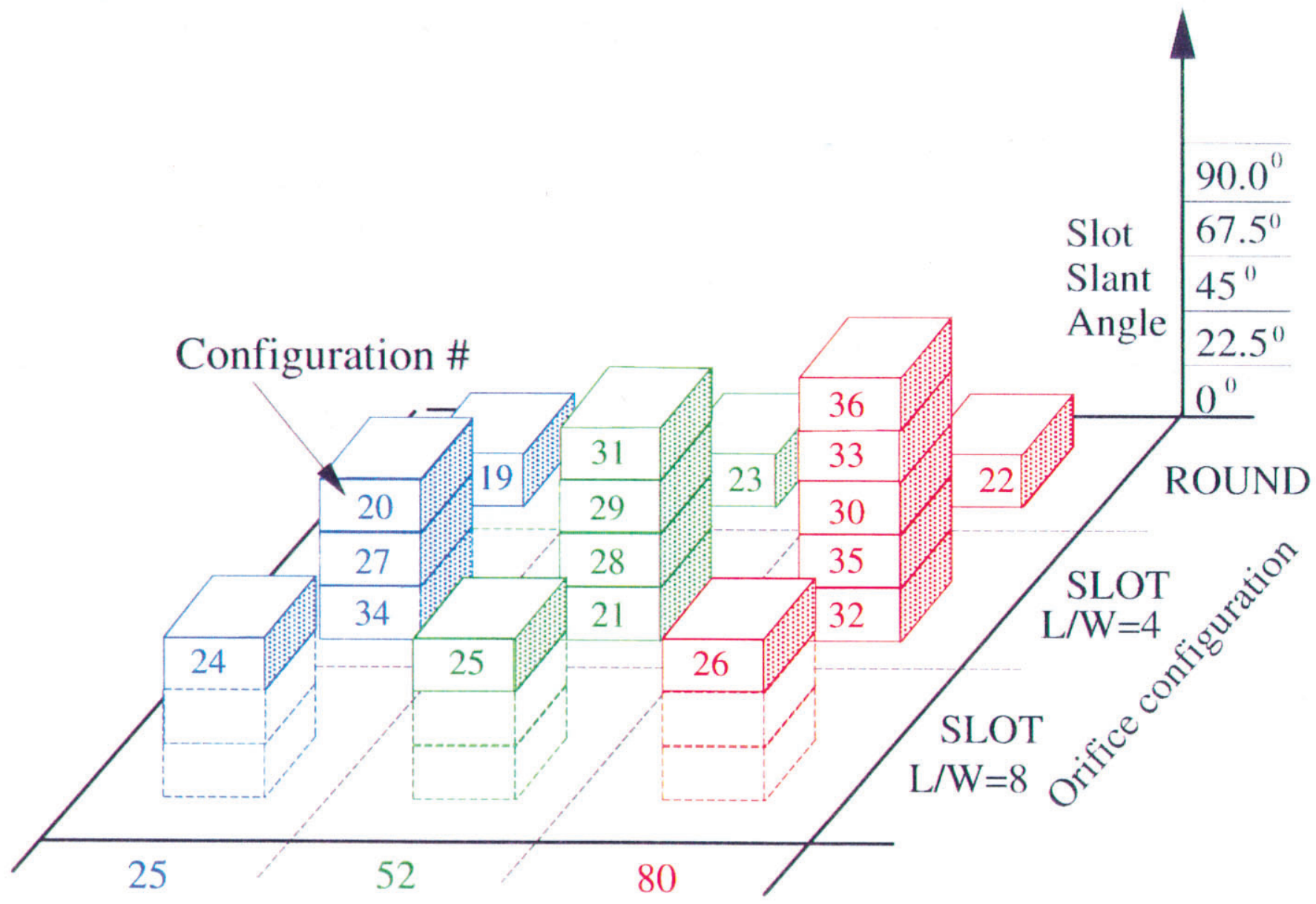

Nominal jet-to-mainstream momentum flux ratio $(\mathbf{J})$

Figure-2. Matrix depiction of the analyzed configurations in a circular mixer 
a. Example plot of the equivalence raito and velocity distributions Plane in the axial-radial direction through the center of the orifice NORMALZZED MANSTREAM $=1.0$

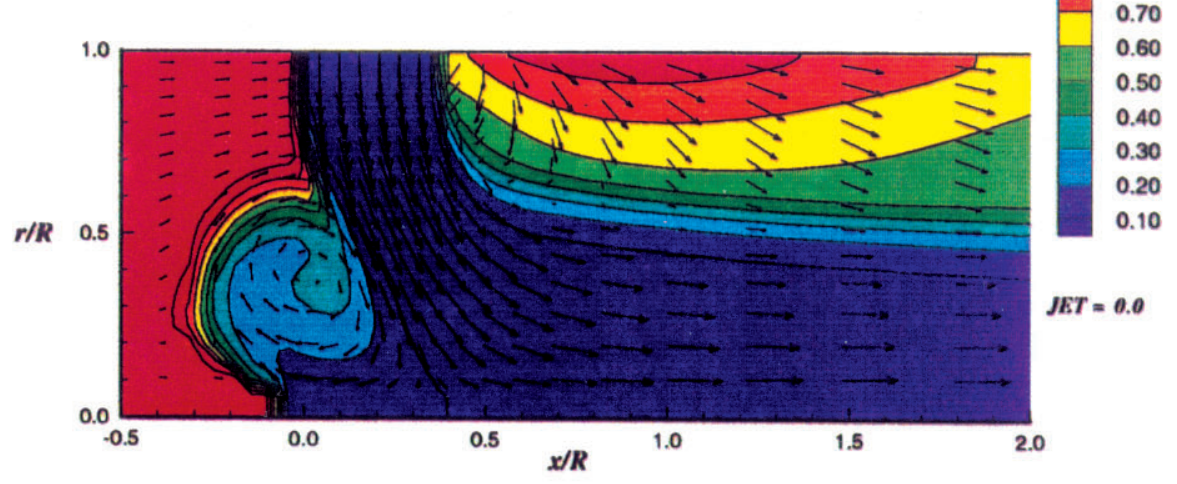

c. Example plot of the iso-contour of constant $\mathrm{NO}_{x}$ production at $10^{3}$ gr of $\mathrm{NO}_{x} /\left\{\mathrm{sec}^{3}\right\}$. Mixer domain is $0<x / R<1$

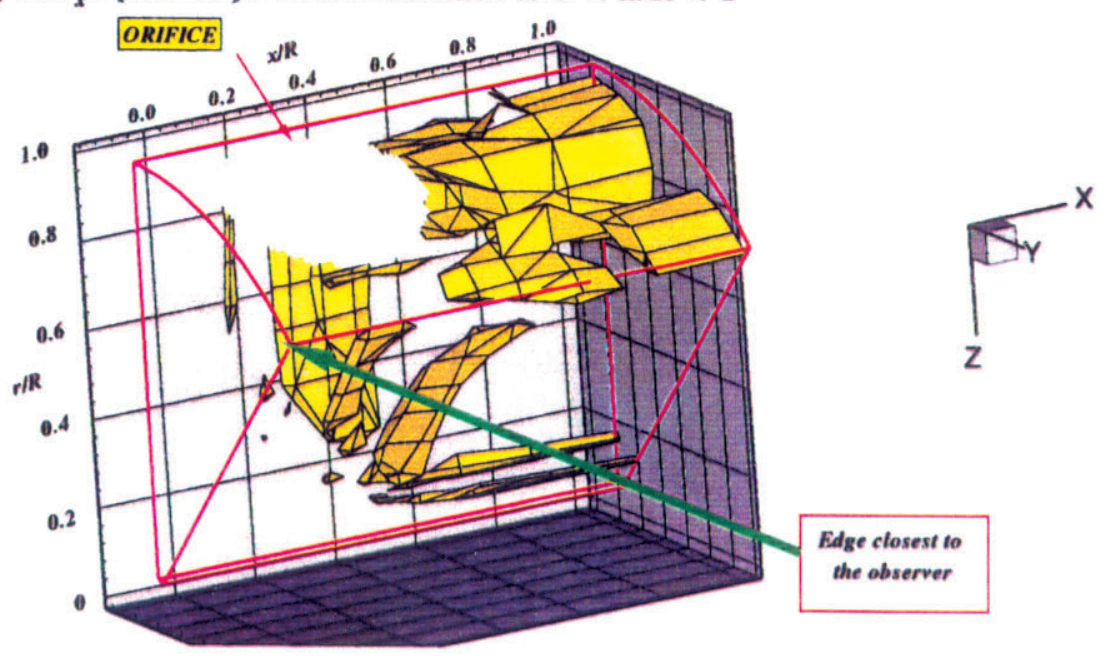

\section{b. Example plot of the $\mathrm{NO}_{x}$ production evolution in the mixing section}

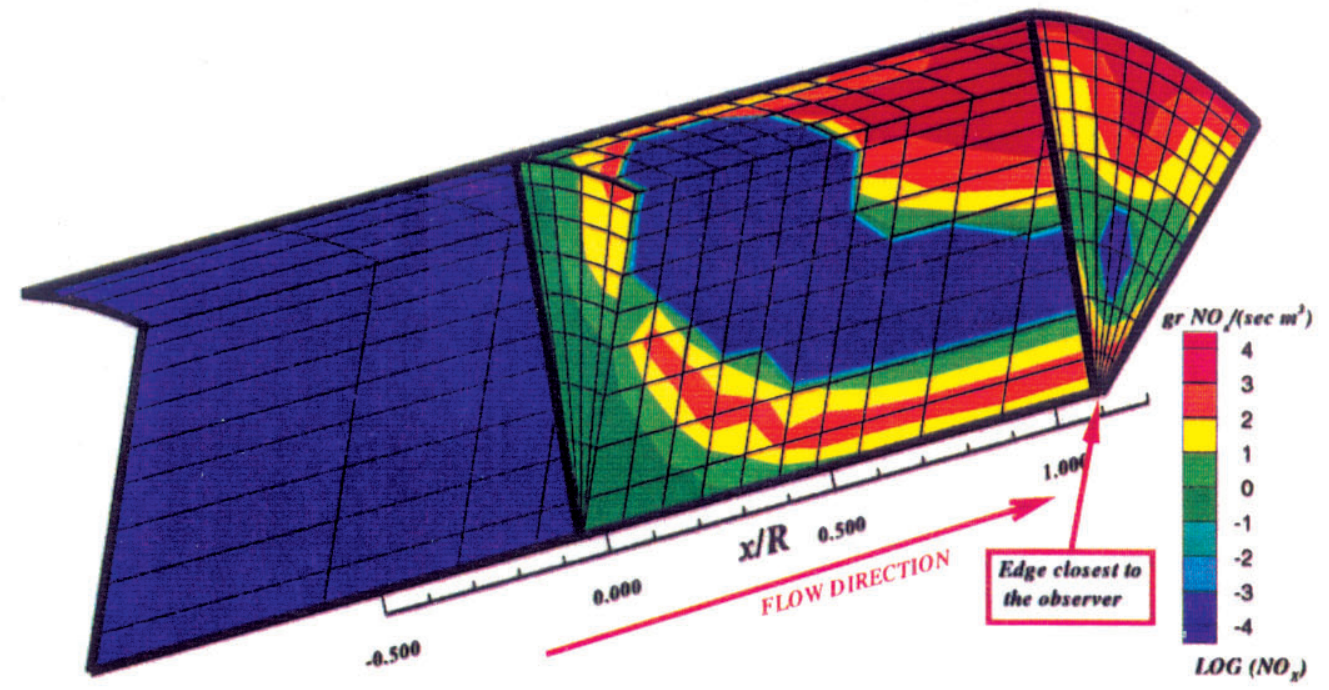

d. Example plot of the sub-volume division in the mixer domain for the $\mathrm{NO}_{x}$ analysis

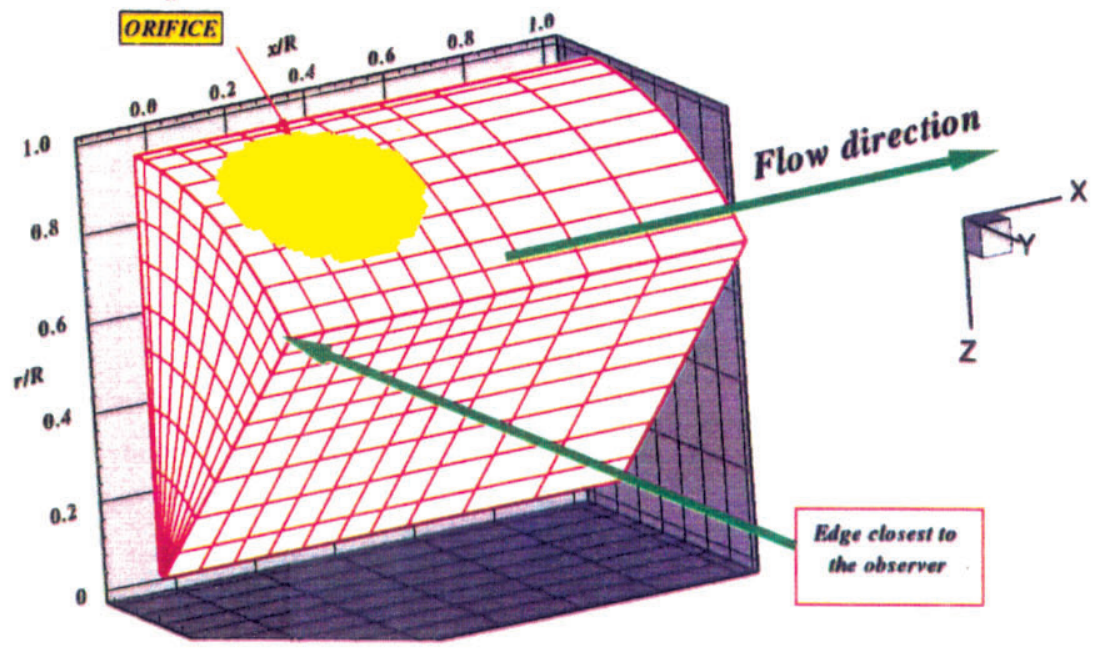

Figure-3. Example plots for the observational analysis 


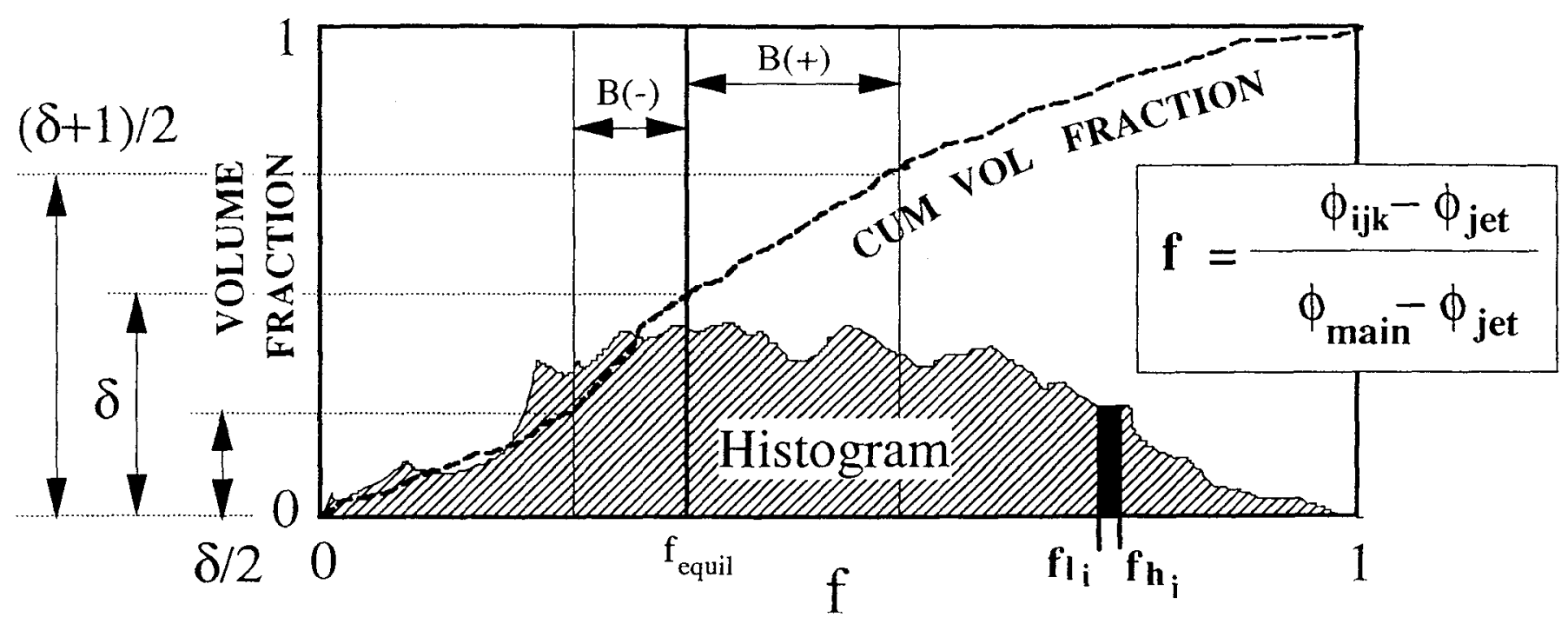

Figure-4. Description of the statistical analysis for the mixing non-uniformity evaluation

a.

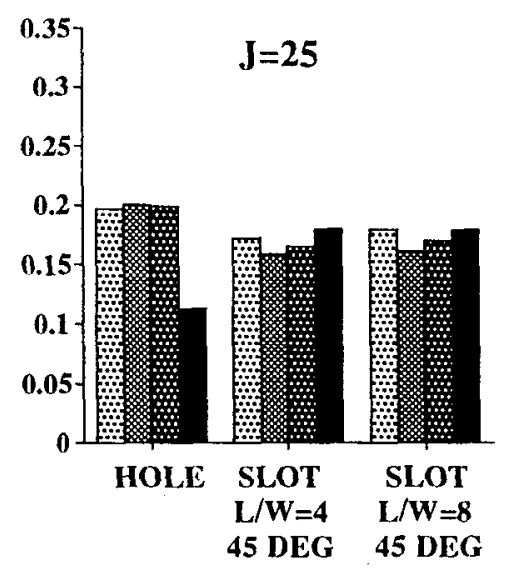

b.

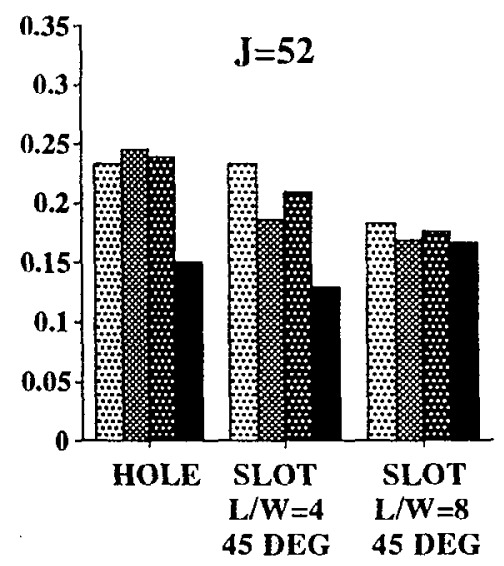

c.

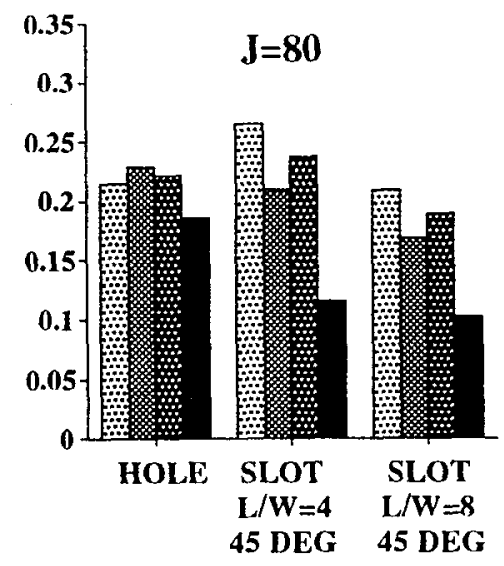

Figure-5. Effect of the change in orifice shape on the mixing non-uniformity and NOx production

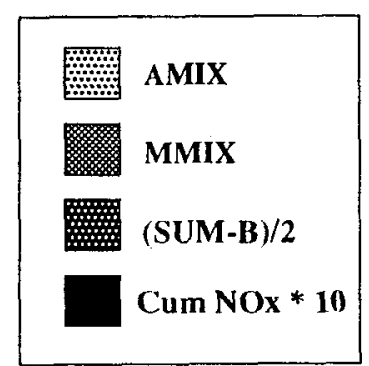




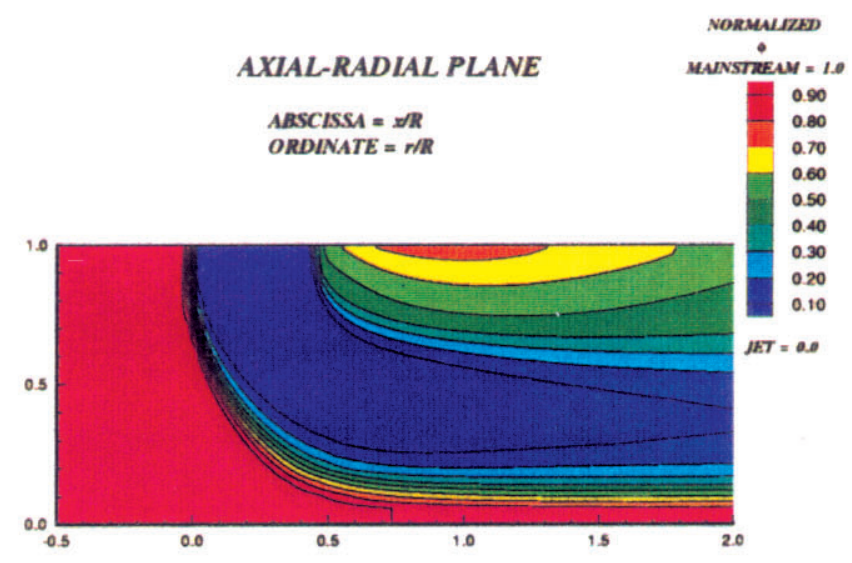

AXIAL-RADLAL PLANE

ABSCISSA $= \pm R$ ORDINATE $=r / R$

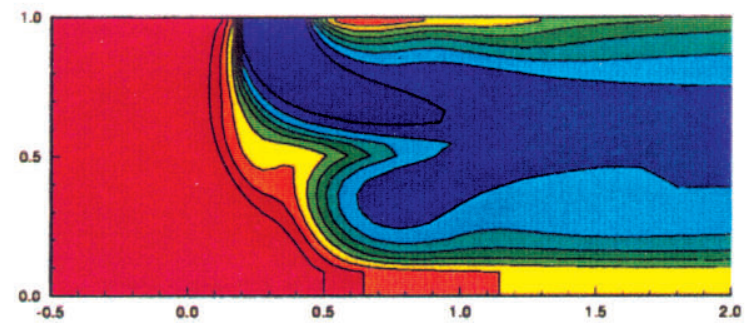

AXIAL-RADIAL PLANE

ABSCISSA $=x / R$ ORDINATE $=r / R$

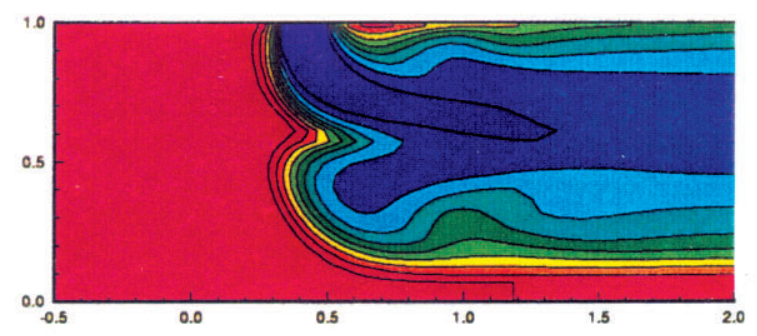

Equivalence ratio
AXLAL-RADLAL PLANE

ABSCISSA $=$ ER ORDINATE $=$ T/R

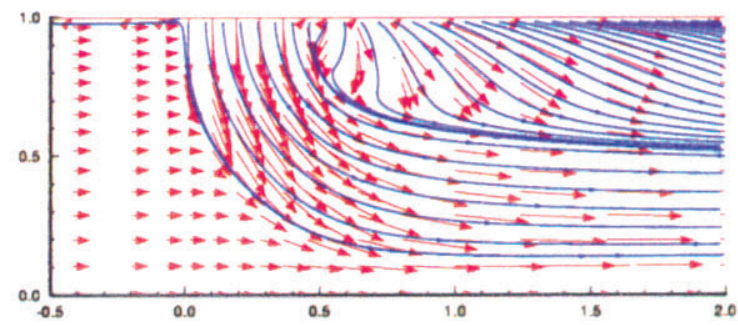

AXIAL-RADIAL PLANE

ABSCISSA $=x / R$ ORDINATE $=r / R$

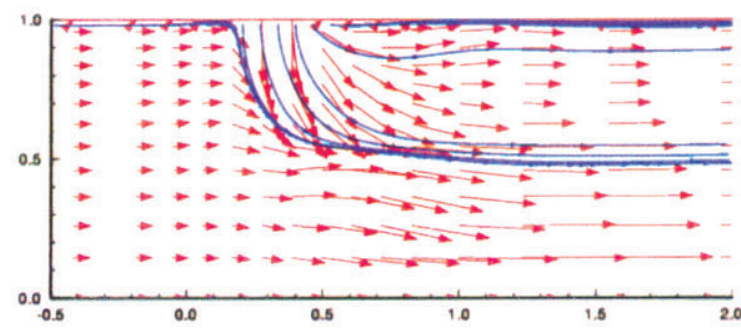

AXIAL-RADIAL PLANE

ABSCISSA $=x / R$ ORDINATE $=r R$

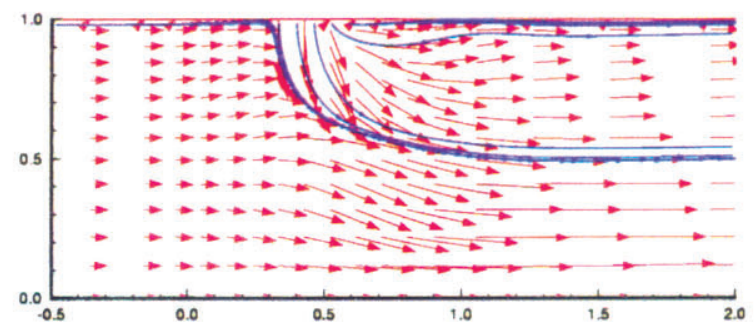

velocity

Figure-6. Effect of the change in orifice geometry on the equivalence ratio and velocity distributions

Top to bottom: round, $45^{\circ}$ slot with $L / W=4$, and $45^{\circ}$ slot with $L / W=8$ $J=25, M R=2.96, D R=2.28,8$ orifices/row 
a.

Round hole, $J=26.7, M R=2.96, D R=2.28$
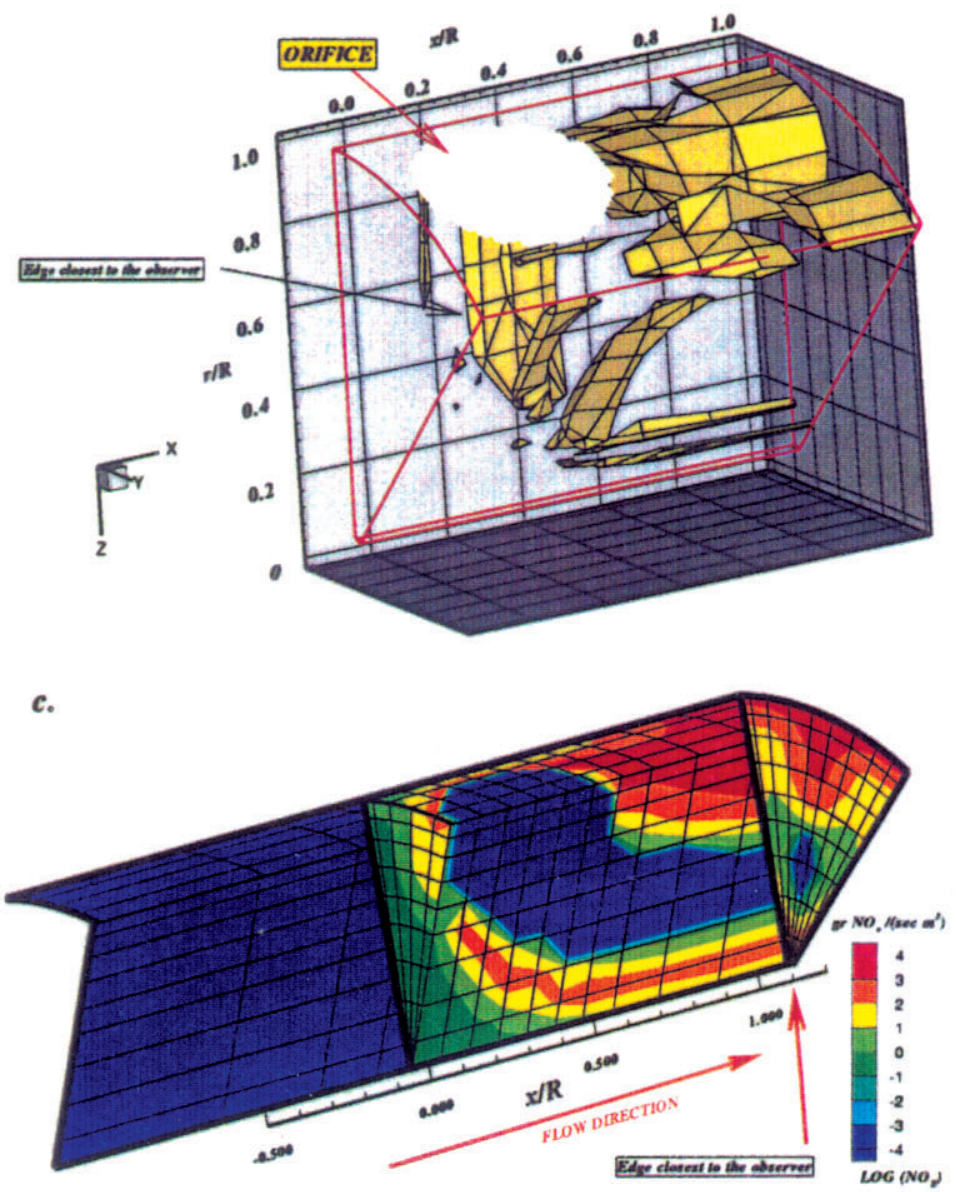

e.

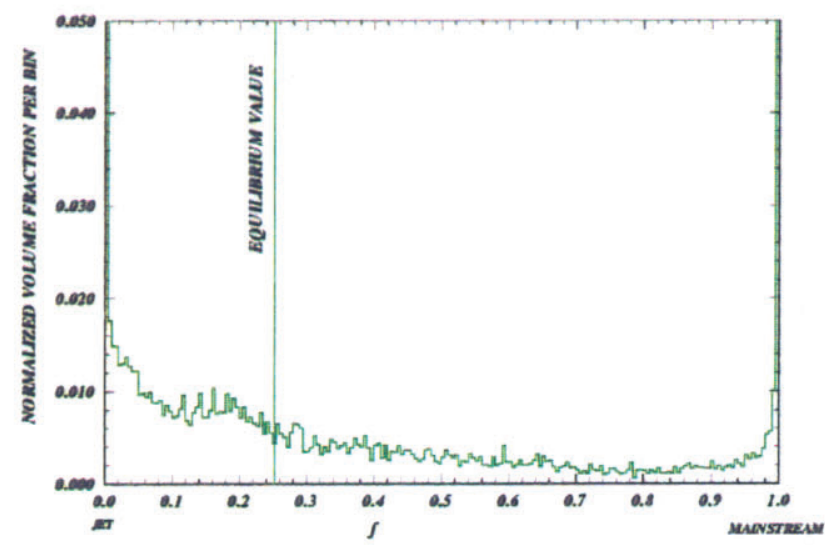

BEST CONFIGURATION b. $\quad 45^{\circ}$ slot, $L W=8, J=28.1, M R=2.96, D R=2.28$
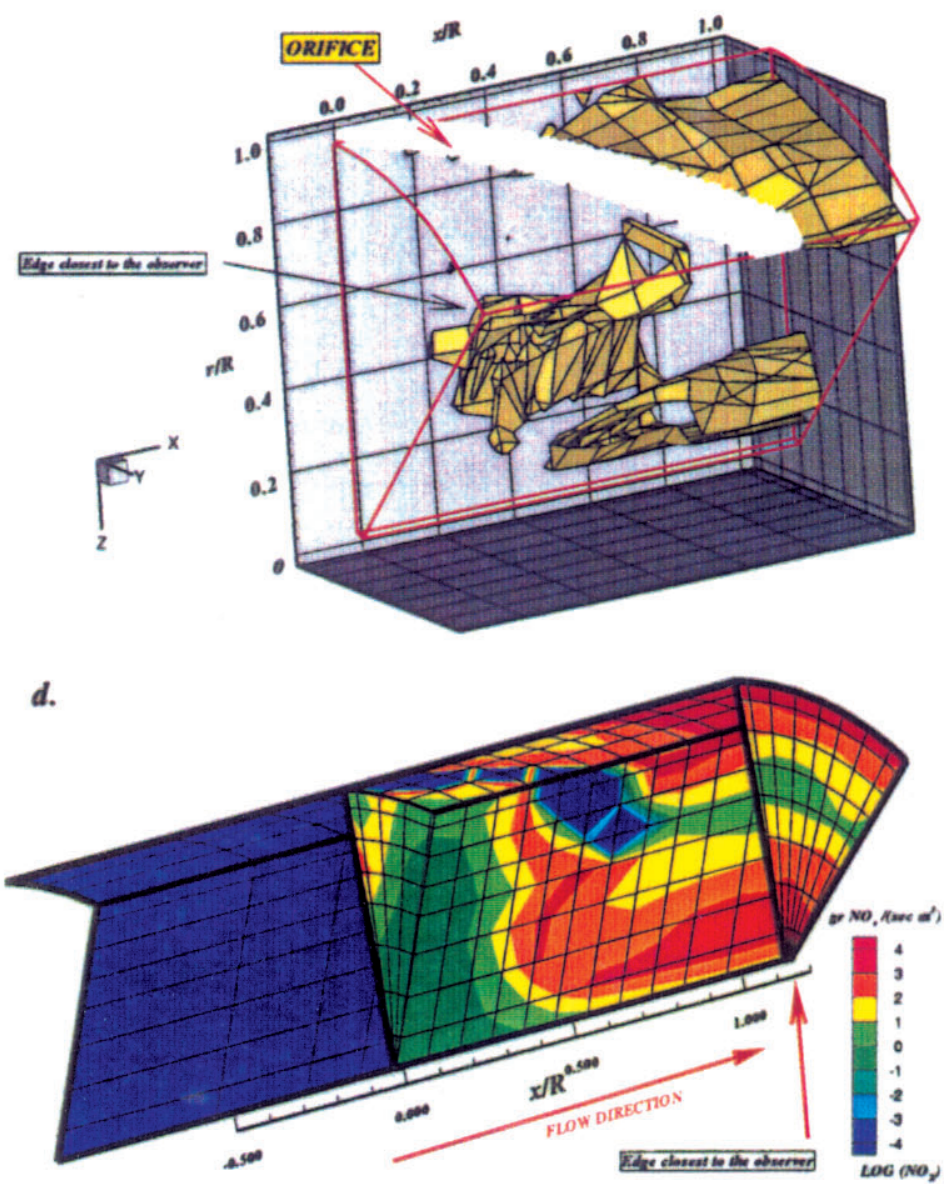

f.

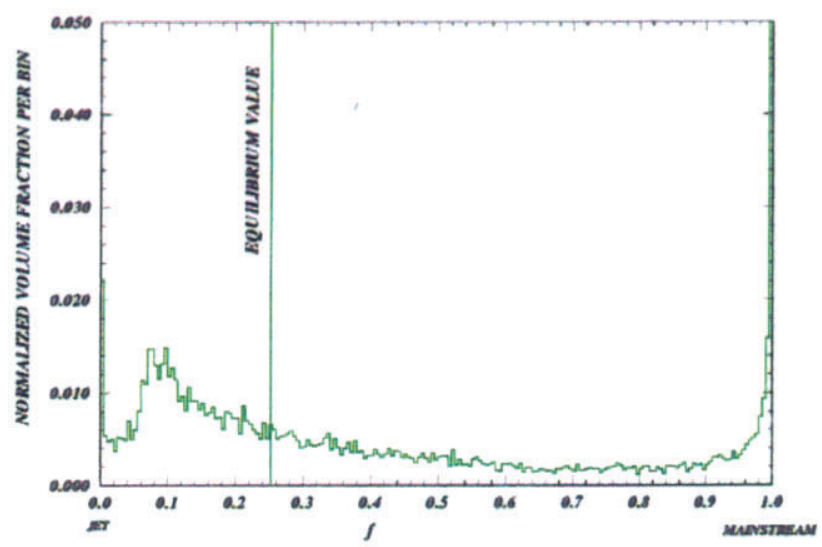

WORST CONFIGURATION

(a, b) Interpolated $\mathrm{NO}_{x}$ production isopleth at $10^{3} \mathrm{gr}$ of $\mathrm{NO}_{x} /\left[\mathrm{sec} \mathrm{m}^{3}\right\}$

$(c, d) \mathrm{NO}_{x}$ production development through the mixing section

$(e, f)$ volume histograms depicting the mixing non-uniformity for the mixing domain $(0<x / R<1)$

Figure-7. Comparison of the best (left column) and worst (right column) NO ${ }_{x}$ production configurations with variation of the orifice configuration at $J=25$. 


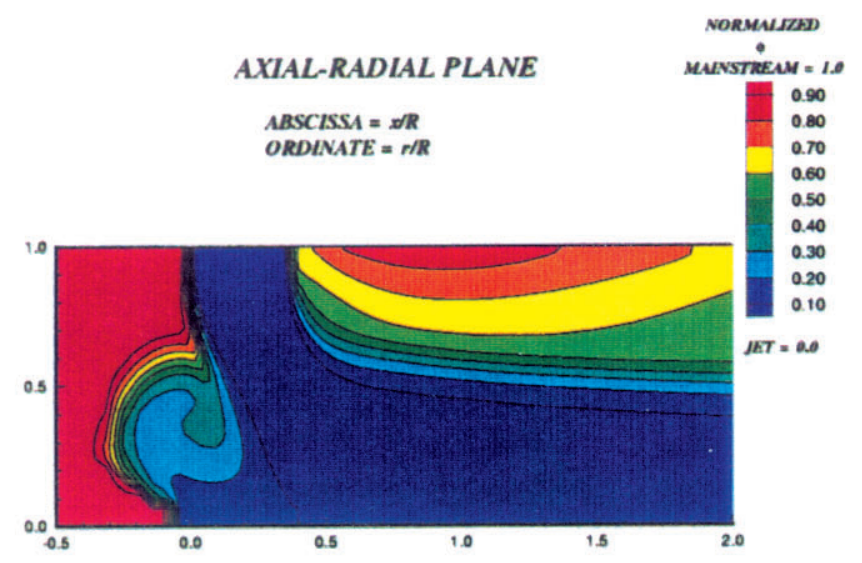

AXLAL-RADLAL PLANE

ABSCISSA $= \pm \mathbb{R}$ ORDINATE $=r / R$

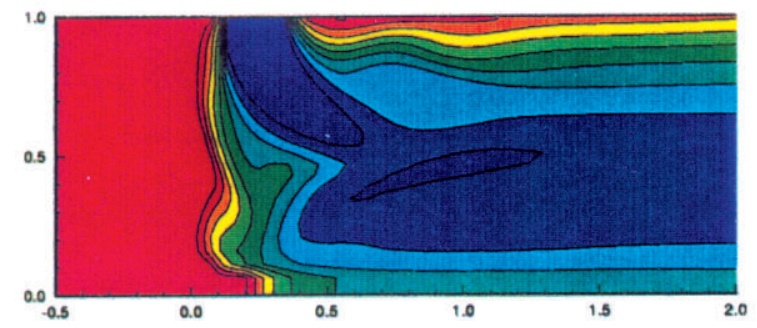

AXIAL-RADIAL PLANE

ABSCISSA $=x / R$

ORDINATE $=r / R$

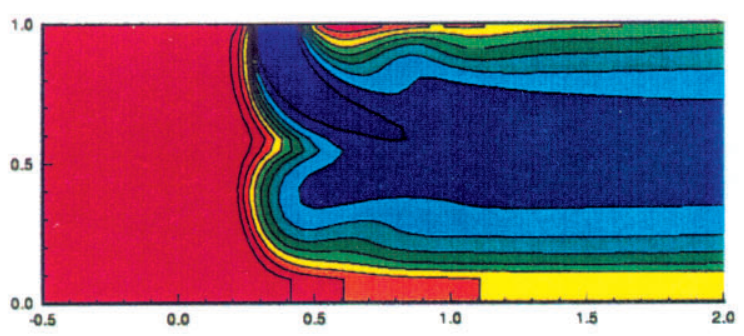

Equivalence ratio
AXIAL-RADIAL PLANE

ABSCISSA $=x / R$ ORDINATE $=r / R$

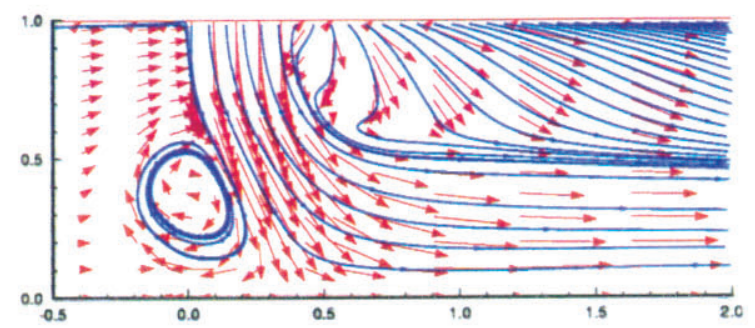

AXIAL-RADLAL PLANE

ABSCISSA $=\mathbb{N} / \boldsymbol{R}$ ORIDINATE $=r / R$

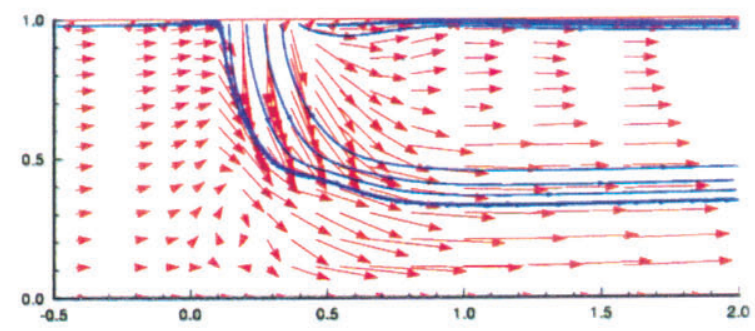

AXIAL-RADIAL PLANE

ABSCISSA $=\mathbb{X} / \mathbb{R}$ ORDINATE $=r$

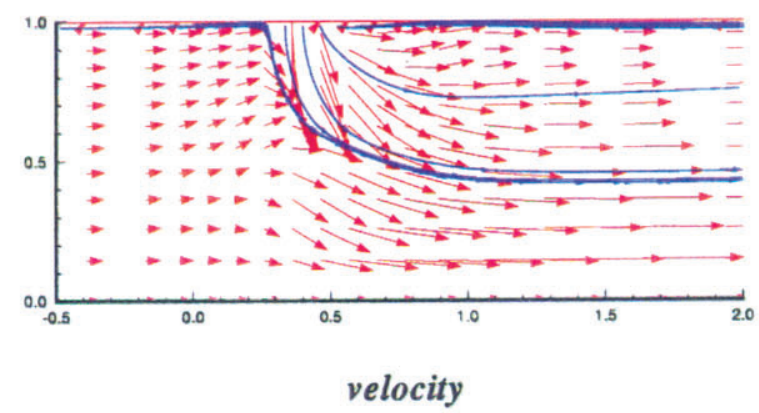

Figure-8. Effect of the change in orifice geometry on the equivalence ratio and velocity distributions

Top to bottom: round, $45^{\circ}$ slot with $L / W=4$, and $45^{\circ}$ slot with $L / W=8$ $J=52, M R=2.96, D R=2.28,8$ orifices $/$ row 

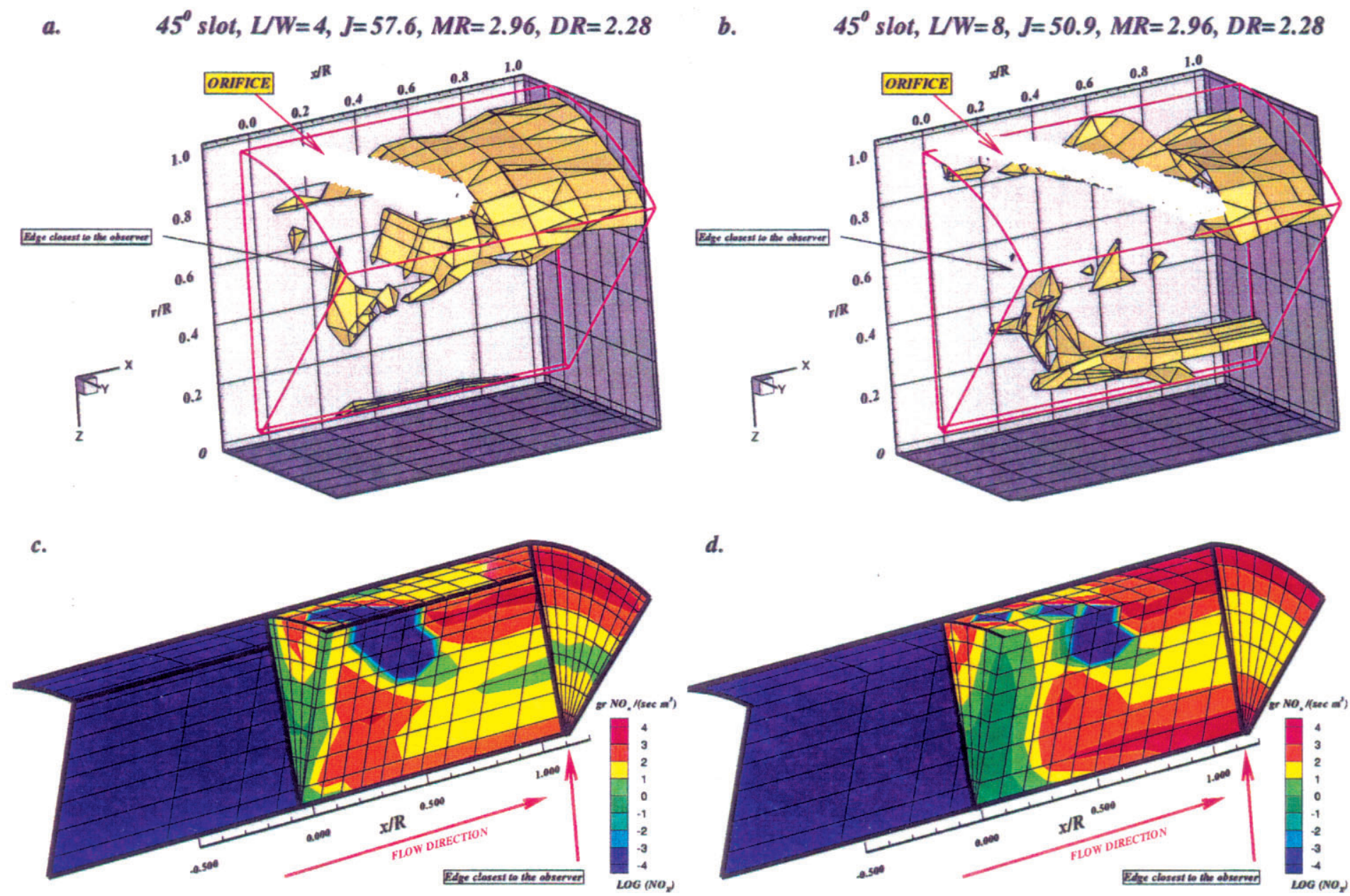

e.

$f$.

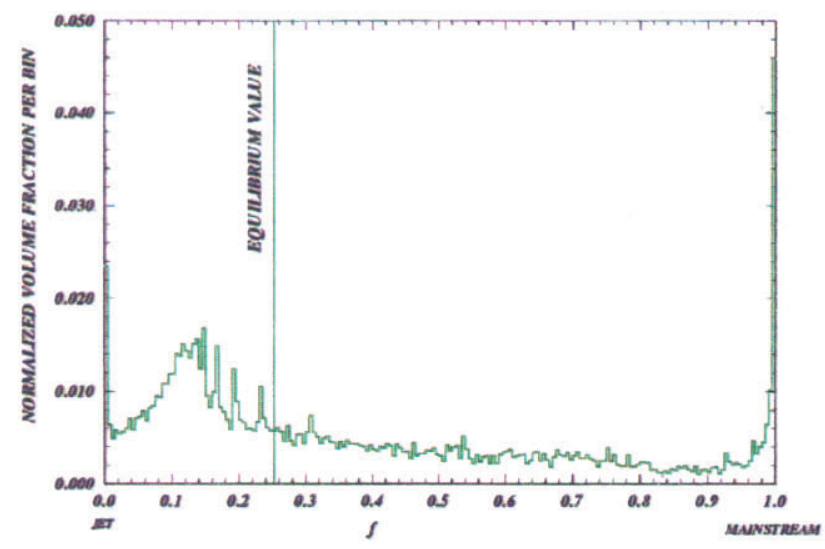

\section{BEST CONFIGURATION}

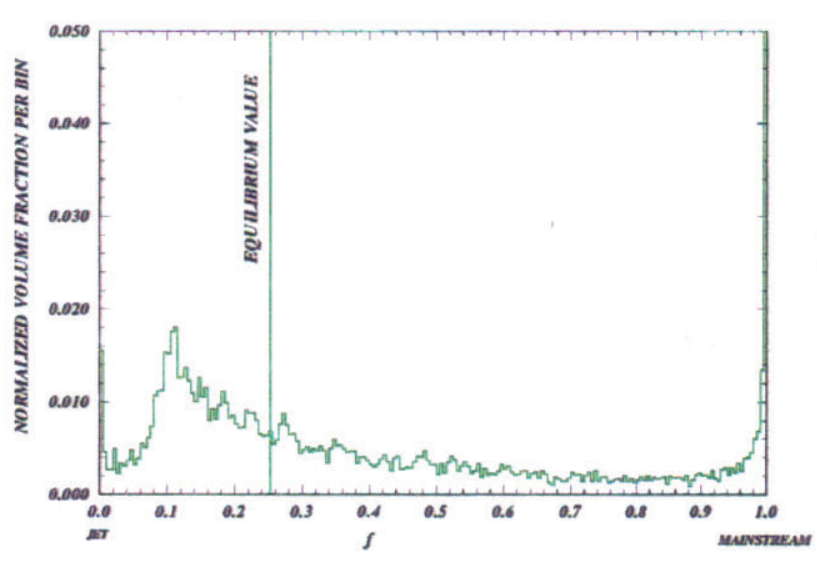

WORST CONFIGURATION

(a, b) Interpolated $\mathrm{NO}_{x}$ production isopleth at $10^{3} \mathrm{gr}$ of $\mathrm{NO}_{x} /\left\{\mathrm{sec} \mathrm{m}^{3}\right\}$

(c, d) $\mathrm{NO}_{x}$ production development through the mixing section

$(e, f)$ volume histograms depicting the mixing non-uniformity for the domain $(0<x / R<1)$

Figure-9. Comparison of the best (left column) and worst (right column) NO production configurations with variation of the orifice configuration at $J=52$. 


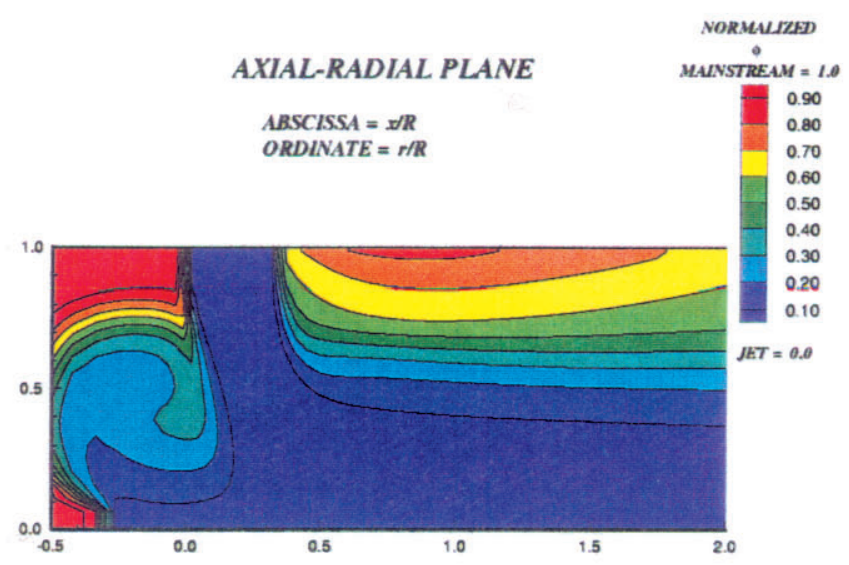

AXIAL-RADIAL PLANE

ABSCISSA $=\mathscr{X} / \mathbb{R}$

ORDINATE $=r / R$

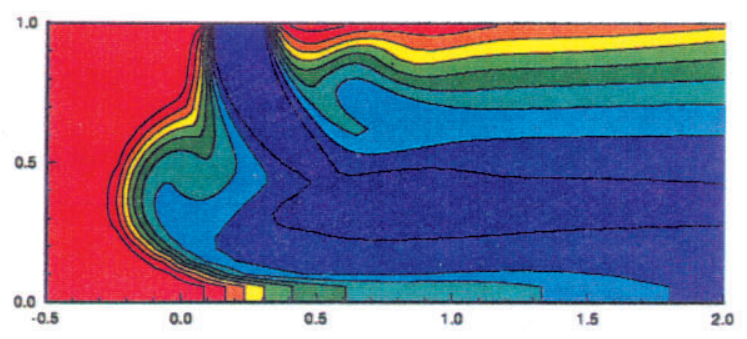

AXIAL-RADIAL PLANE

$A B S C L S S A=x / R$

ORDINATE $=r / R$

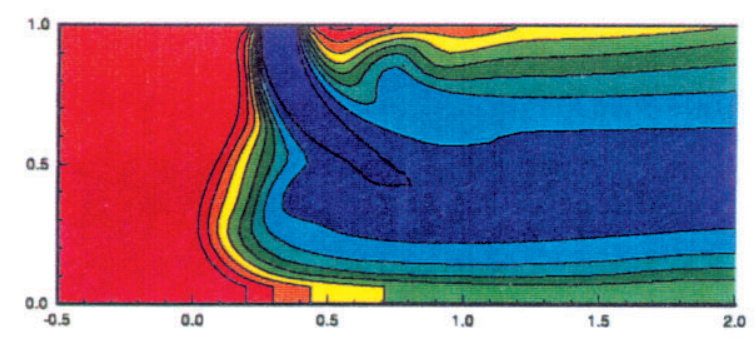

Equivalence ratio

\section{AXIAL-RADIAL PLANE}

ABSCISSA $=x / R$

ORDINATE $=r / R$

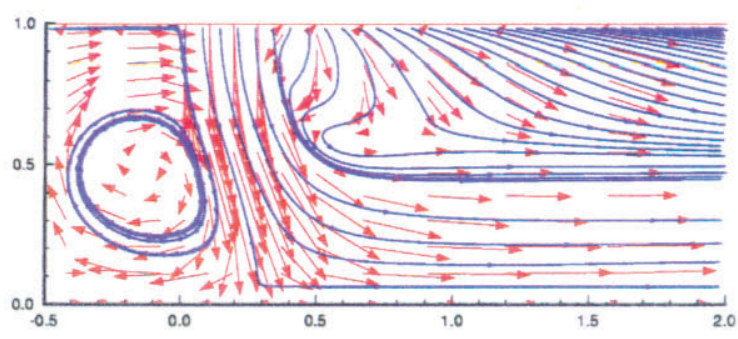

AXIAL-RADIAL PLANE

ABSCISS $A=x / R$

ORDINATE $=r / R$

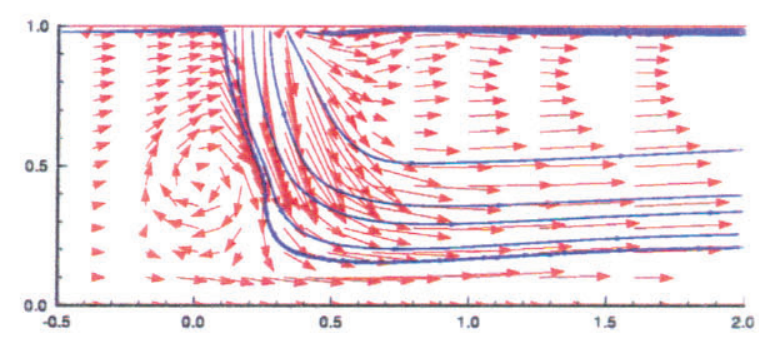

AXIAL-RADIAL PLANE

ABSCISSA $=\mathscr{D} / R$

ORDINATE $=r / R$

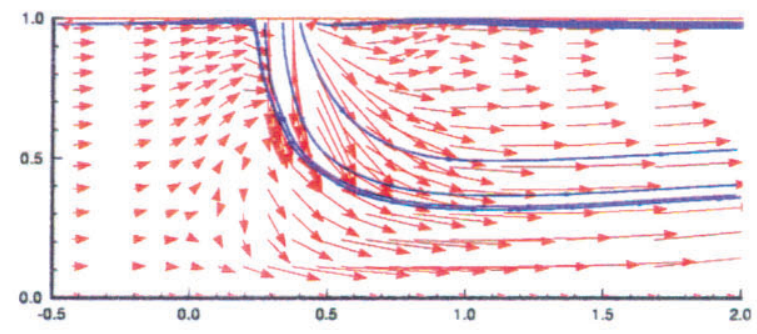

velocity

Figure-10. Effect of the change in orifice geometry on the equivalence ratio and velocity distributions Top to bottom: round, $45^{\circ}$ slot with $L / W=4$, and $45^{\circ}$ slot with $L / W=8$ $J=80, M R=2.96, D R=2.28,8$ orifices/row 

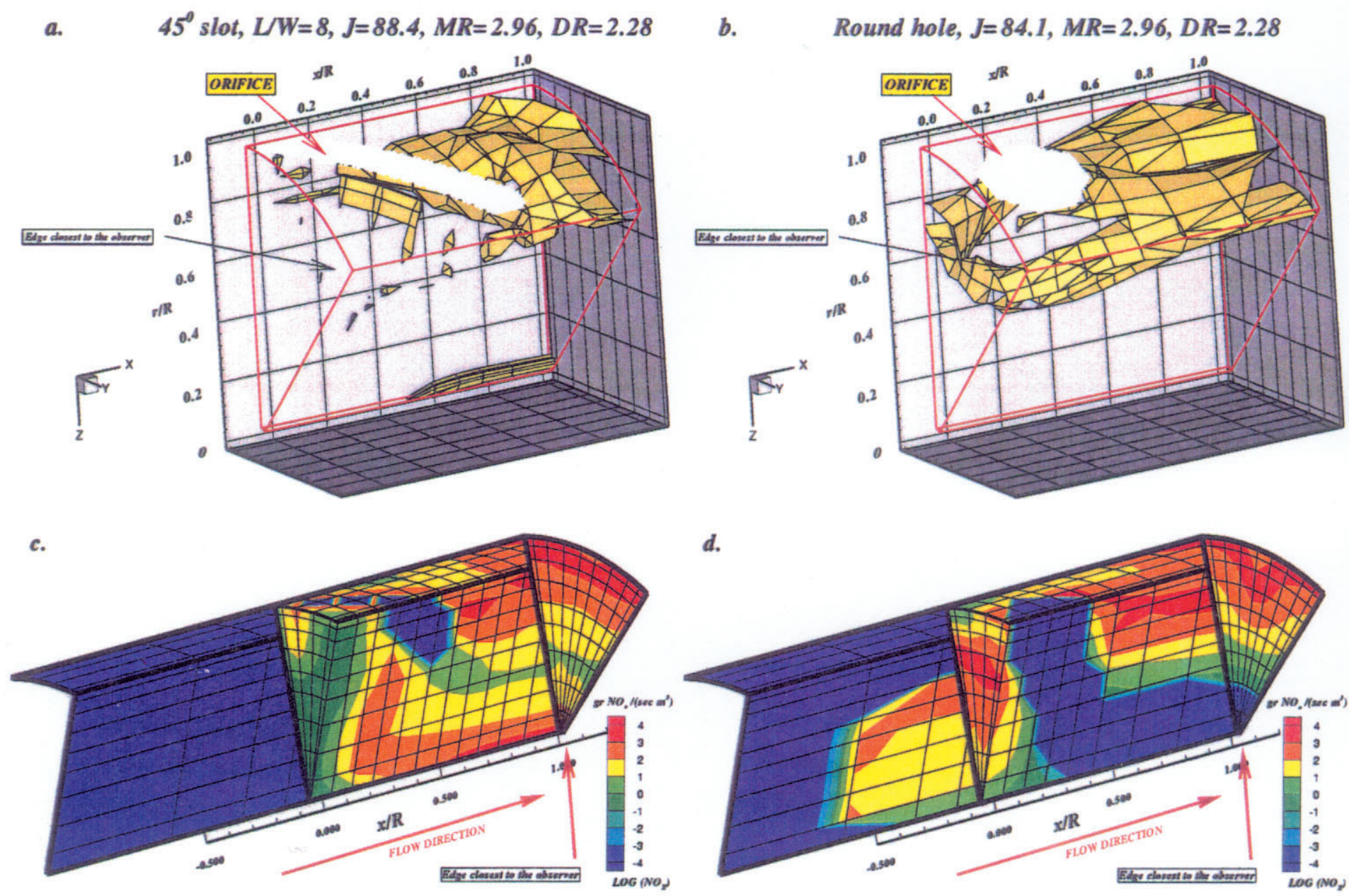

e.

f.

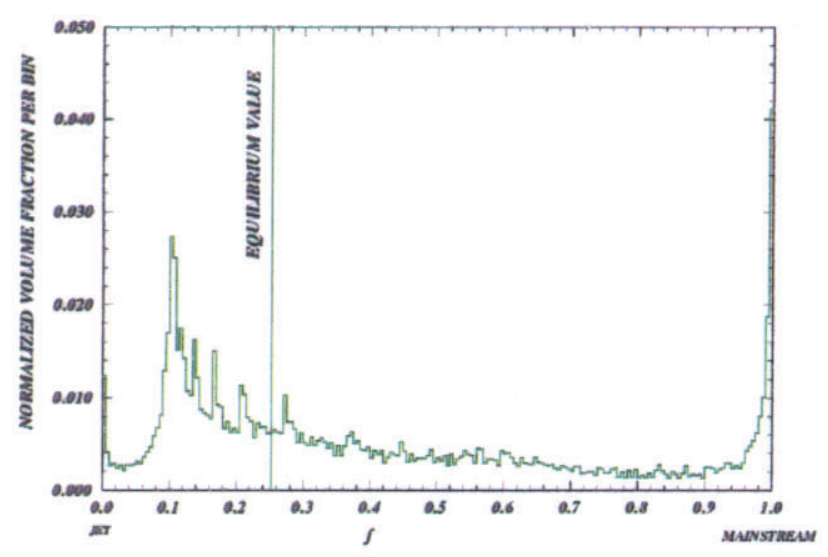

\section{BEST CONFIGURATION}

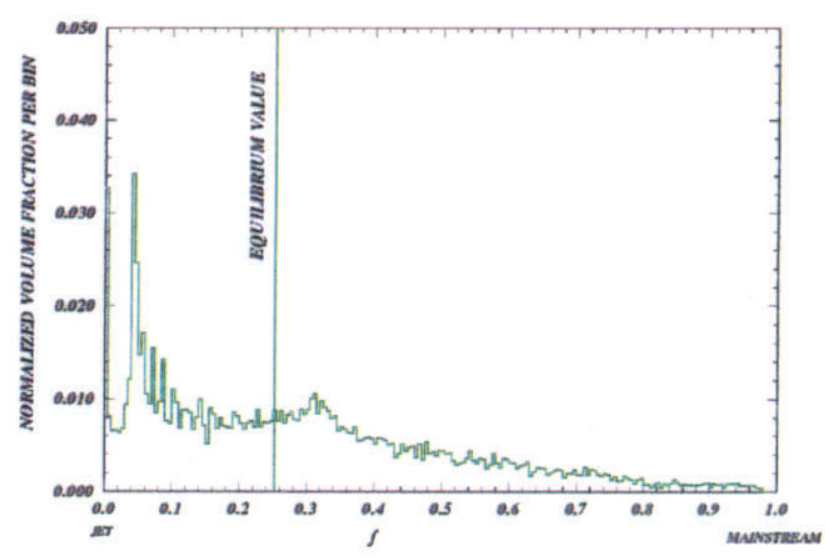

WORST CONFIGURATION

(a, b) Interpolated $\mathrm{NO}_{x}$ production isopleth at $10^{3} \mathrm{gr}$ of $\mathrm{NO}_{x} /\left\{\mathrm{sec} \mathrm{m}^{3}\right\}$

(c, d) $\mathrm{NO}_{x}$ production development through the mixing section

$(e, f)$ volume histograms depicting the mixing non-uniformity for the domain $(\theta<x / R<1)$

Figure-11. Comparison of the best (left column) and worst (right column) $N O_{x}$ production configurations with variation of orifice configuration at $\mathrm{J}=80$.. 

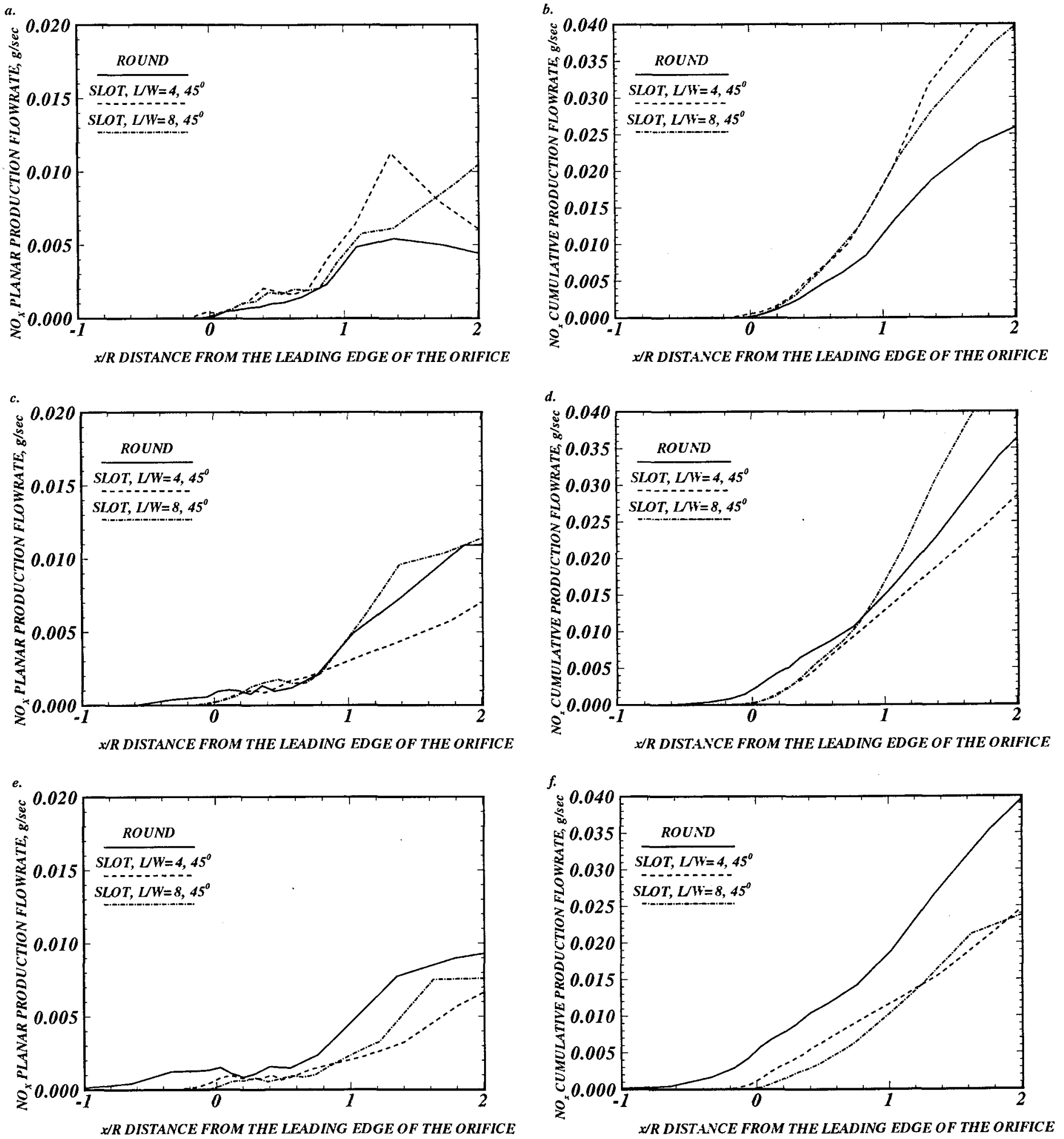

$(a, b)$ Effect of the change in orifice shape on $N O_{x}$ production at $J=25$

$(c, d)$ Effect of the change in orifice shape on $N O_{x}$ production at $J=52$

$(e, f)$ Effect of the change in orifice shape on $N O_{x}$ production at $J=80$

Figure-12. NO $\mathrm{x}_{x}$ production development throughout the mixing section. $N O_{x}$ planar production (left column) and $\mathrm{NO}_{x}$ cumulative production (right column). 
a.

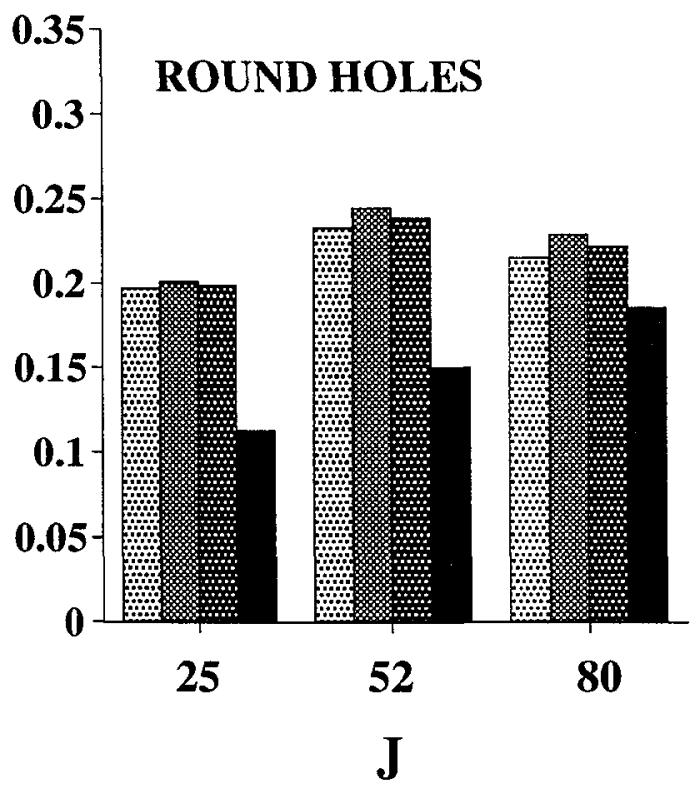

C.

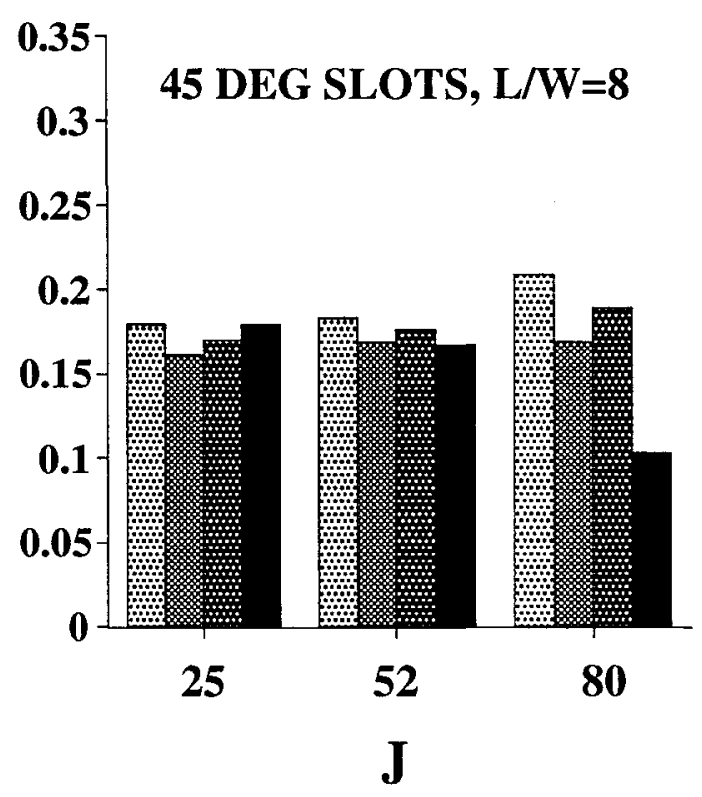

b.

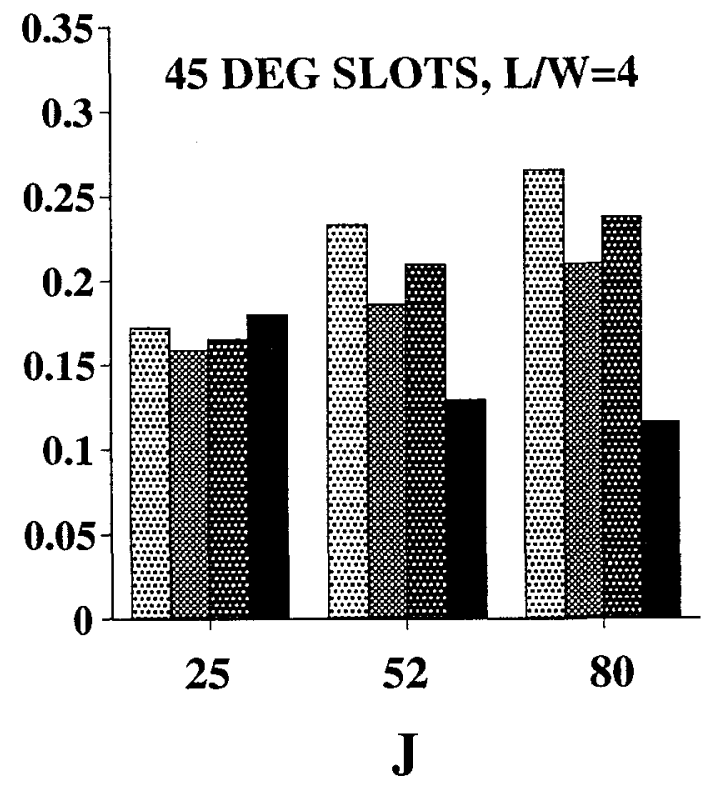

Figure-13. Effect of the change in J on the mixing non-uniformity and NOx production rate. 


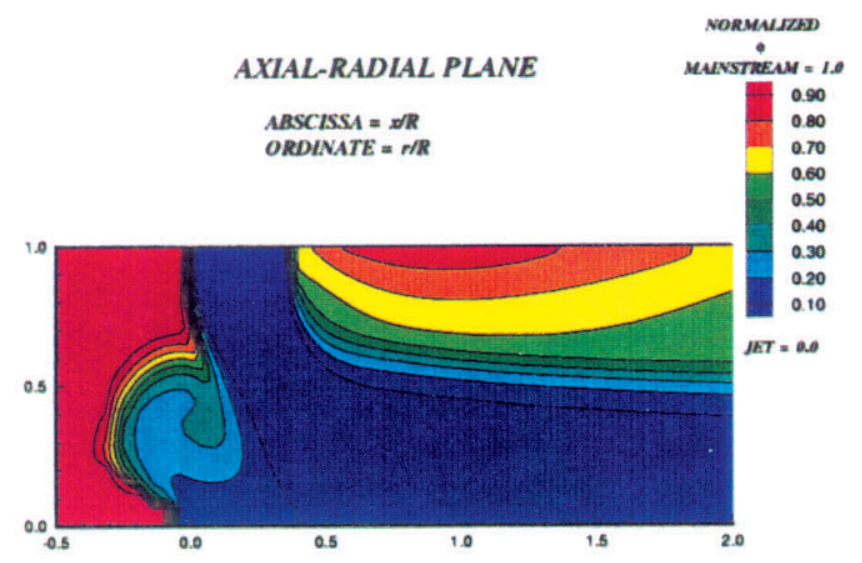

AXLAL-RADLAL PLANE

ABSCISSA $= \pm \mathbb{R}$ ORDINATE $=r / R$

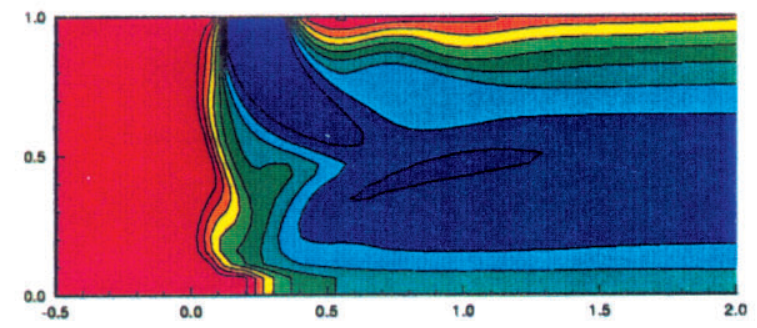

AXIAL-RADIAL PLANE

ABSCISSA $=x / R$

ORDINATE $=r / R$

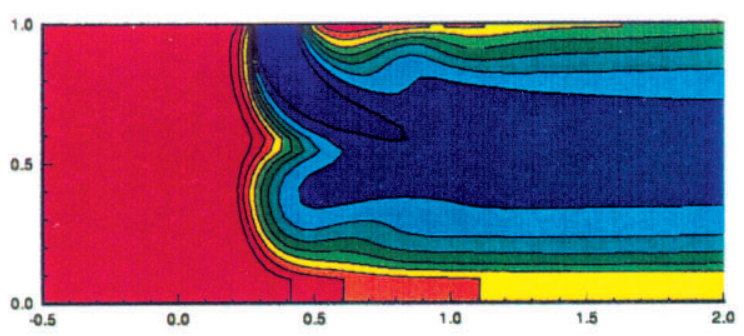

Equivalence ratio
AXIAL-RADIAL PLANE

ABSCISSA $=x / R$ ORDINATE $=r / R$

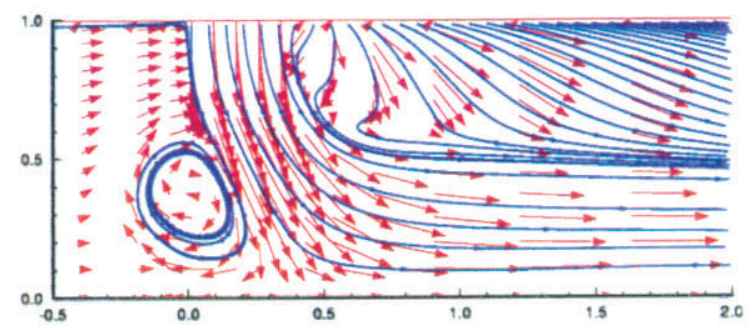

AXIAL-RADLAL PLANE

ABSCISSA $=\mathbb{N} / \boldsymbol{R}$ ORIDINATE $=r / R$

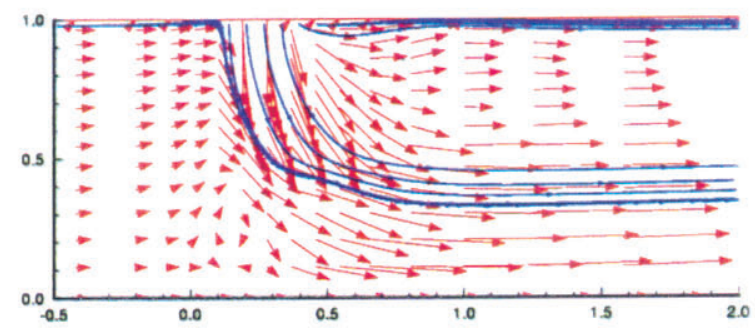

AXIAL-RADIAL PLANE

ABSCISSA $=\mathbb{X} / \mathbb{R}$ ORDINATE $=r$

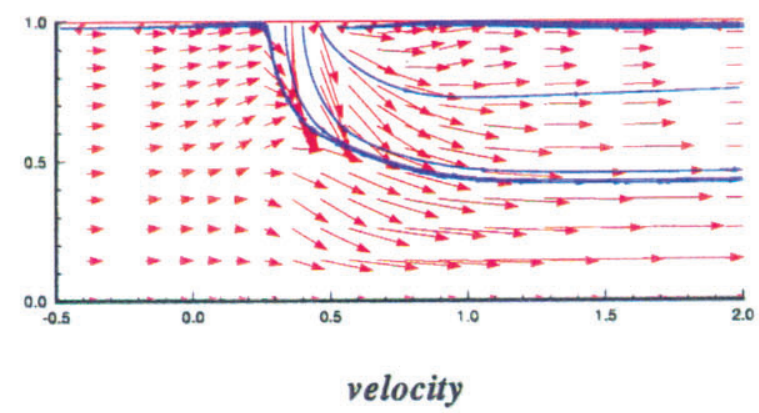

Figure-8. Effect of the change in orifice geometry on the equivalence ratio and velocity distributions

Top to bottom: round, $45^{\circ}$ slot with $L / W=4$, and $45^{\circ}$ slot with $L / W=8$ $J=52, M R=2.96, D R=2.28,8$ orifices $/$ row 
a. Round hole, $J=26.7, M R=2.96, D R=2.28$
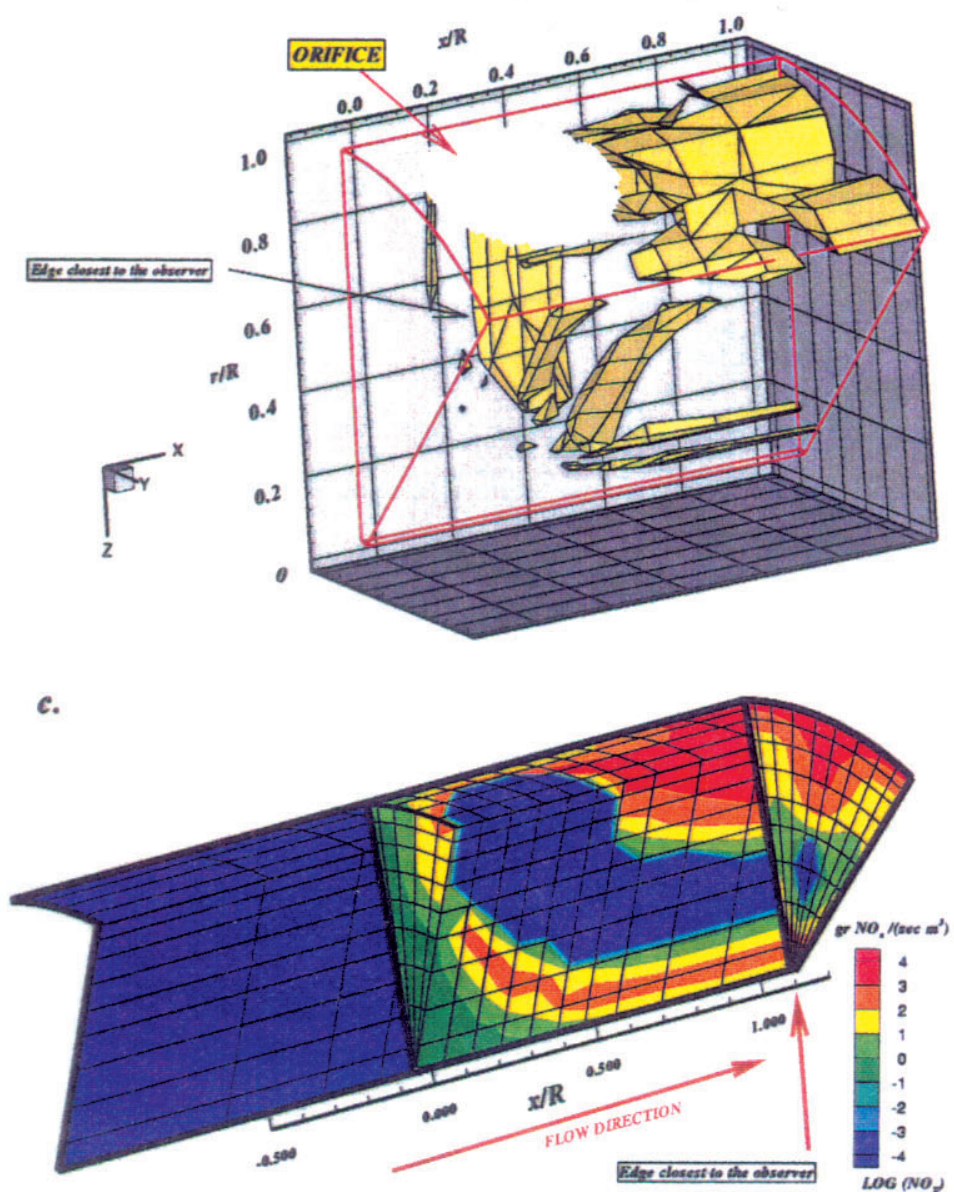

e.

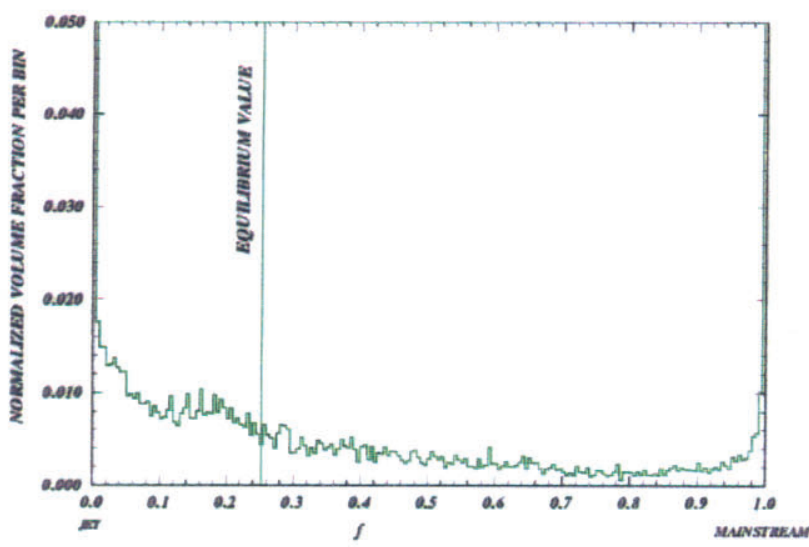

\section{BEST CONFIGURATION}

b. Round hole, $J=84.1, M R=2.96, D R=2.28$
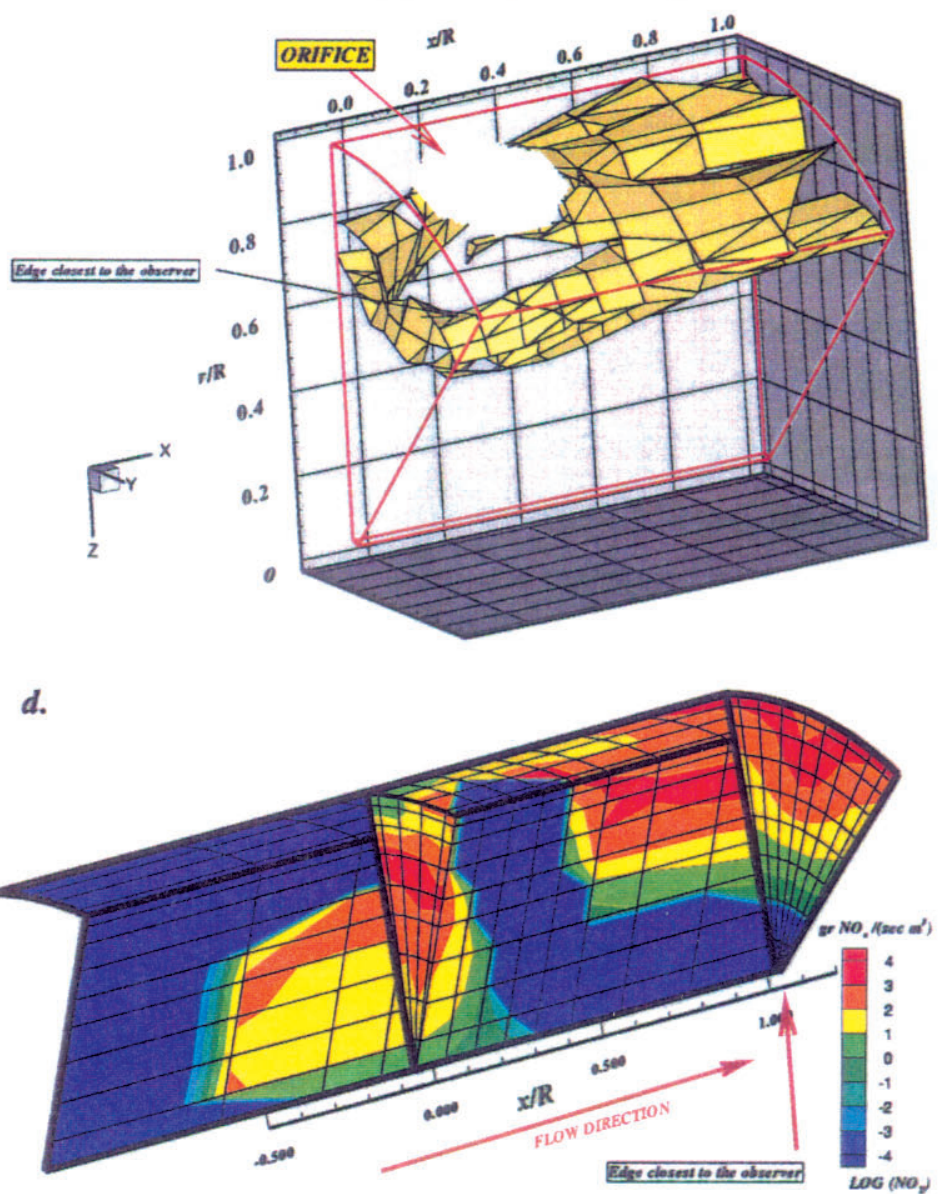

f.

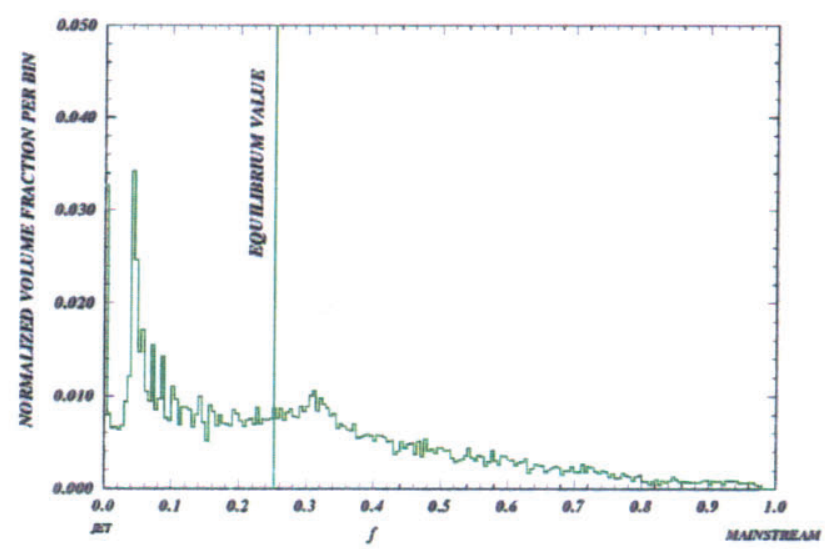

WORST CONFIGURATION

$(a, b)$ Interpolated $\mathrm{NO}_{x}$ production isopleth at $10^{3} \mathrm{gr}$ of $\mathrm{NO}_{x} /\left\{\mathrm{sec} \mathrm{m}^{3}\right\}$

(c, d) NO production development through the mixing section

$(e, f)$ volume histograms depicting the mixing non-uniformity for the domain $(0<x / R<1)$

Figure-15. Comparison of the best (left column) and worst (right column) $\mathrm{NO}_{x}$ production configurations with variation of $J$ for the round holes. 


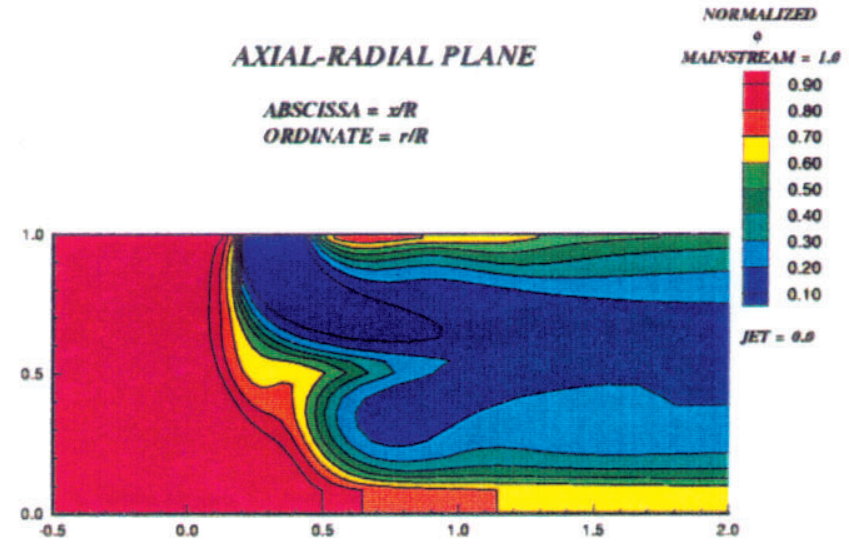

AXIAL-RADLAL PLANE

ABSCISSA $=\mathbb{D R}$

ORDINATE $=r / R$

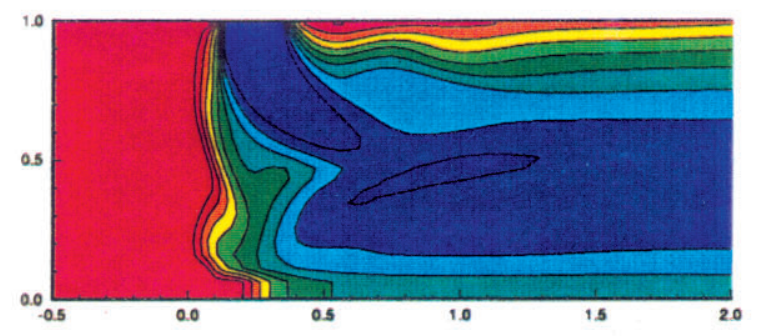

AXIAL-RADIAL PLANE

$A B S C I S S A=x / R$ ORDINATE $=r / R$

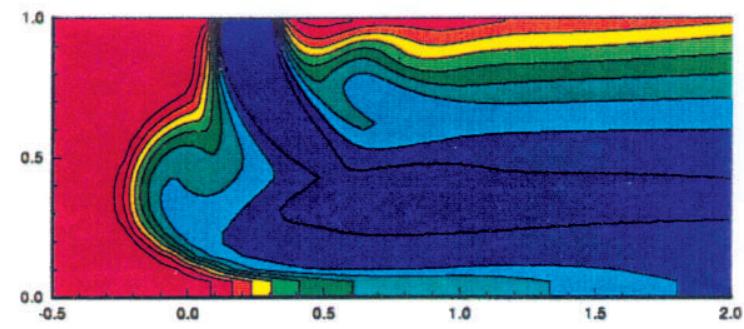

Equivalence ratio
AXIAL-RADLAL PLANE

ABSCISSA $=\mathbb{D R}$

ORDLNATE $=r / R$

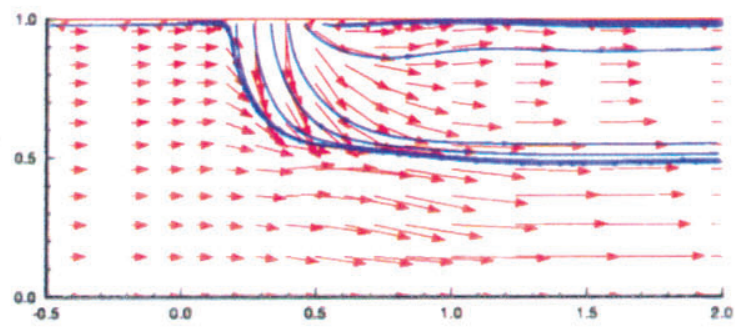

AXIAL-RADLAL PLANE

ABSCISSA $=\mathbb{X} / \mathbb{R}$

ORDINATE $=r / R$

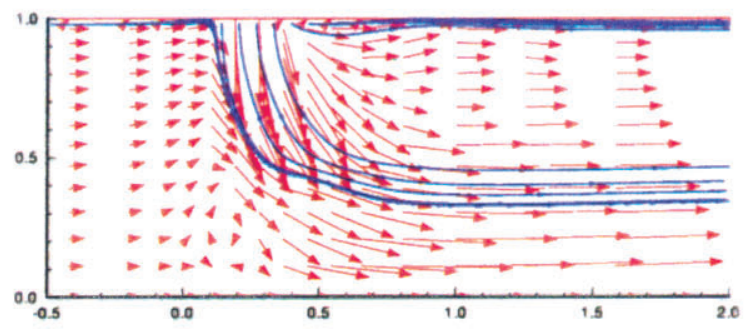

AXIAL-RADLAL PLANE

$A B S C I S S A=x / R$ ORDINATE $=r / R$

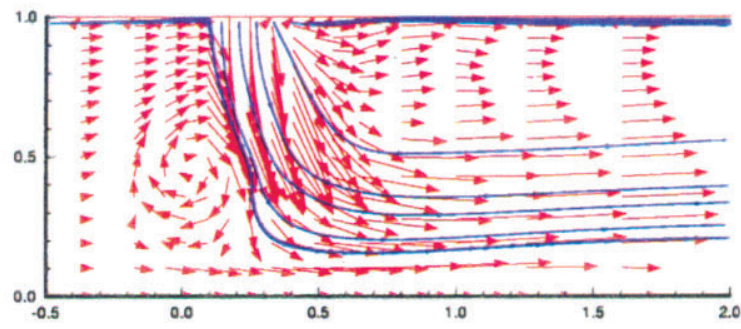

velocity

Figure-16. Effect of the change in $J$ on the equivalence ratio and velocity distributions

Top to bottom: $J=25,52$, and 80 $45^{\circ}$ slots, $L W=4, M R=2.96, D R=2.28,8$ orifices/row 

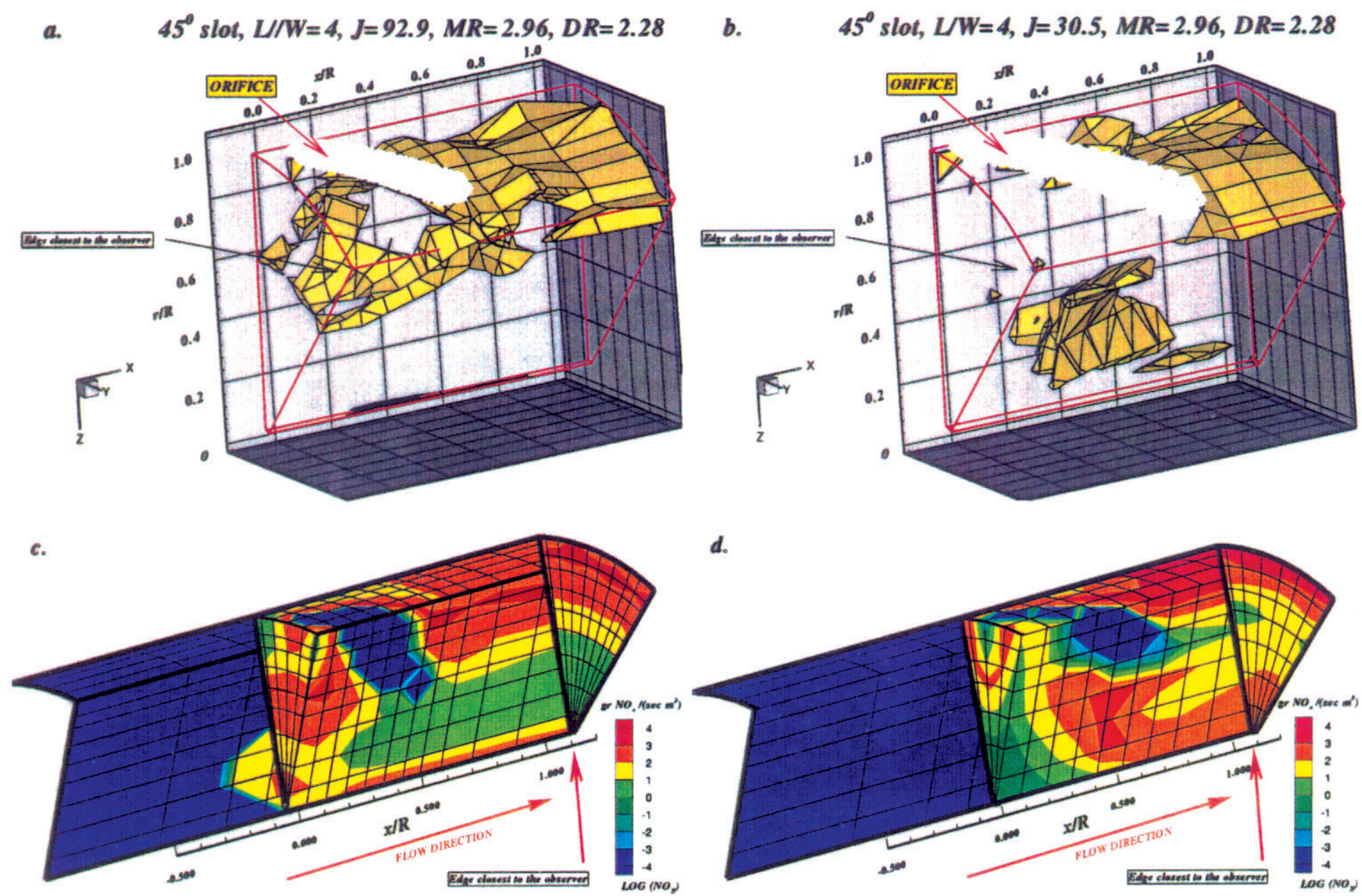

e.

$f$.

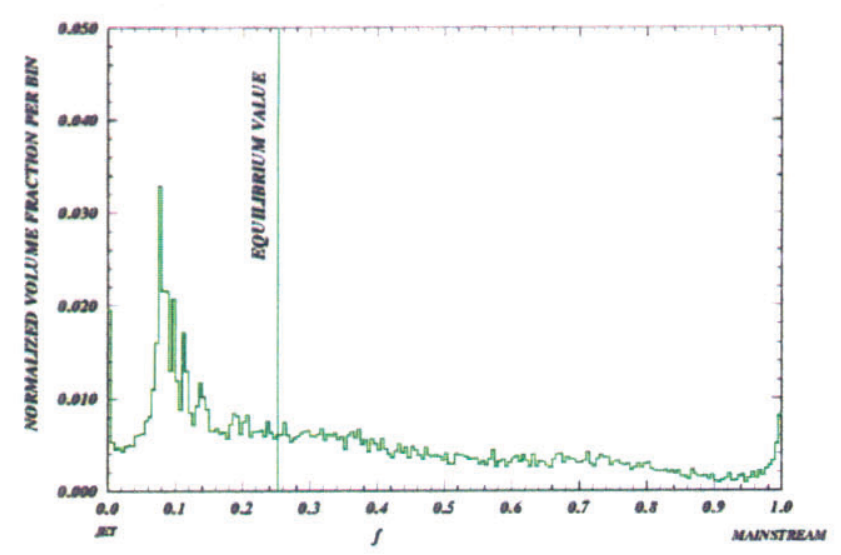

\section{BEST CONFIGURATION}

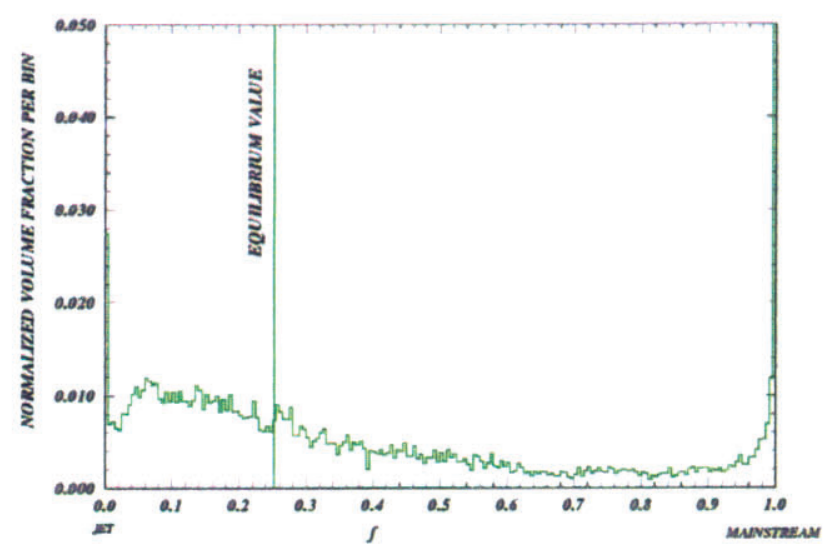

WORST CONFIGURATION

$(a, b)$ Interpolated $\mathrm{NO}_{x}$ production isopleth at $10^{3} \mathrm{gr}$ of $\mathrm{NO}_{x} /\left[\mathrm{sec} \mathrm{m}^{3}\right]$

(c, d) NO production development through the mixing section

$(e, f)$ volume histograms depicting the mixing non-uniformity for the domain $(0<x / R<1)$

Figure-17. Comparison of the best (left column) and worst (right column) $\mathrm{NO}_{x}$ production configurations with variation of $J$ from 25 to 80 for the $45^{\circ}$ slots with an aspect ratio $L W=4$. 


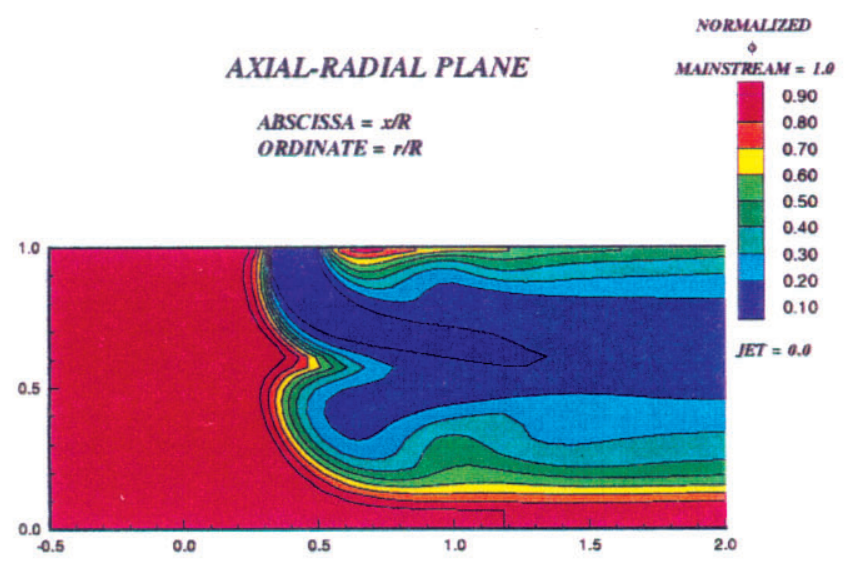

AXIAL-RADLAL PLANE

ABSCISSA $=x R$

ORDINATE $=r / R$

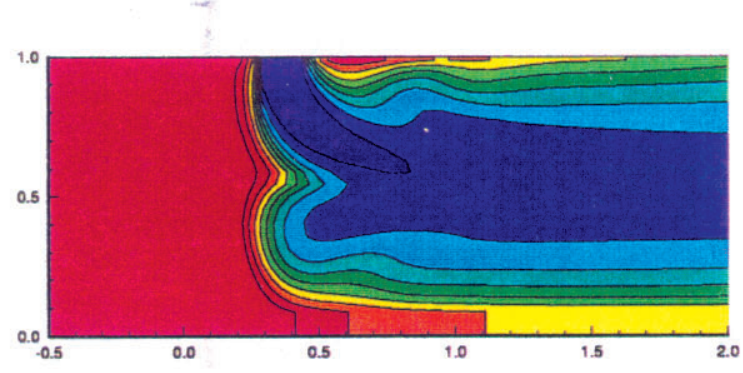

AXIAL-RADLAL PLANE

ABSCISSA $=x / R$ ORDINATE $=r / R$

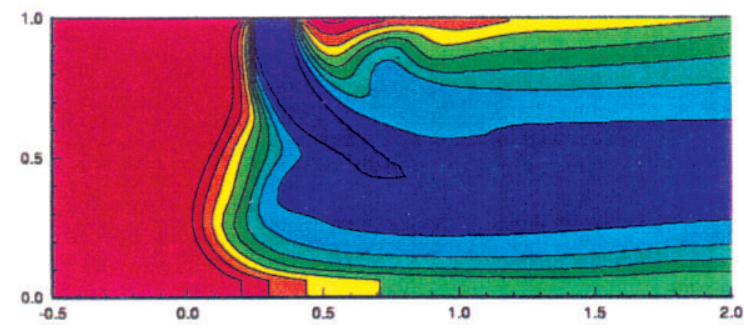

Equivalence ratio
AXIAL-RADIAL PLANE

$A B S C I S S A=x / R$ ORDINATE $=r / R$

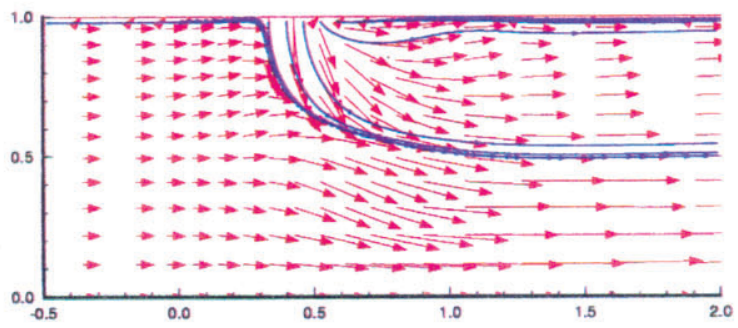

AXIAL-RADIAL PLANE

ABSCISSA $=\mathbb{E} / \boldsymbol{R}$

ORDINATE $=r / R$

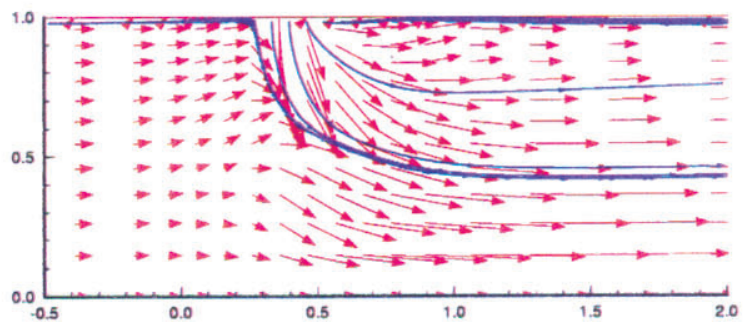

AXIAL-RADIAL PLANE

$A B S C I S S A=x / R$ ORDINATE $=r / R$

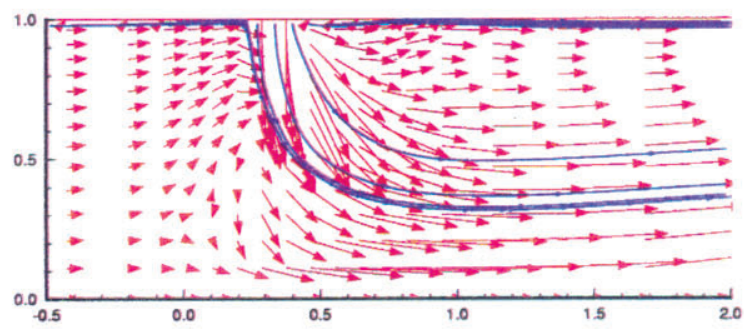

velocity

Figure-18. Effect of the change in J on the equivalence ratio and velocity distributions

Top to bottom: $J=25,52$, and 80 $45^{\circ}$ slots, $L W=8, M R=2.96, D R=2.28,8$ orifices/row 
a. $45^{\circ}$ slot, $L W=8, J=88.4, M R=2.96, D R=2.28$
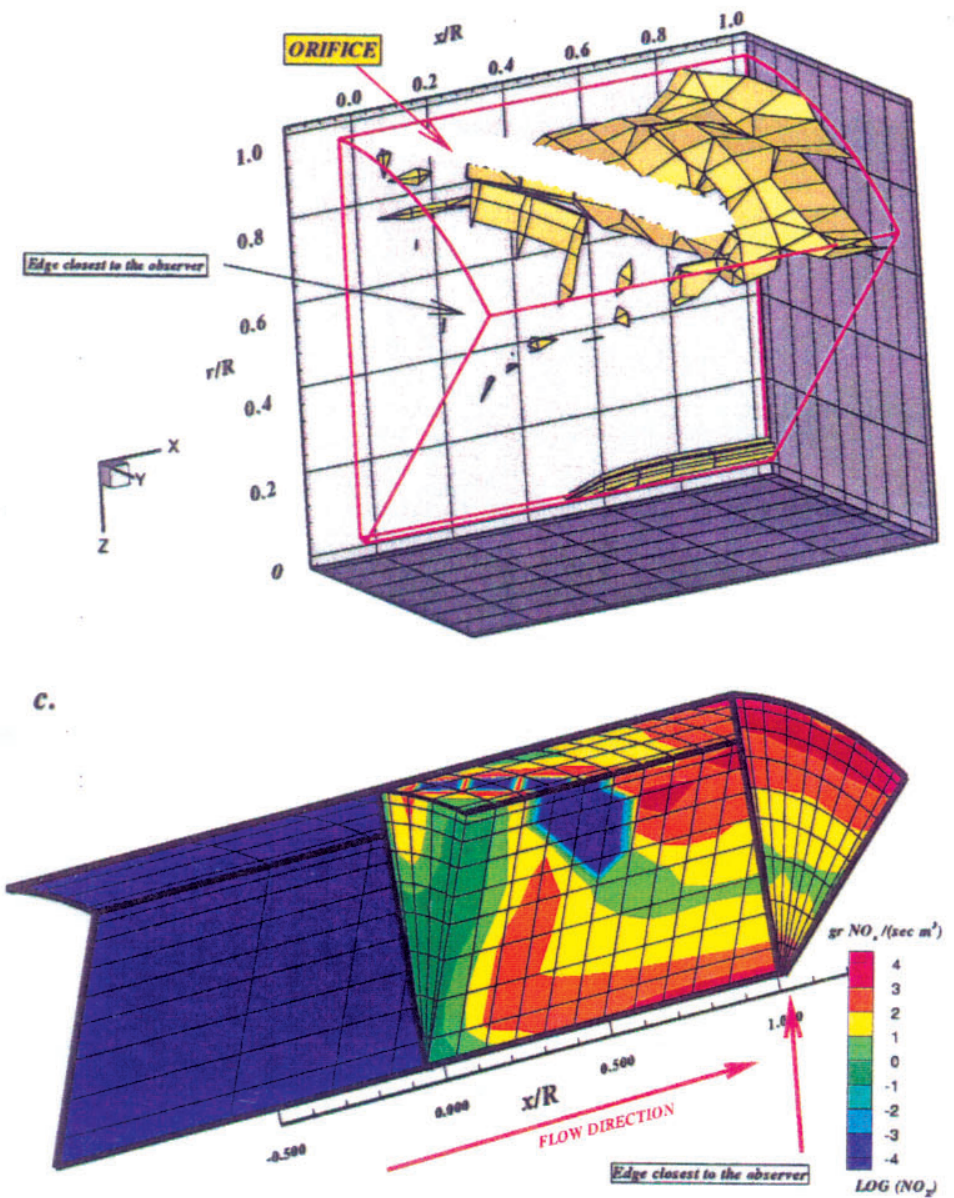

e.

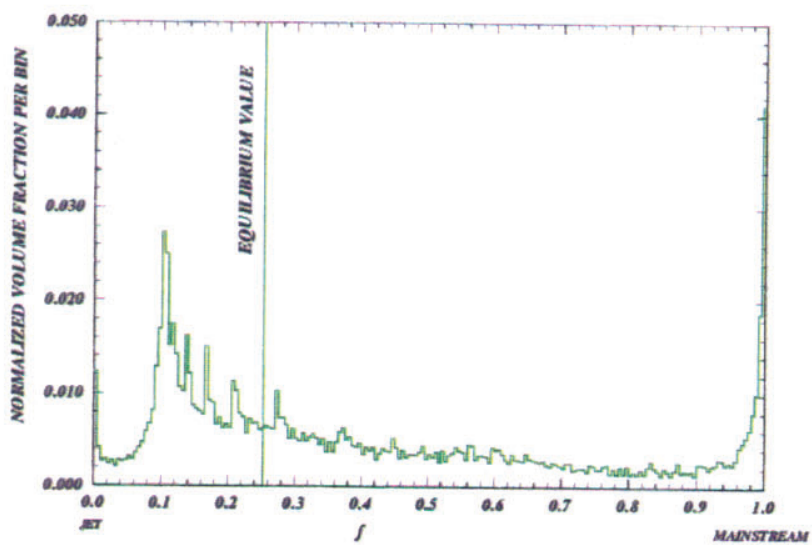

BEST CONFIGURATION b. $\quad 45^{\circ}$ slot, $L / W=8, J=28.1, M R=2.96, D R=2.28$
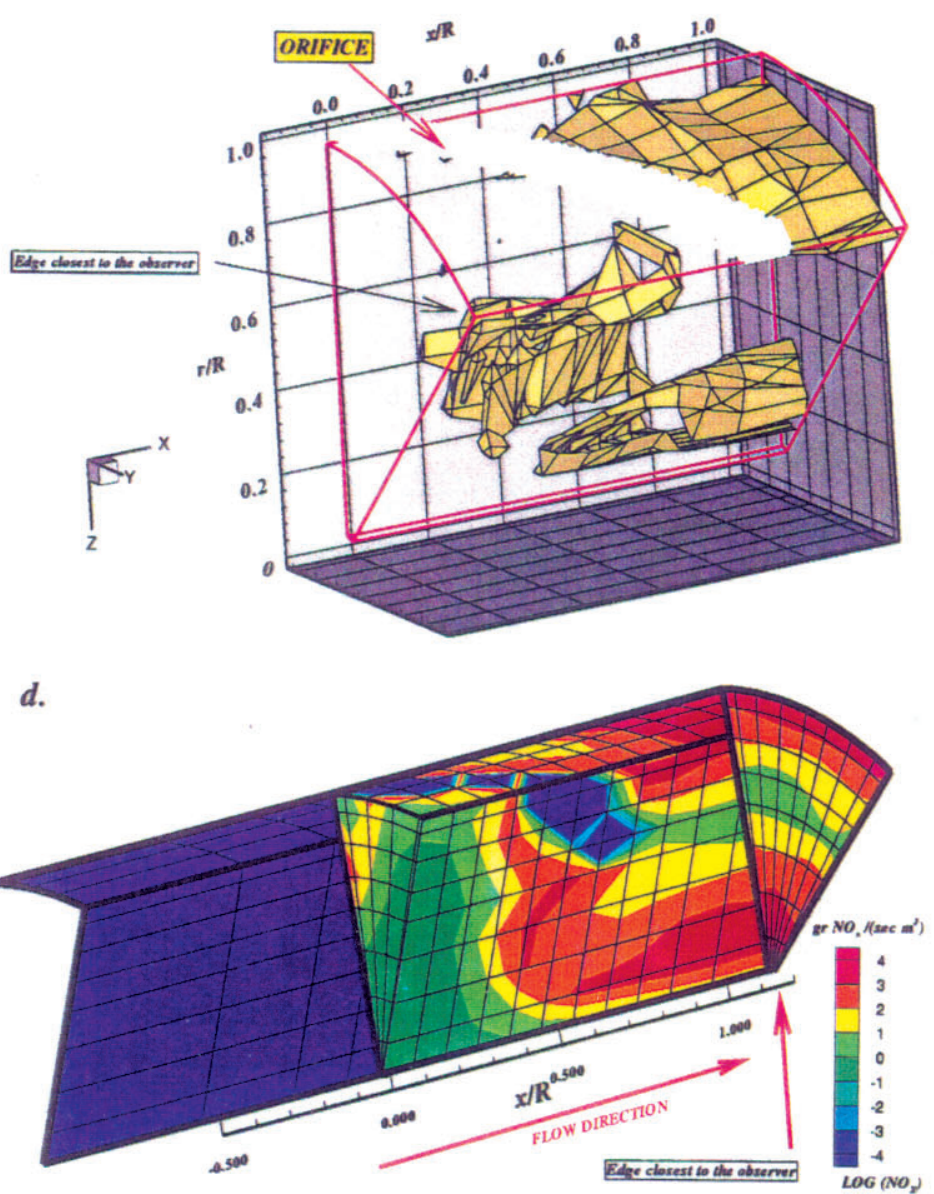

$f$.

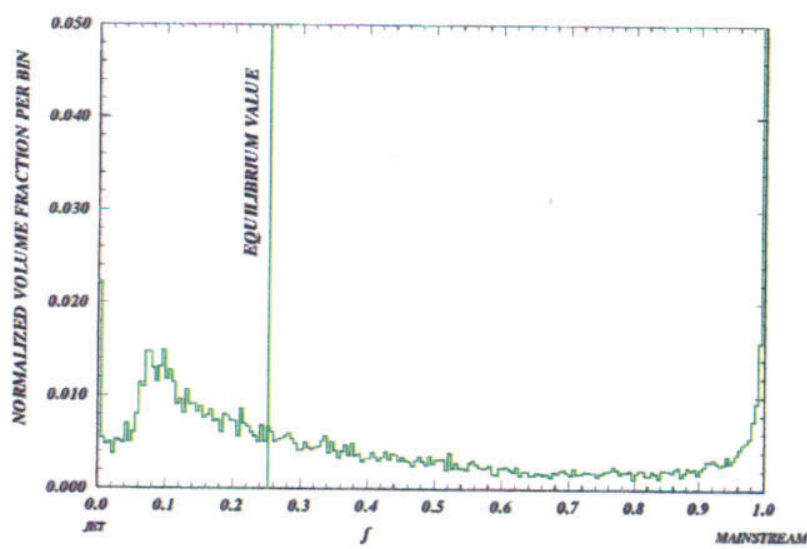

WORST CONFIGURATION

(a, b) Interpolated $\mathrm{NO}_{x}$ production isopleth at $10^{3} \mathrm{gr}$ of $\mathrm{NO}_{x} /\left\{\mathrm{sec} \mathrm{m}^{3}\right\}$

(c, d) $\mathrm{NO}_{x}$ production development through the mixing section

$(e, f)$ volume histograms depicting the mixing non-uniformity for the domain $(0<x / R<1)$

Figure-19. Comparison of the best (left column) and worst (right column) NO $O_{x}$ production configurations with variation of J from 25 to 80 for the $45^{\circ}$ slanted slots with aspect ratio of $L W=8$ 

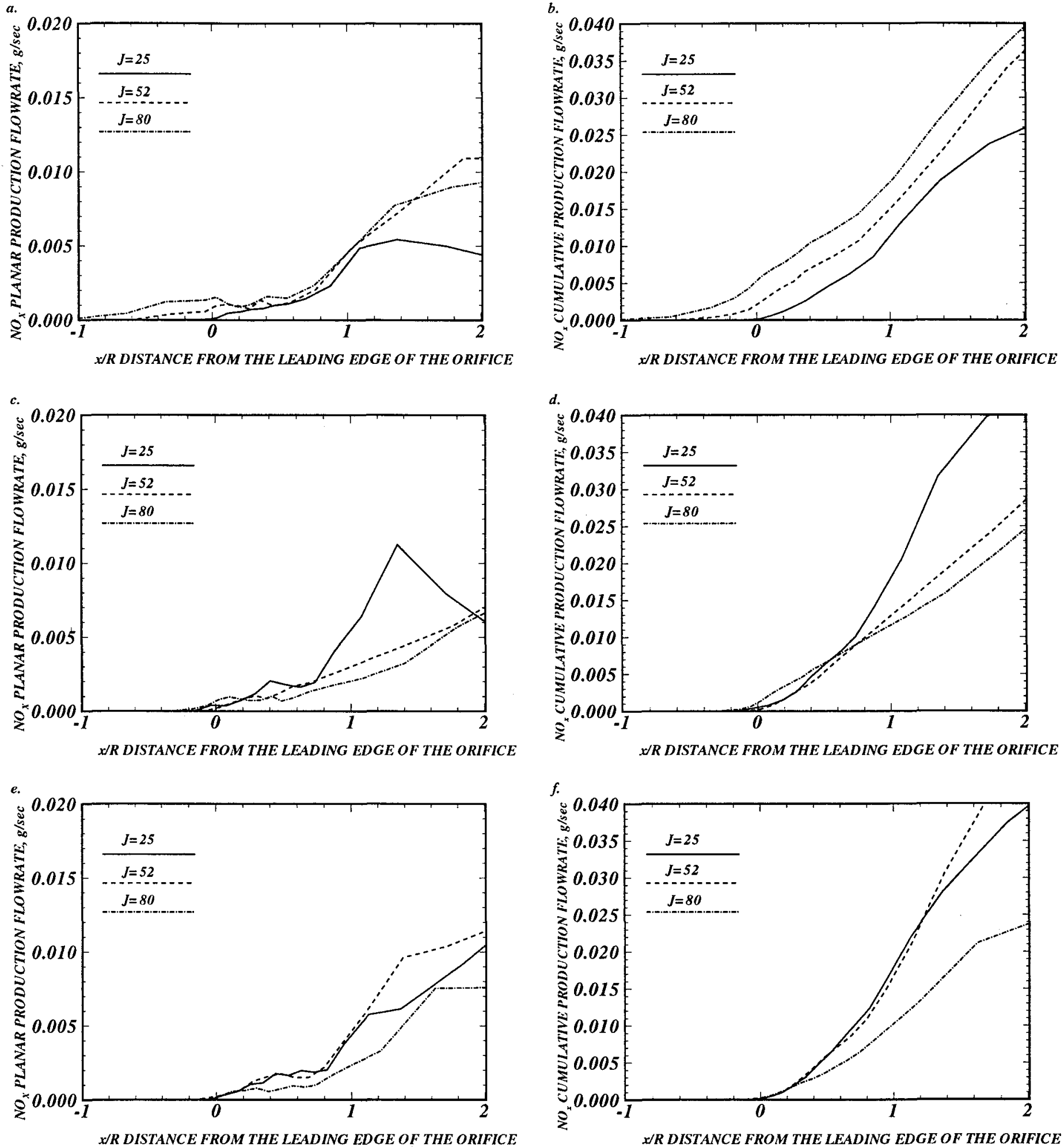

$(a, b)$ Effect of the change in $J$ for the round holes

$(c, d)$ Effect of the change in $J$ for the $45^{\prime}$ slots with aspect ratio $(L / W)=4$

$(e, f)$ Effect of the change in $J$ for the $45^{\prime}$ slots with aspect ratio $(L / W)=8$

Figure-20. $N O_{x}$ production development throughout the mixing section. NO $O_{x}$ planar production (left column) and $\mathrm{NO}_{x}$ cumulative production (right column). 
a.

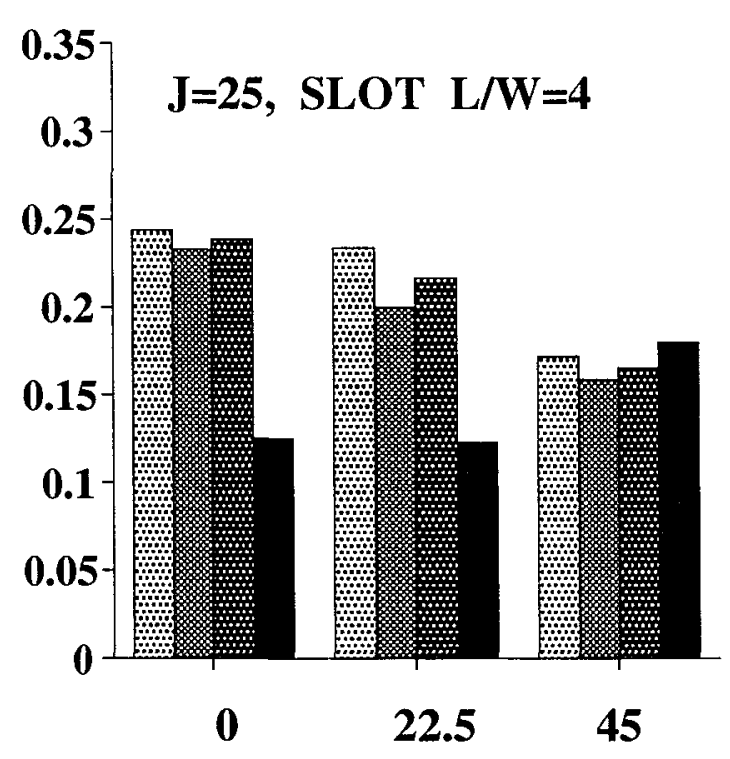

SLOT SLANT ANGLE, DEG

c.

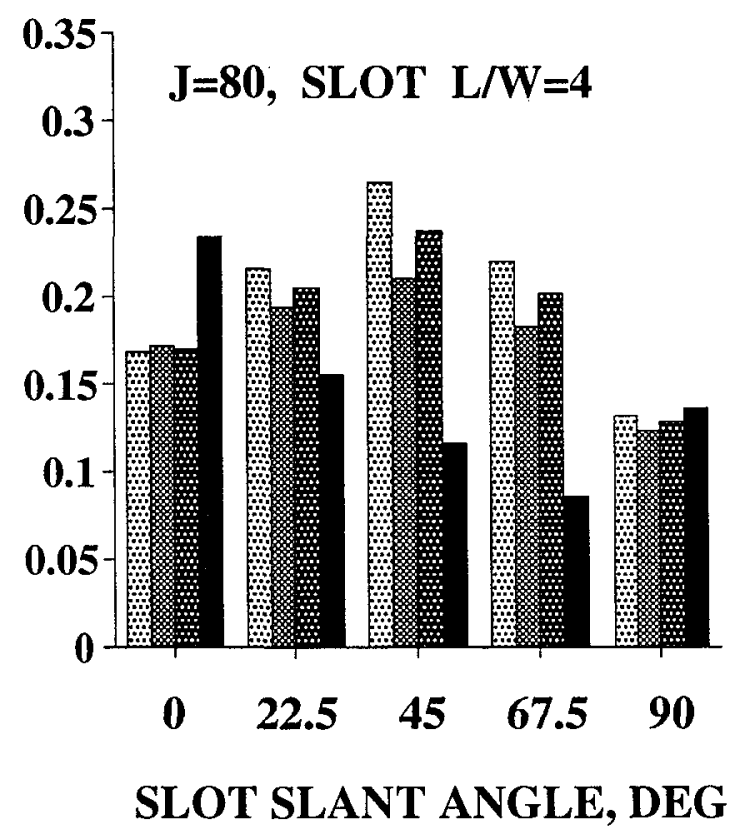

b.

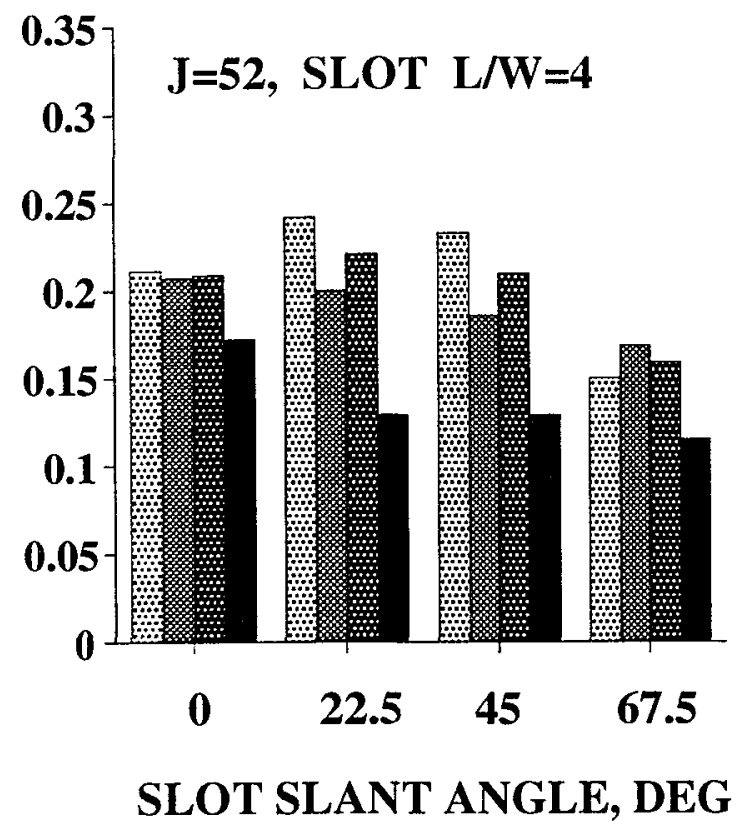

Figure-21. Effect of the change in slot slant angle on the mixing non-uniformity and NOx production rate for the $\mathrm{L} / \mathrm{W}=4$ slot 


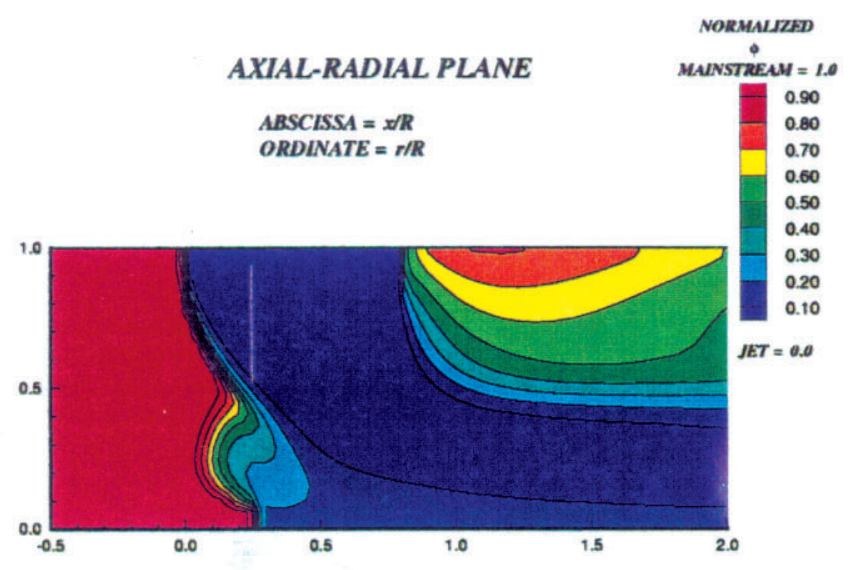

AXIAL-RADLAL PLANE

ABSCISSA $=x / R$

ORDINATE $=r / R$

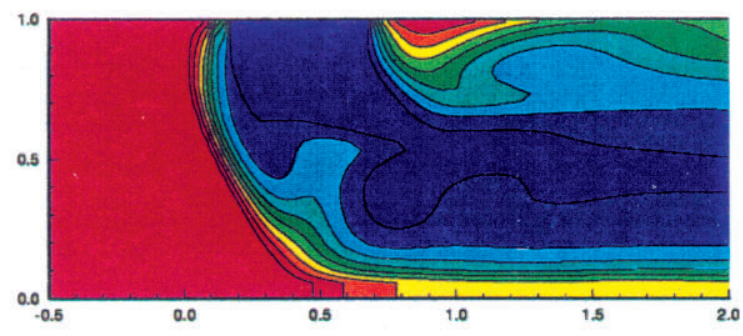

AXIAL-RADIAL PLANE

ABSCISSA $=$ XVR ORDINATE $=r / R$

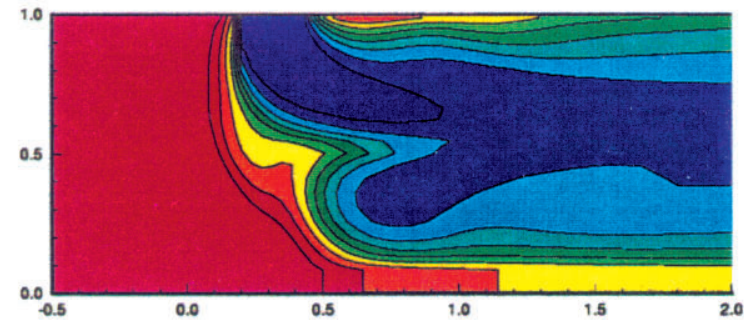

Equivalence ratio
AXIAL-RADIAL PLANE

ABSCISSA $=x / R$ ORDINATE $=r / R$

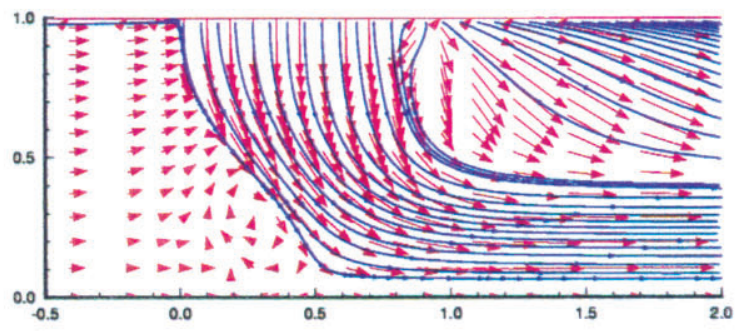

AXIAL-RADIAL PLANE

ABSCISSA $=x / \mathrm{K}$

ORDINATE $=r / R$

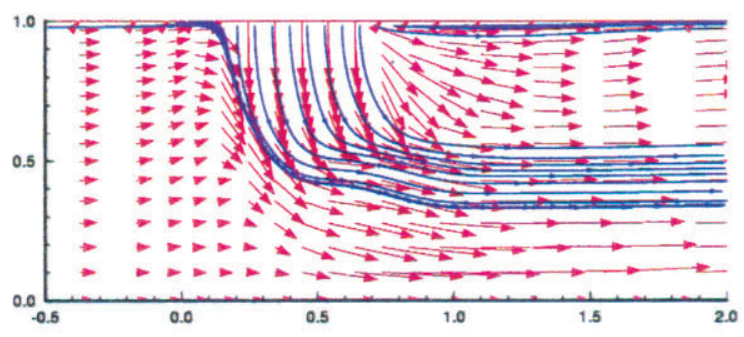

AXIAL-RADLAL PLANE

ABSCISSA $=x / R$ ORDINATE $=r / R$

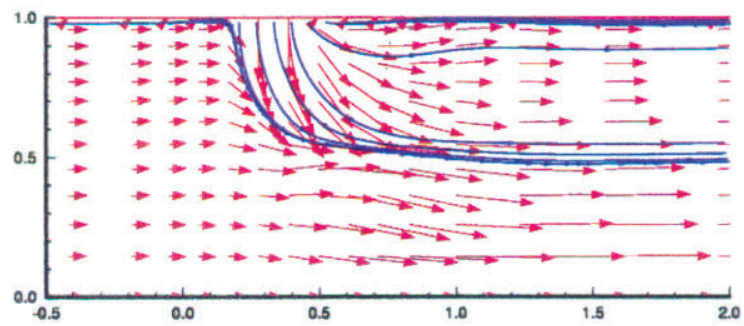

velocity

Figure-22. Effect of the change in slot slant angle on the equivalence ratio and velocity distributions

Top to bottom: slant angle $=0^{\circ}$ (in-line), $22.5^{\circ}$, and $45^{\circ}$

$J=25$, slot aspect ratio $L / W=4, M R=2.96, D R=2.28,8$ orifices/row 
a. $\theta^{0}$ (aligned slot), $L W=4, J=26.0, M R=2.96, D R=2.28$
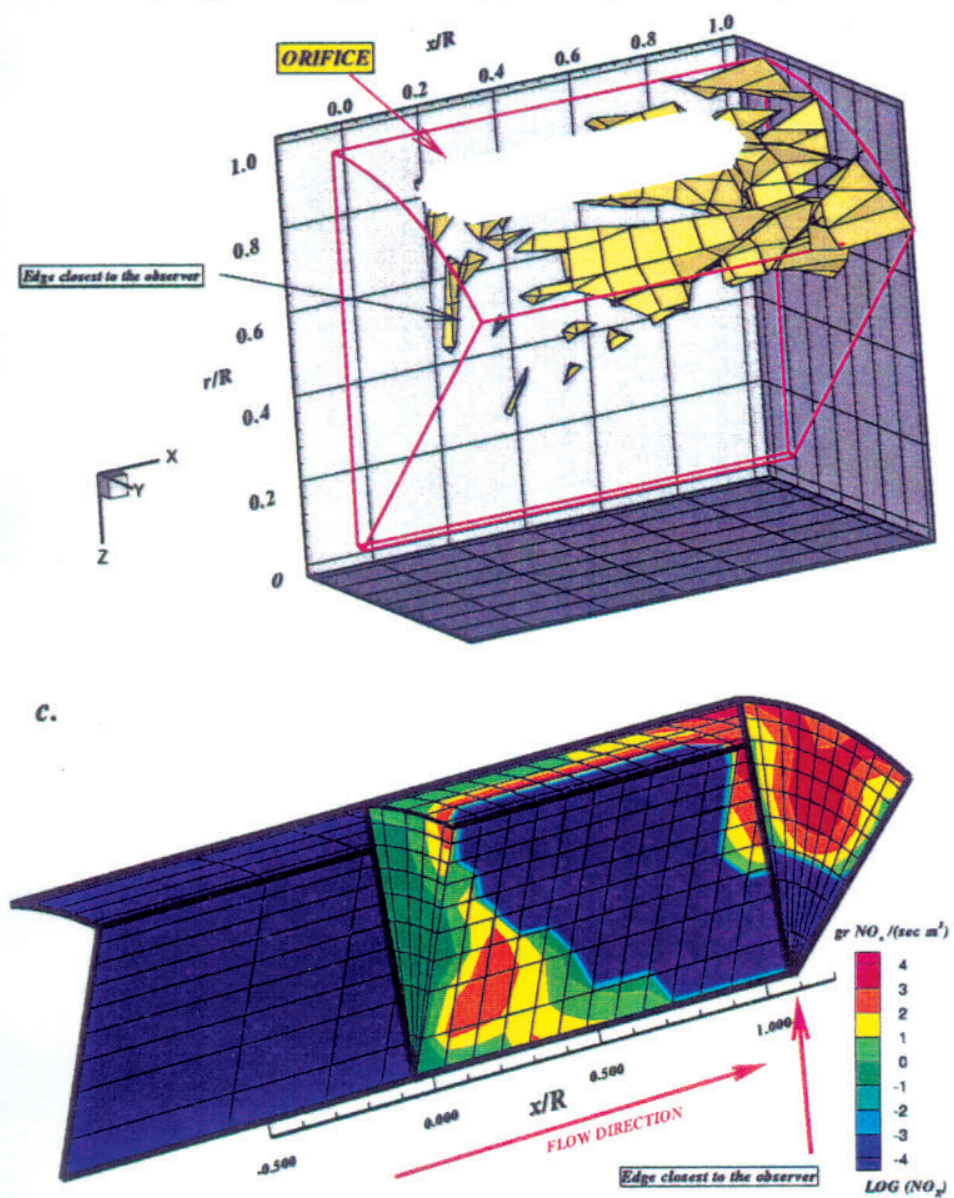

e.

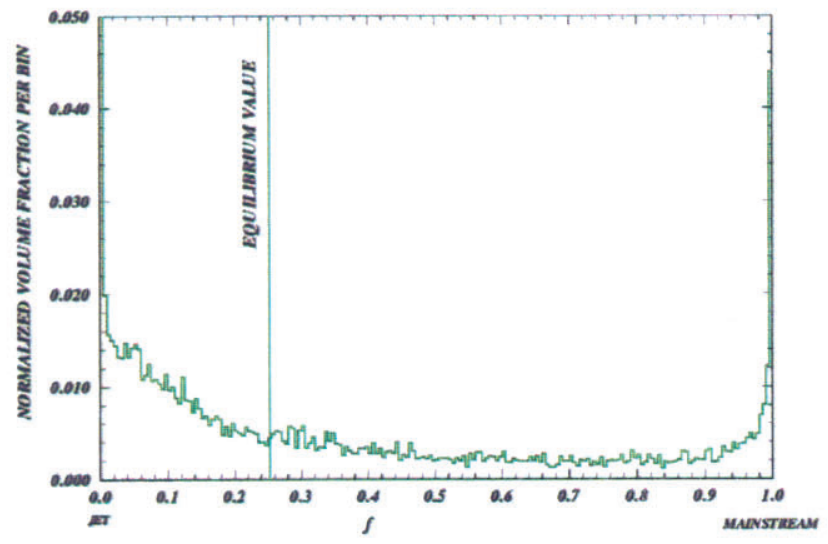

BEST CONFIGURATION b.

$45^{\circ}$ slot, $L W=4, J=30.5, M R=2.96, D R=2.28$
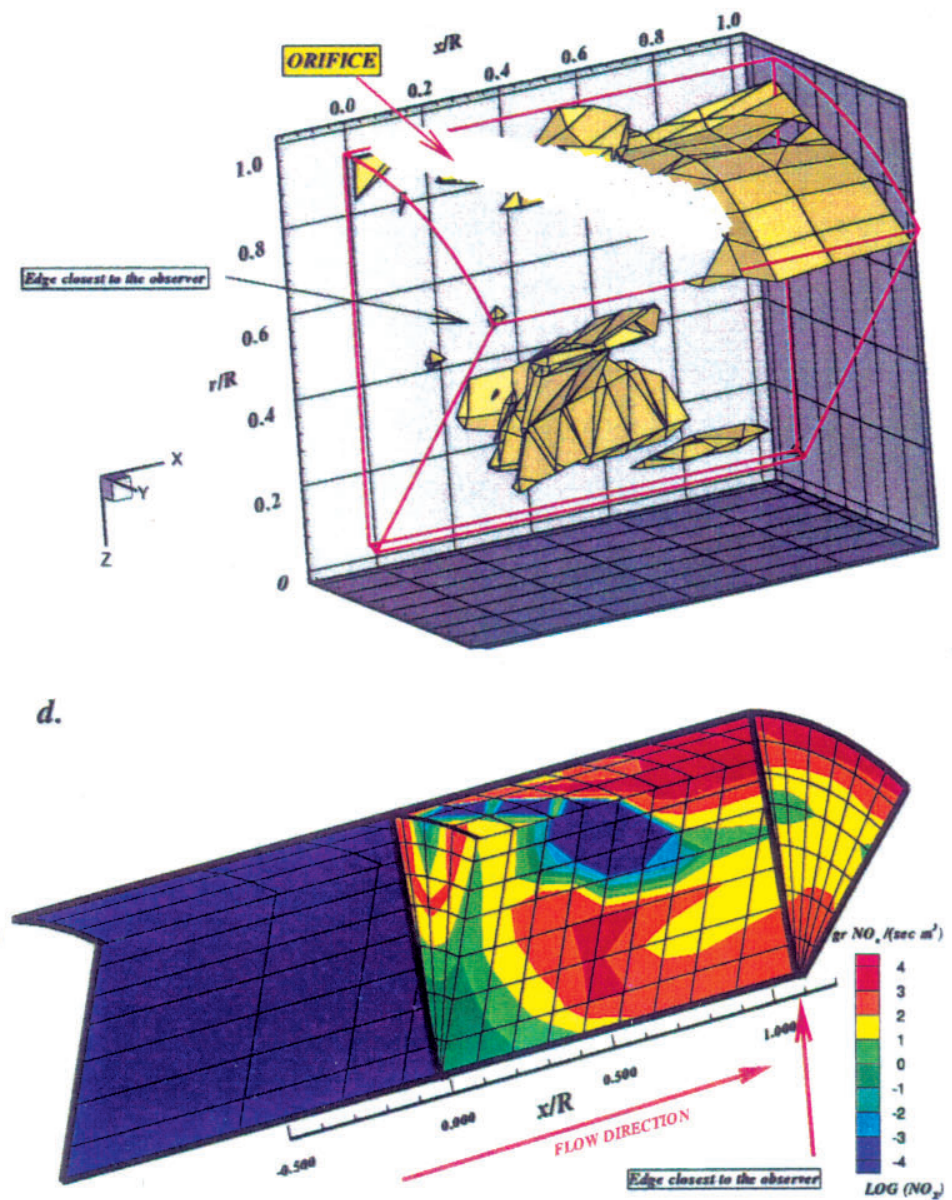

f.

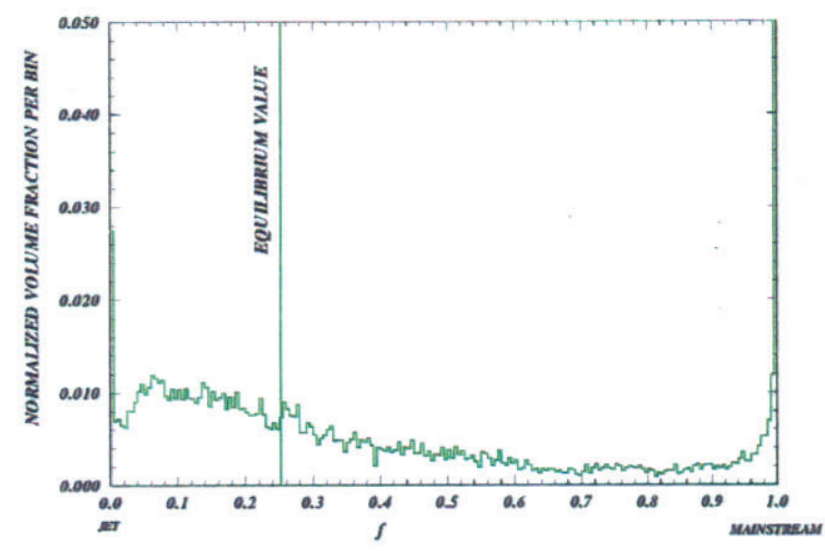

WORST CONFIGURATION

(a, b) Interpolated $\mathrm{NO}_{x}$ production isopleth at $10^{3} \mathrm{gr}$ of $\mathrm{NO}_{x} /\left\{\mathrm{sec} \mathrm{m}^{3}\right\}$

(c, d) $\mathrm{NO}_{x}$ production development through the mixing section

$(e, f)$ volume histograms depicting the mixing non-uniformity for the domain $(0<x / R<1)$

Figure-23. Comparison of the best (left column) and worst (right column) $N O_{x}$ production configurations with variation of slot slant angle from $0^{\circ}$ to $45^{\circ}$ for the aspect ratio slot of $L W=4$, at $J=25$ 

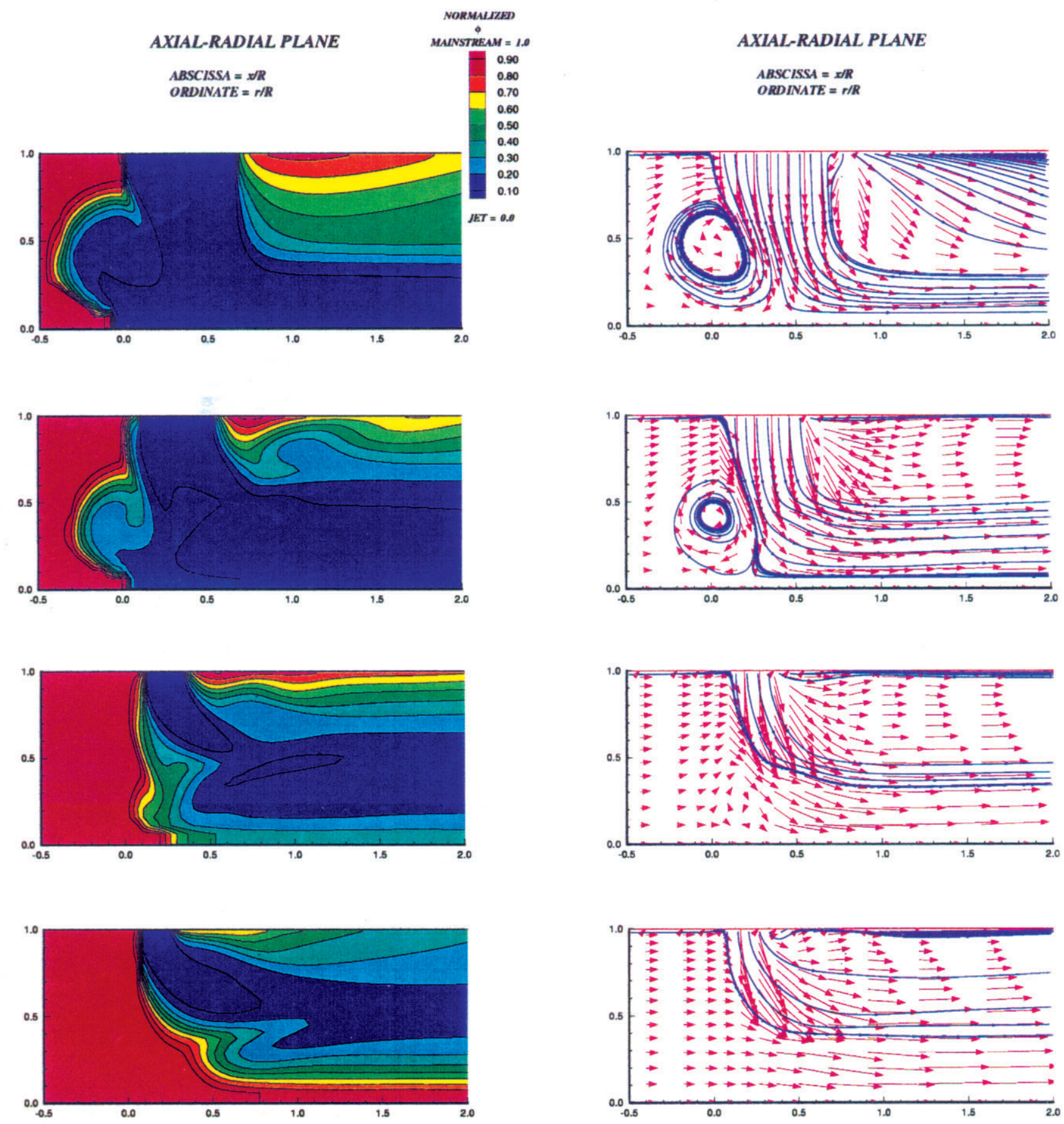

Equivalence ratio

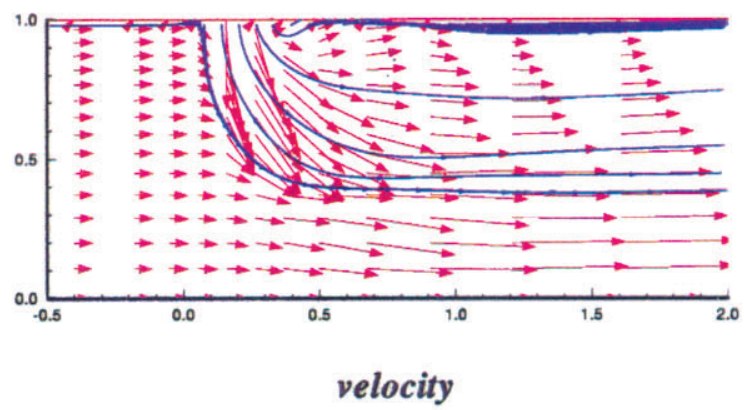

Figure-24. Effect of the change in slot slant angle on the equivalence ratio and velocity distributions

Top to bottom: slant angle $=0^{\circ}$ (in-line), $22.5^{\circ}, 45^{\circ}$, and $67.5^{\circ}$ $J=52$, slot aspect ratio $L / W=4, M R=2.96, D R=2.28,8$ orifices/row 


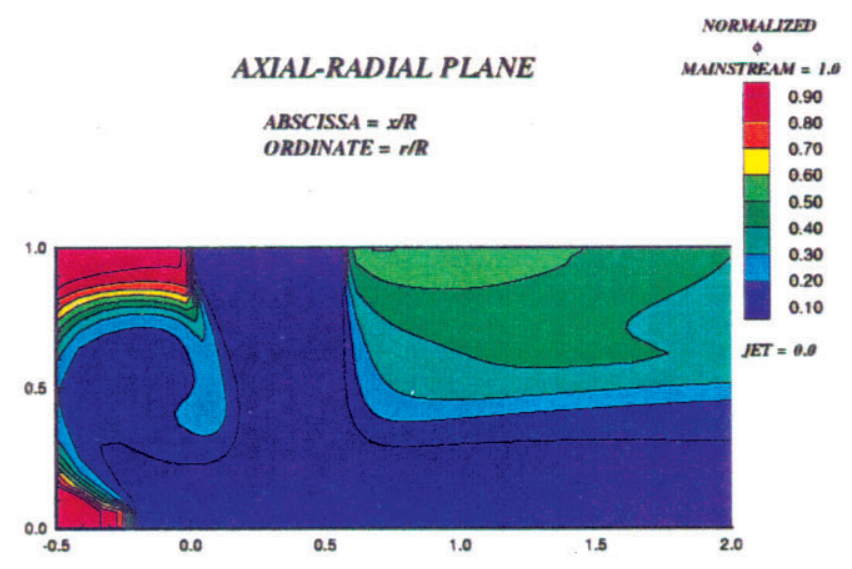

AXIAL-RADIAL PLANE

ABSCISSA $=x / R$

ORDINATE $=r / R$
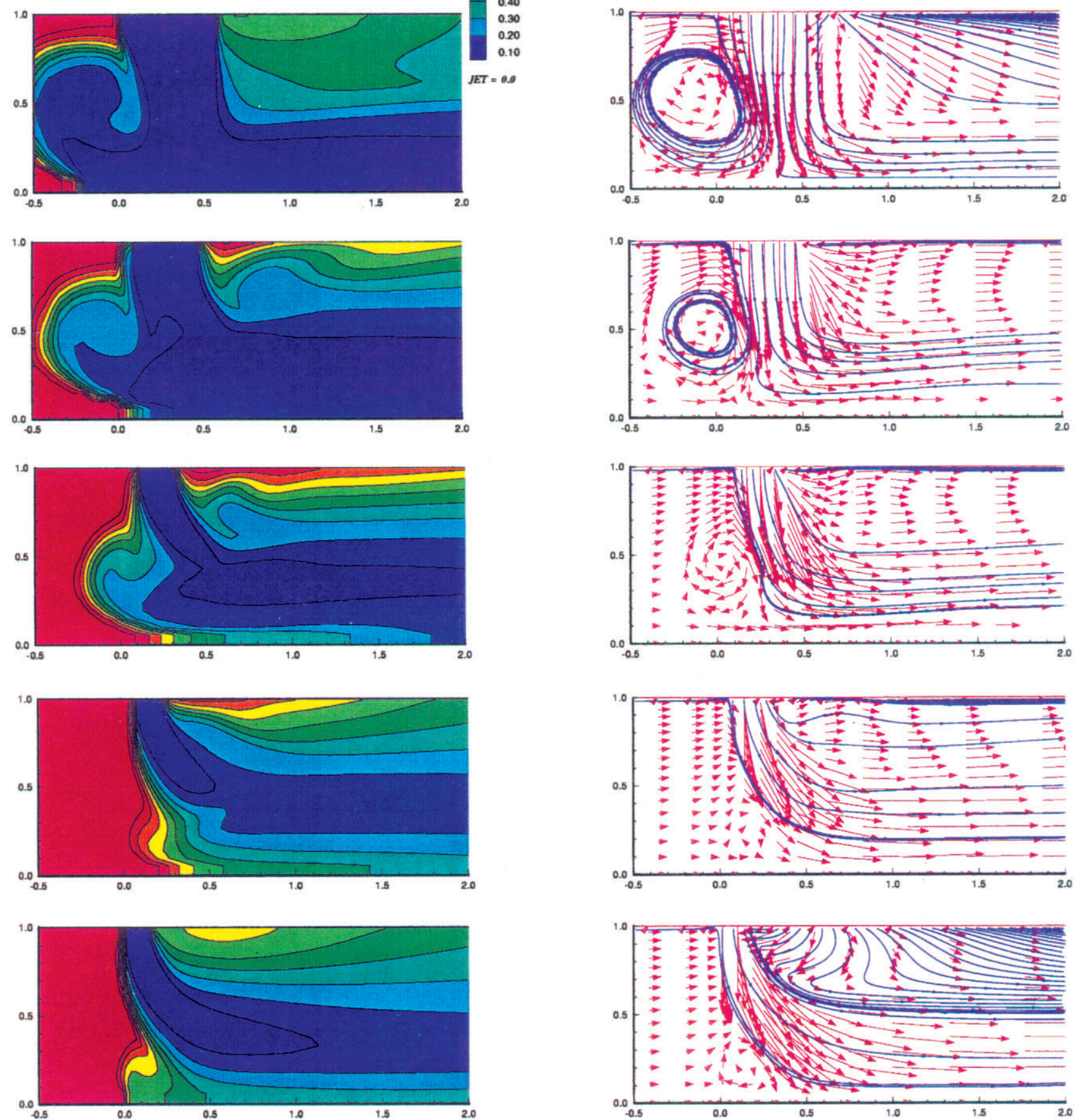

Equivalence ratio

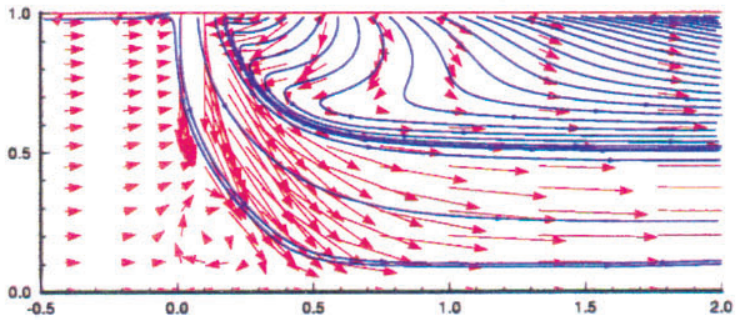

velocity

Figure-26. Effect of the change in slot slant angle on the equivalence ratio and velocity distributions

Top to bottom: slant angle $=0^{\circ}$ (in-line), $22.5^{\circ}, 45^{\circ}, 67.5^{\circ}$, and $90^{\circ}$ (transverse to the flow)

$J=80$, slot aspect ratio $L / W=4, M R=2.96, D R=2.28,8$ orifices/row 

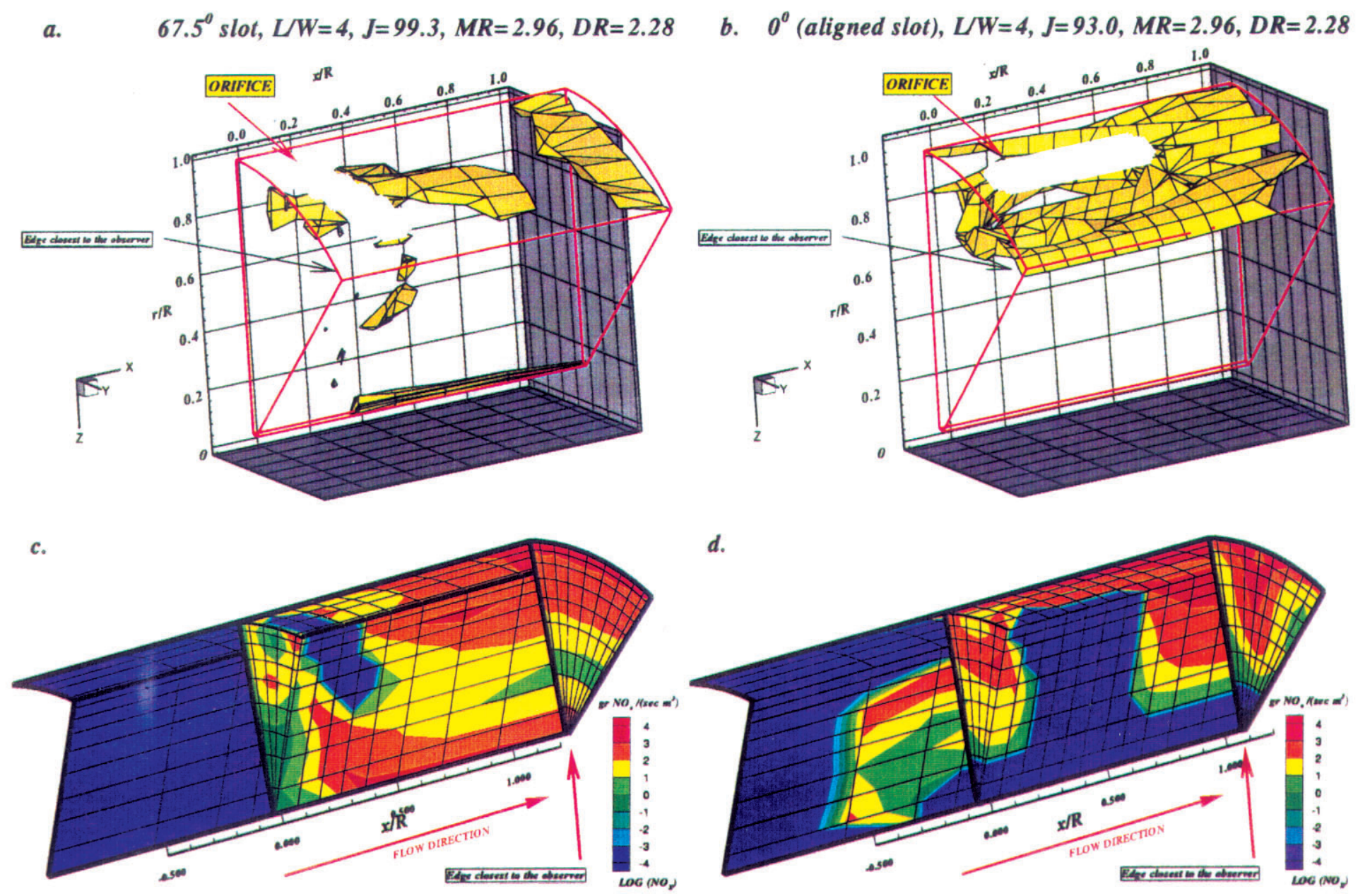

e.

$f$.

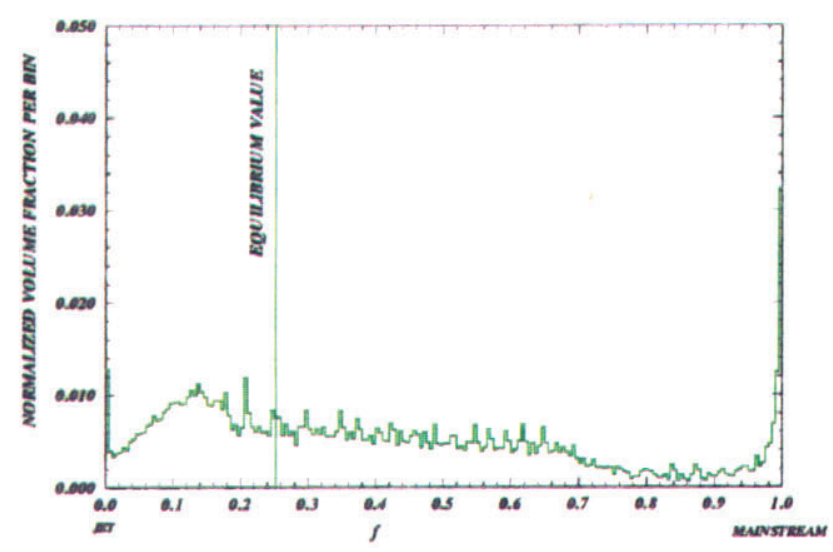

\section{BEST CONFIGURATION}

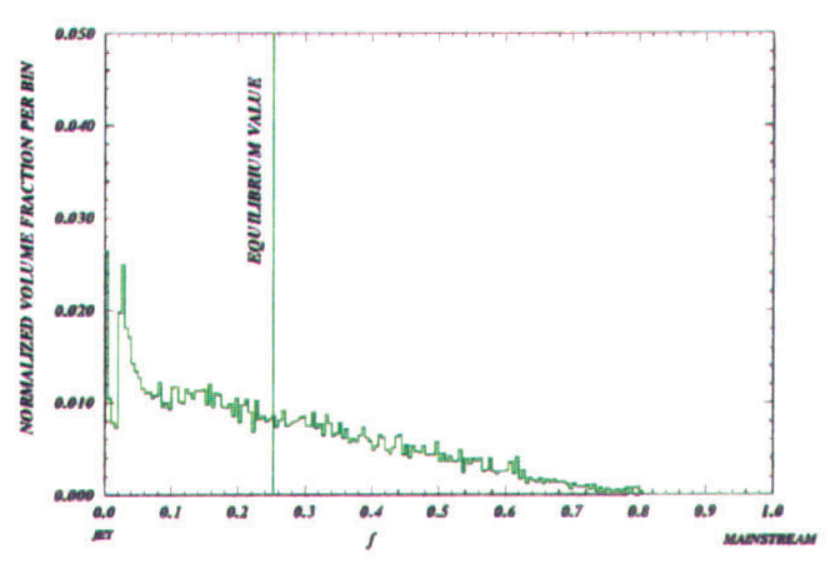

WORST CONFIGURATION

$(a, b)$ Interpolated $\mathrm{NO}_{x}$ production isopleth at $10^{3} \mathrm{gr}$ of $\mathrm{NO}_{x} /\left[\mathrm{sec} \mathrm{m}^{3}\right\}$

(c, d) $\mathrm{NO}_{x}$ production development through the mixing section

$(e, f)$ volume histograms depicting the mixing non-uniformity for the domain $(0<x / R<1)$

Figure-27. Comparison of the best (left column) and worst (right column) $\mathrm{NO}_{x}$ production configurations with variation of slot slant angle from $0^{\circ}$ to $90^{\circ}$ for the aspect ratio slot of $L W=4$, at $J=80$. 


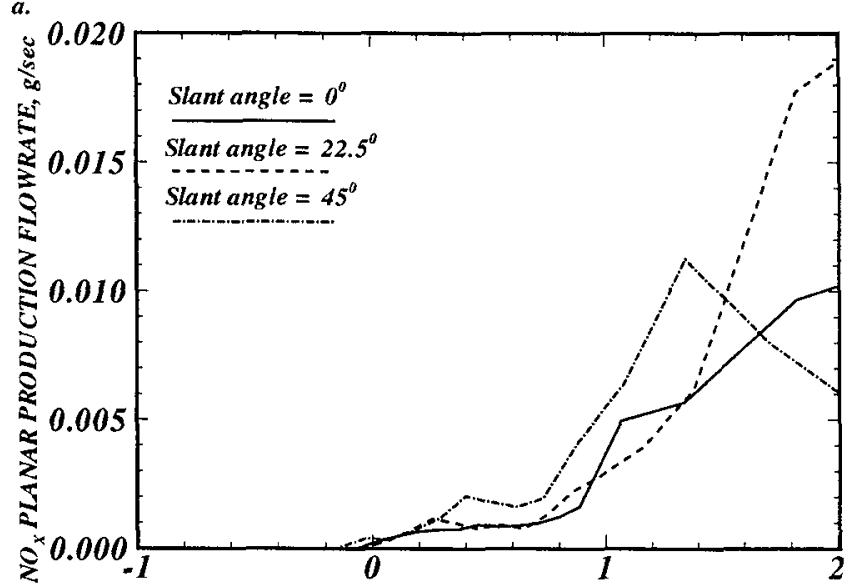

x/R DISTANCE FROM THE LEADING EDGE OF THE ORIFICE

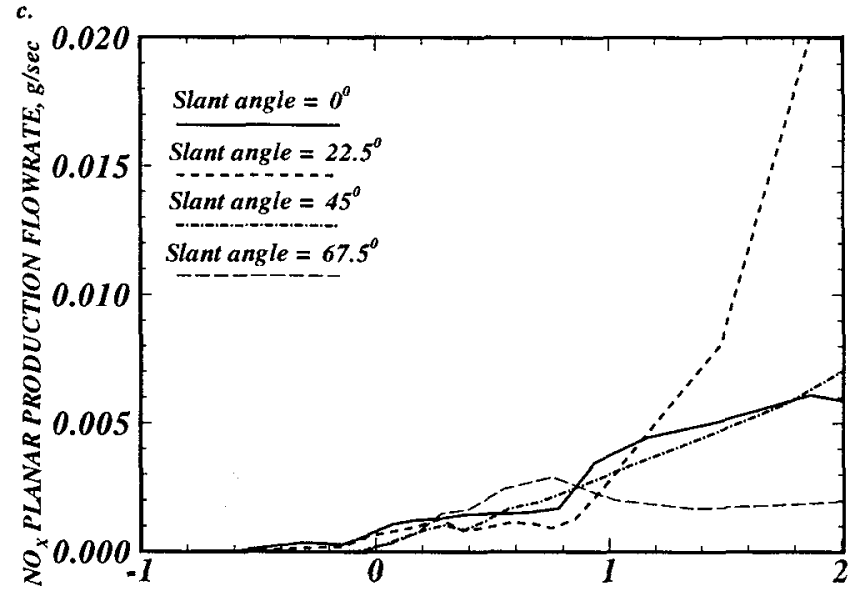

x/R DISTANCE FROM THE LEADING EDGE OF THE ORIFICE

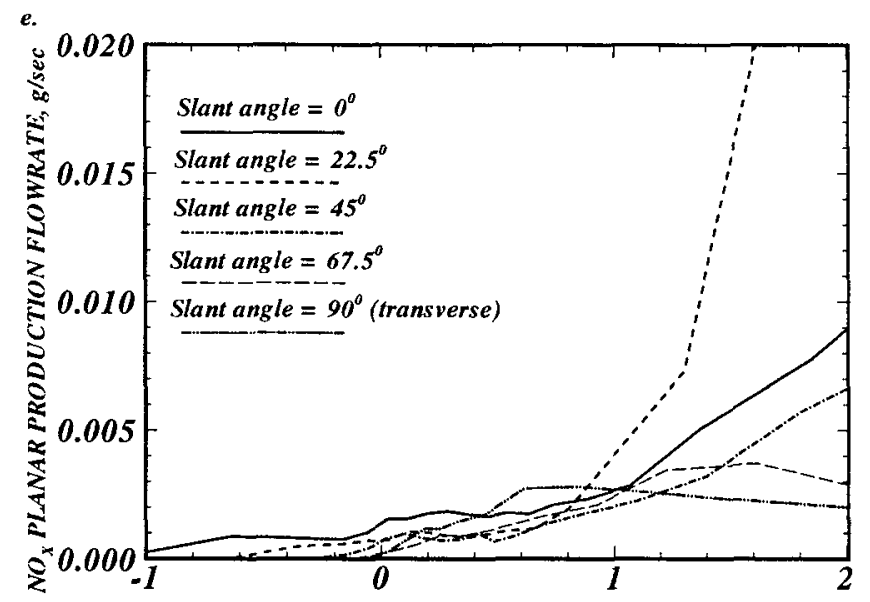

$x / R$ DISTANCE FROM THE LEADING EDGE OF THE ORIFICE b.

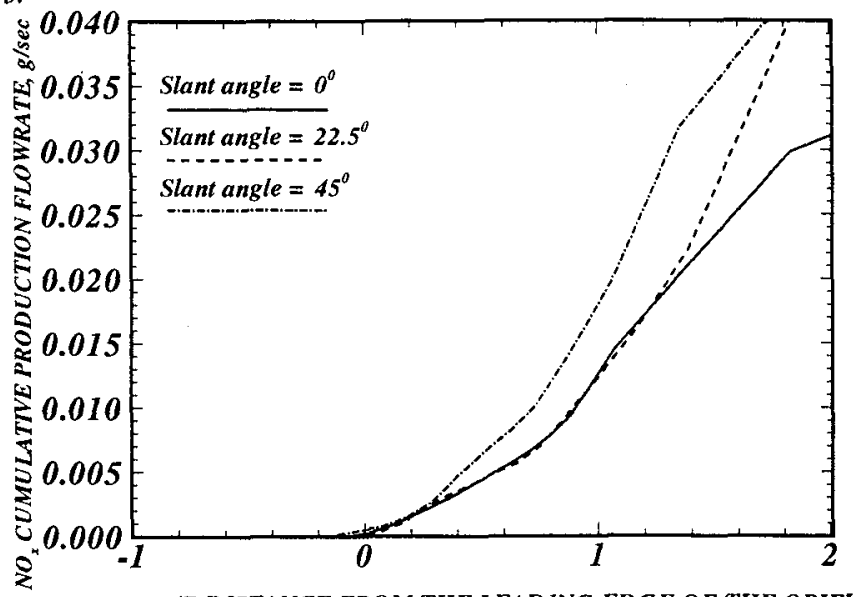

‘/R DISTANCE FROM THE LEADING EDGE OF THE ORIFICE

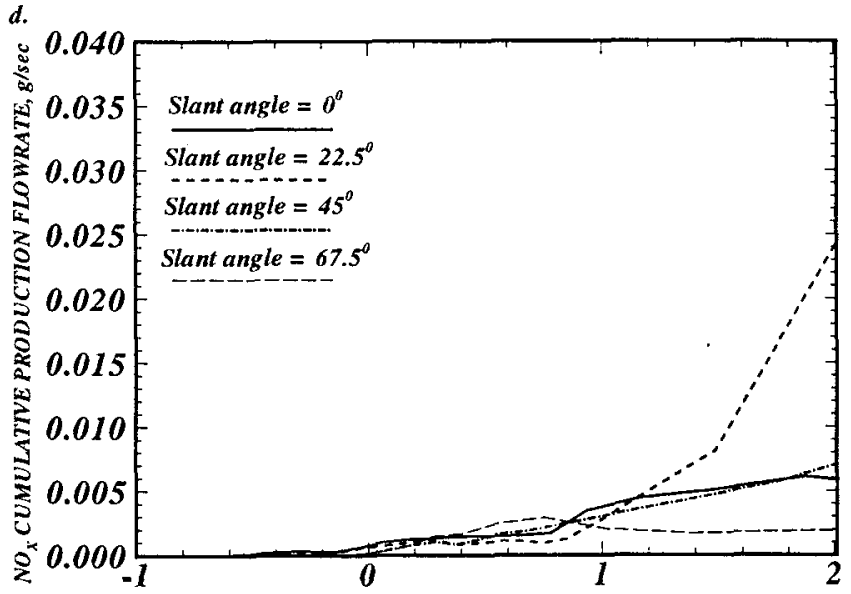

XIR DISTANCE FROM THE LEADING EDGE OF THE ORIFICE

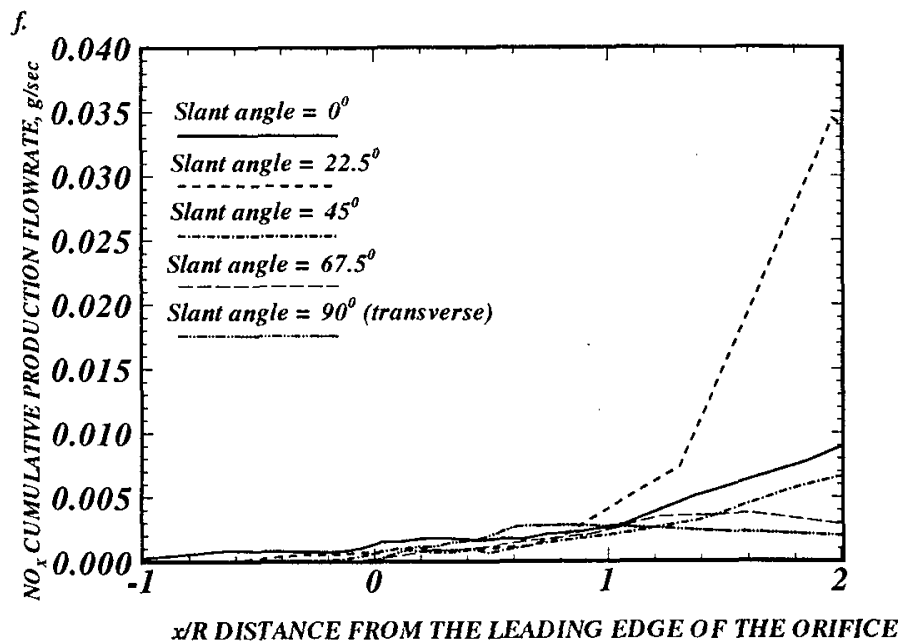

$(a, b)$ Effect of the change in slot slant angle on $N O_{x}$ formation at $J=25$

$(c, d)$ Effect of the change in slot slant angle on $\mathrm{NO}_{x}$ formation at $\mathrm{J}=52$

$(e, f)$ Effect of the change in slot slant angle on $N O_{x}$ formation at $J=80$

Figure-28. NO $O_{x}$ production development throughout the mixing section. $N O_{x}$ planar production (left column) and $\mathrm{NO}_{x}$ cumulative production (right column). 


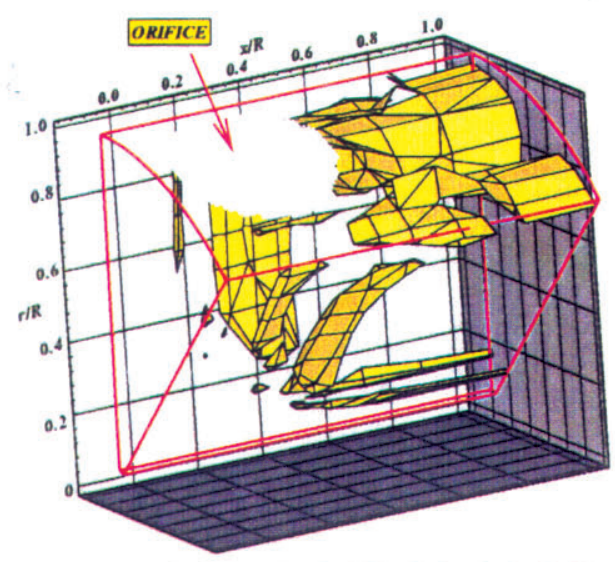

a. Round hole, $J=26.7, M R=2.96, D R=2.28$

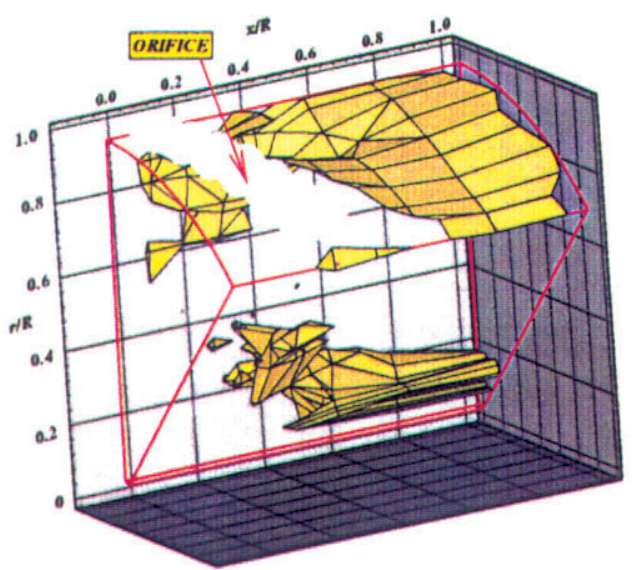

c. $67.5^{\circ}$ slot, $L W=4, J=59.9, M R=2.96, D R=2.28$

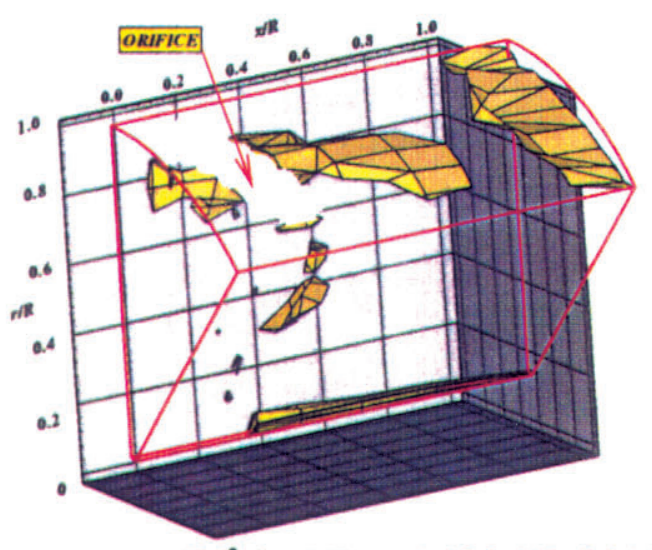

e. $67.5^{\circ}$ slot, $L W=4, J=99.3, M R=2.96, D R=2.28$

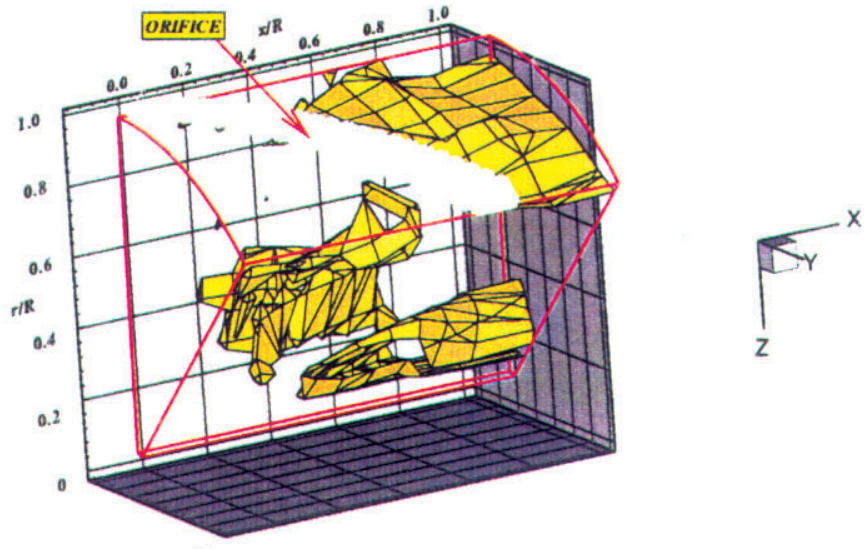

b. $45^{\circ}$ slot, $L W=8, J=28.1, M R=2.96, D R=2.28$

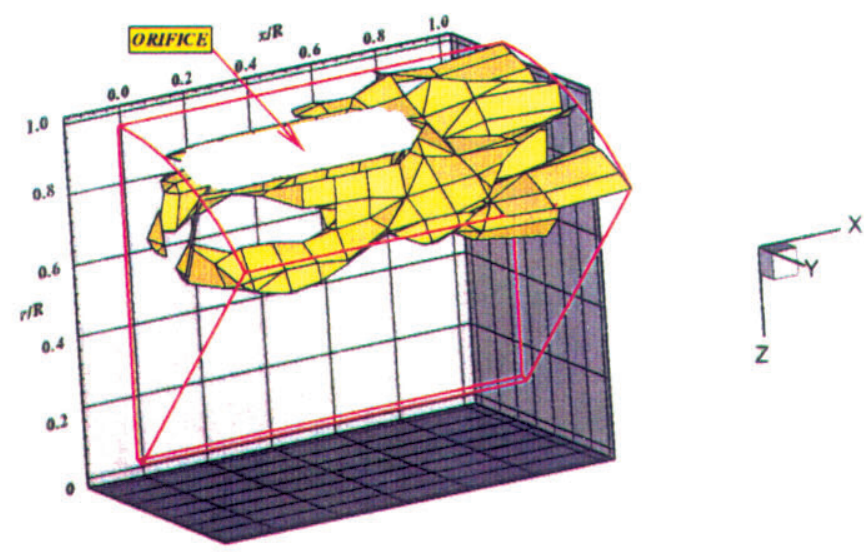

d. Aligned slot, $L W=4, J=51.1, M R=2.96, D R=2.28$

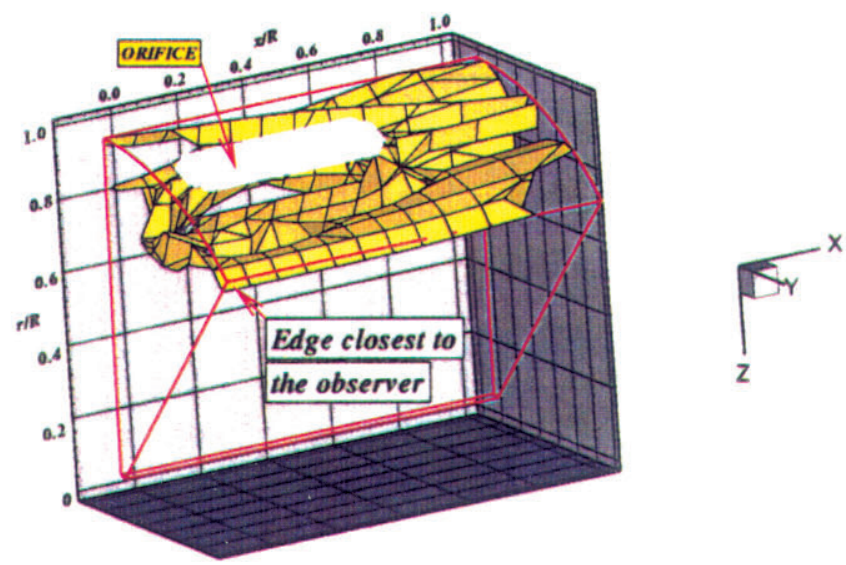

f. Aligned slot, $L W=4, J=93.0, M R=2.96, D R=2.28$

Figure-29. Comparison of the best (left column) and worst (right) local $N \mathrm{O}_{x}$ production configurations for nominal $\mathrm{J}=25(a, b), 52(c, d)$, and $80(e, f)$. The interpolated surface shown is the $10^{3} \mathrm{gr} \mathrm{NO} \mathrm{x}_{x} /\left\{\mathrm{sec} \mathrm{m}^{3}\right\}$ value. Domain is $0<x / R<1$. 
a.

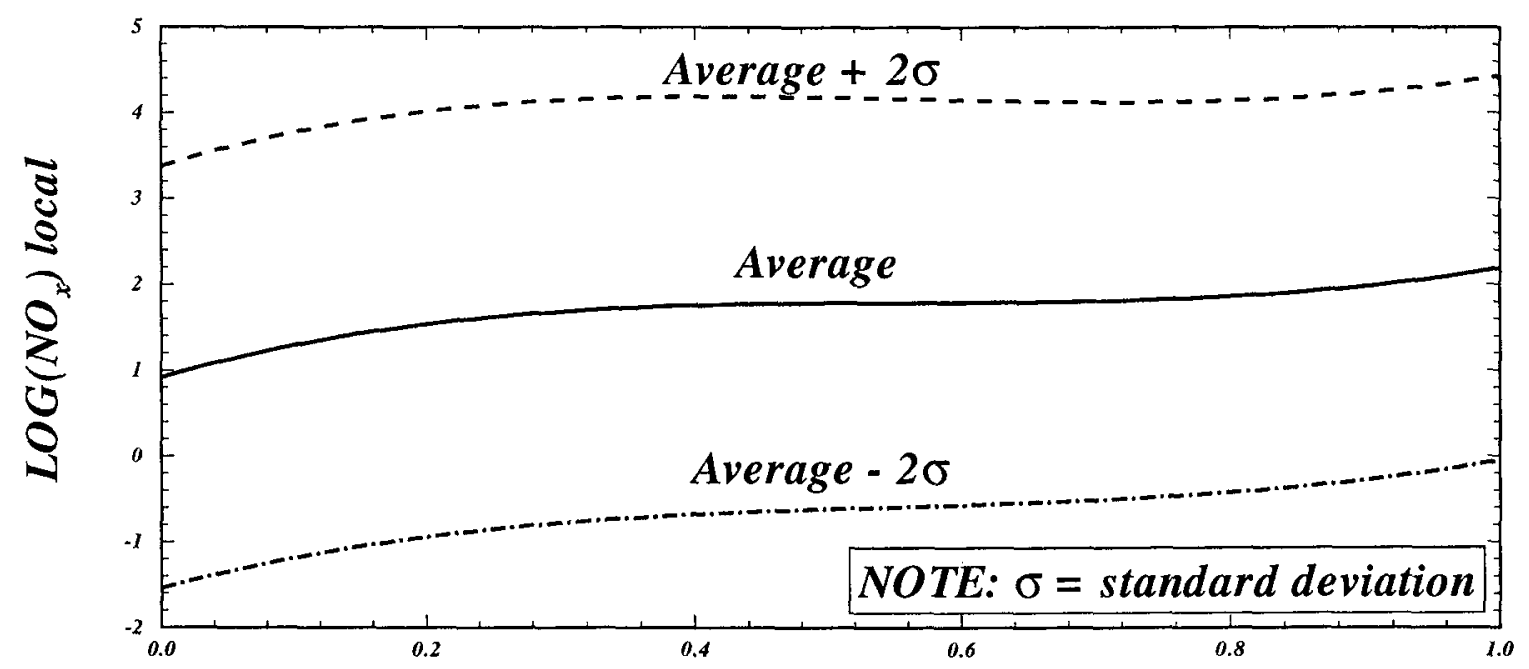

Normalized axial direction $(x / R)$

b.

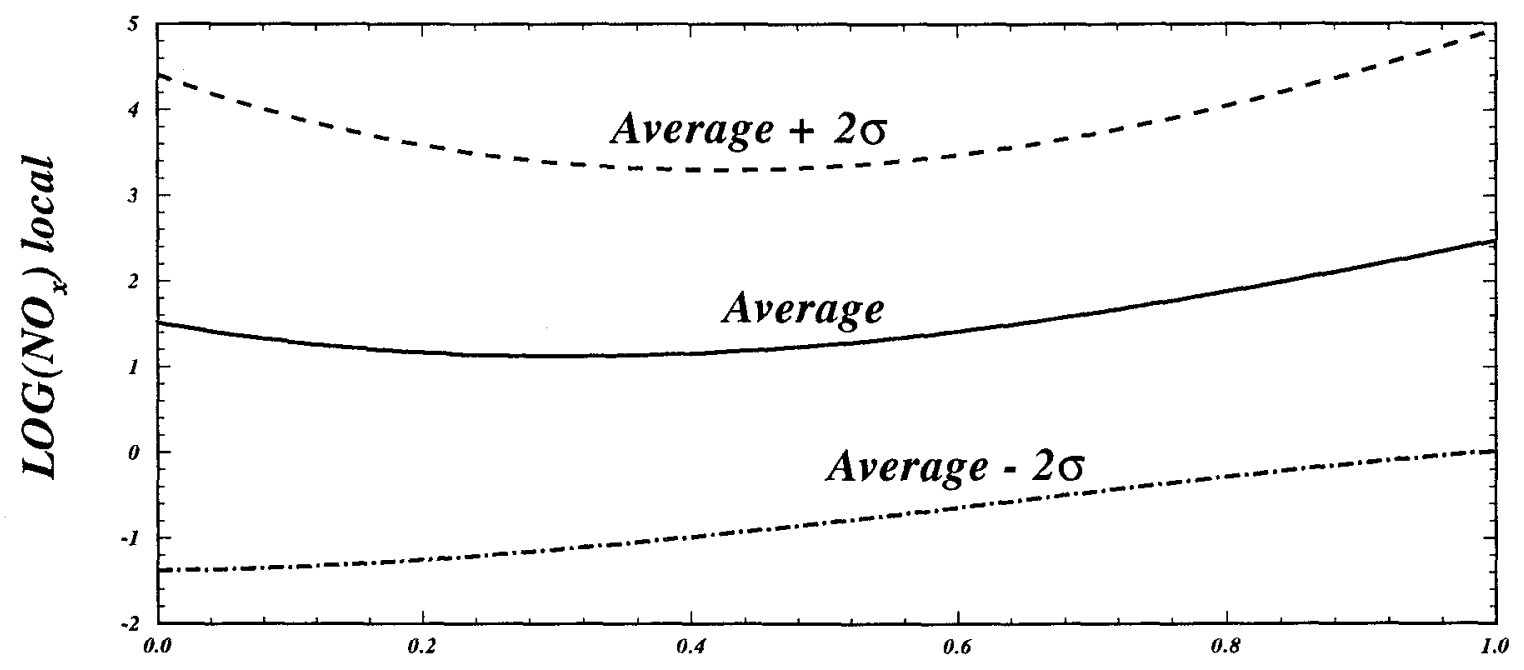

Normalized radial direction $(r / R)$

c.

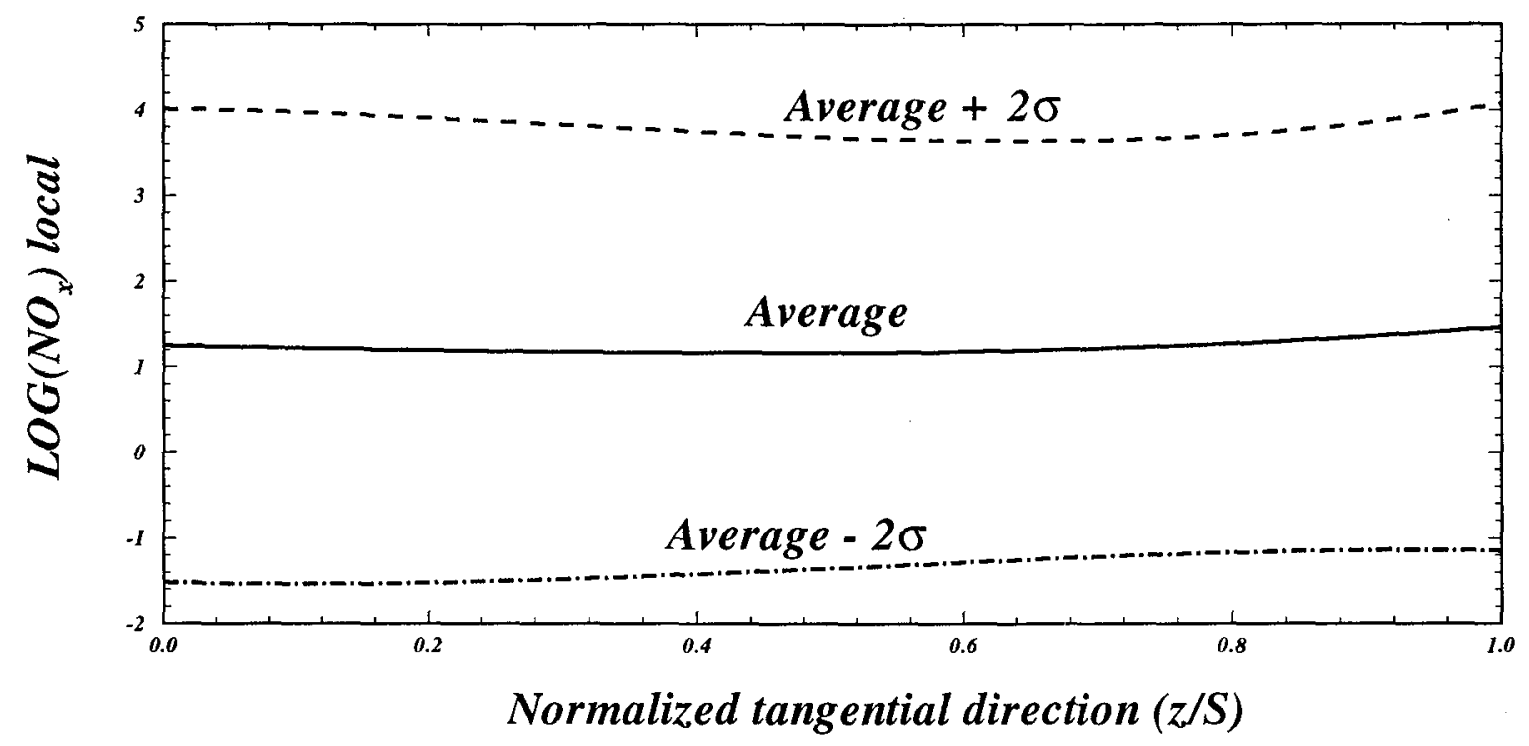

Figure-30. Correlation of the localized $\mathrm{NO}_{x}$ production in (gr of $\mathrm{NO} \mathrm{O}_{x} /\left\{\mathrm{sec} \mathrm{m}^{3}\right\}$ ) with position for all configuraitons \# 19 through 36. Mixer domain is from $0<x / R<1$. 


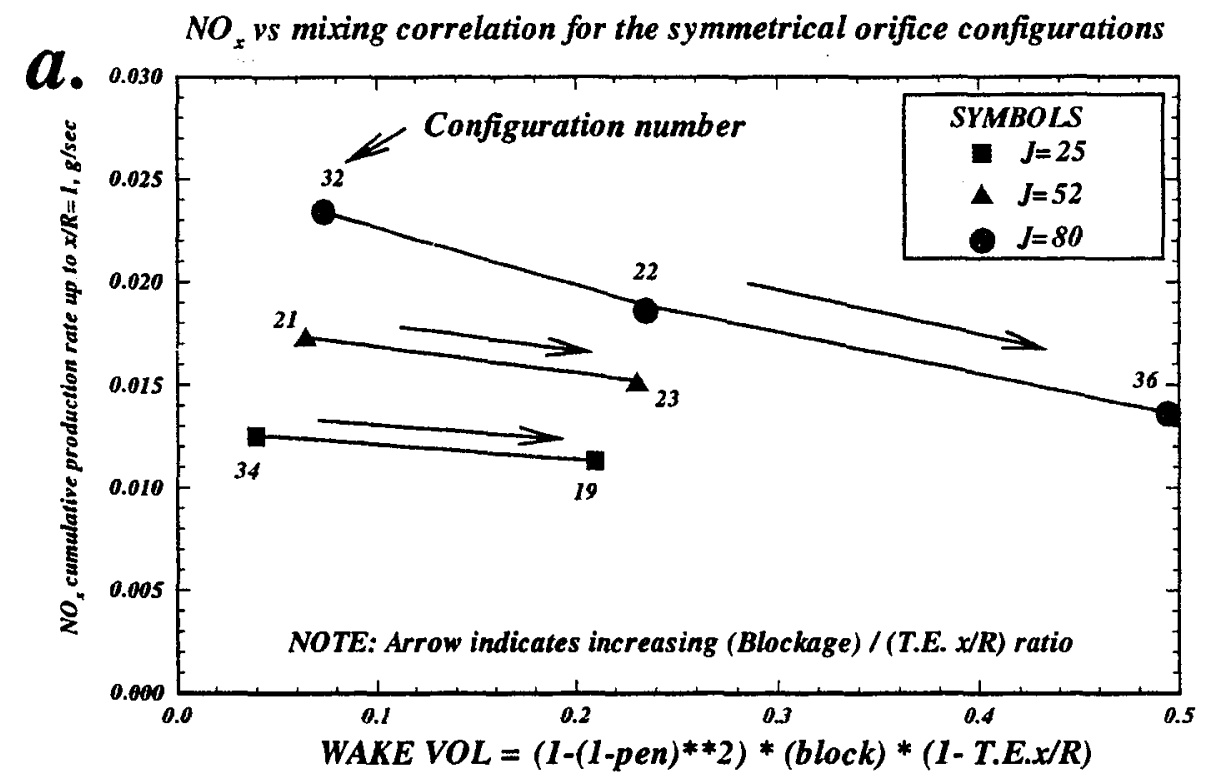

b. No ${ }_{x}$ ss mixing correlation for the non-symmetrical orifice configurations
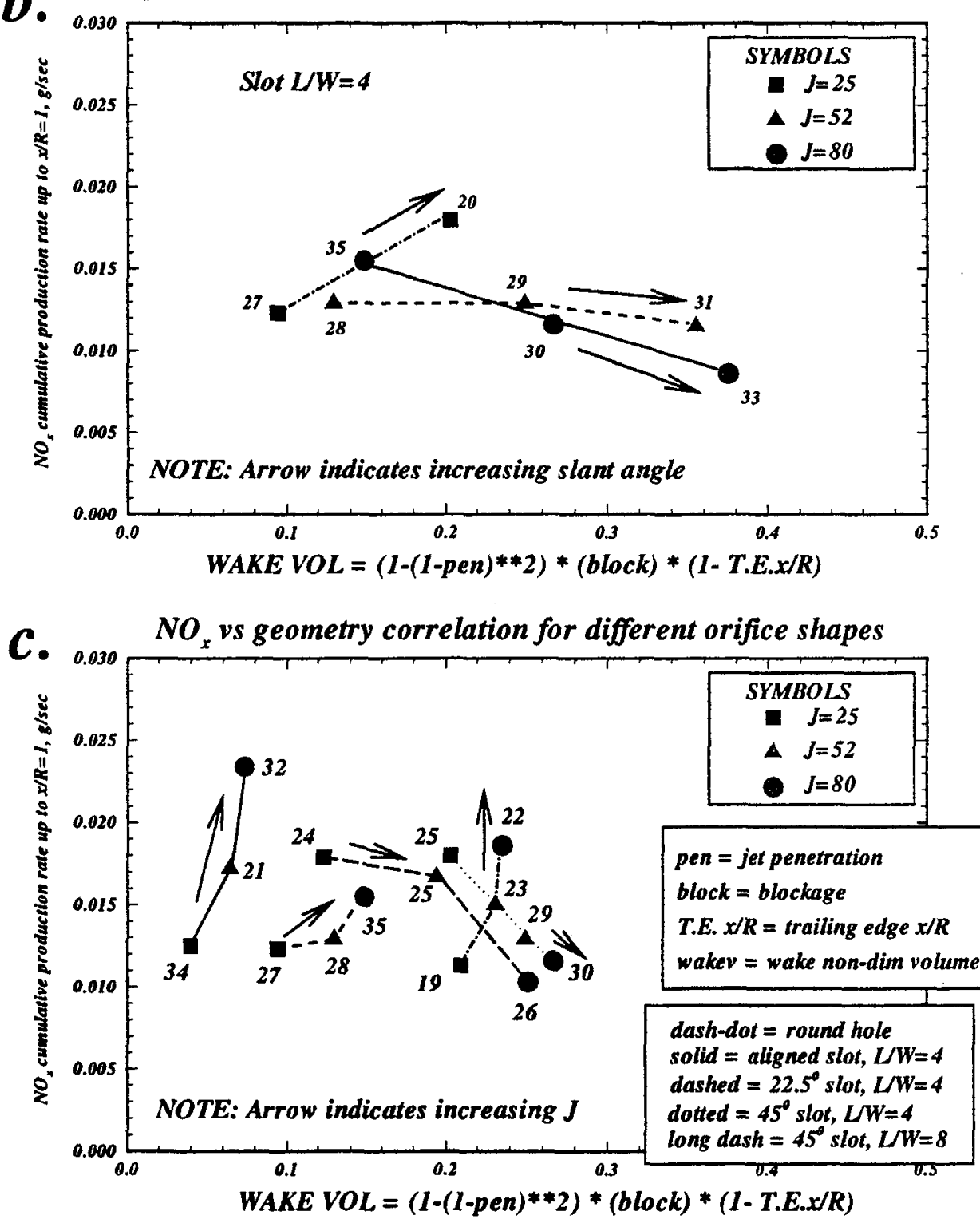

Figure-31. Correlation between $\mathrm{NO}_{x}$ production and orifice geometry for configurations (\#18 through 36) 
Public reporting burden for this collection of information is estimated to average 1 hour per response, including the time for reviewing instructions, searching existing data sources, gathering and maintaining the data needed, and completing and reviewing the collection of information. Send comments regarding this burden estimate or any other aspect of this collection of information, including suggestions for reducing this burden, to Washington Headquarters Services, Directorate for Information Operations and Reports, 1215 Jefferson Davis Highway, Suite 1204, Arlington, VA 22202-4302, and to the Office of Management and Budget, Paperwork Reduction Project (0704-0188), Washington, DC 20503.

\begin{tabular}{|l|l|l|}
\hline 1. AGENCY USE ONLY (Leave blank) & $\begin{array}{c}\text { 2. REPORT DATE } \\
\text { January } 1995\end{array}$ & $\begin{array}{r}\text { 3. REPORT TYPE AND DATES COVERED } \\
\text { Technical Memorandum }\end{array}$ \\
\hline
\end{tabular}

4. TITLE AND SUBTITLE 5. FUNDING NUMBERS

Numerical Mixing Calculations of Confined Reacting Jet Flows in a Cylindrical Duct

6. AUTHOR(S)

WU-537-02-21-00

Victor L. Oechsle and J.D. Holdeman

7. PERFORMING ORGANIZATION NAME(S) AND ADDRESS(ES)

National Aeronautics and Space Administration

Lewis Research Center

Cleveland, Ohio 44135-3191

8. PERFORMING ORGANIZATION REPORT NUMBER

E-9349

9. SPONSORING/MONITORING AGENCY NAME(S) AND ADDRESS(ES)

National Aeronautics and Space Administration

Washington, DC 20546-0001

10. SPONSORING/MONITORING AGENCY REPORT NUMBER

NASA TM-106736

\section{SUPPLEMENTARY NOTES}

Prepared for the 33rd Aerospace Sciences Meeting and Exhibit sponsored by the American Institute of Aeronautics and Astronautics, Reno, Nevada, January 9-12, 1995. Victor L. Oechsle, Allison Engine Company, Indianapolis, Indiana (work funded by NASA Contract NAS3-25950) and J.D. Holdeman, NASA Lewis Research Center. Responsible person, J.D. Holdeman, organization code 2650, (216) 433-5846.

12a. DISTRIBUTION/AVAILABILITY STATEMENT 12b. DISTRIBUTION CODE

Unclassified - Unlimited

Subject Category: 07

Available electronically at http://gltrs.grc.nasa.gov/GLTRS

This publication is available from the NASA Center for AeroSpace Information, (301) 621-0390.

13. ABSTRACT (Maximum 200 words)

The results reported in this paper describe some of the main flow characteristics and NOx production results which develop in the mixing process in a constant cross-sectional cylindrical duct. A 3-dimensional numerical model has been used to predict the mixing flow field and NOx characteristics in a mixing section of an RQL combustor. Eighteen configurations have been analyzed in a circular geometry in a fully reacting environment simulating the operating condition of an actual RQL gas turbine combustion liner. The evaluation matrix was constructed by varying three parameters: 1) jet-to-mainstream momentum-flux ratio (J), 2) orifice shape or orifice aspect ratio, and 3) slot slant angle. The results indicate that the mixing flow field and NOx production significantly vary with the value of the jet penetration and subsequently, slanting elongated slots generally improve the NOx production at high J conditions. Round orifices produce low NOx at low $\mathrm{J}$ due to the strong jet penetration. The NOx production trends do not correlate with the mixing non-uniformity parameters described herein.

14. SUBJECT TERMS

Dilution; Jet mixing flow; Gas turbines; Combustion chamber; Emissions 15. NUMBER OF PAGES 71

17. SECURITY CLASSIFICATION OF REPORT

Unclassified
18. SECURITY CLASSIFICATION OF THIS PAGE

Unclassified
19. SECURITY CLASSIFICATION OF ABSTRACT

Unclassified 